University of Louisville

ThinkIR: The University of Louisville's Institutional Repository

$5-2012$

\title{
An examination of factors that impact persistence among adult students in a degree completion program at a four-year university.
}

Mathew J. Bergman

University of Louisville

Follow this and additional works at: https://ir.library.louisville.edu/etd

\section{Recommended Citation}

Bergman, Mathew J., "An examination of factors that impact persistence among adult students in a degree completion program at a four-year university." (2012). Electronic Theses and Dissertations. Paper 102.

https://doi.org/10.18297/etd/102

This Doctoral Dissertation is brought to you for free and open access by ThinkIR: The University of Louisville's Institutional Repository. It has been accepted for inclusion in Electronic Theses and Dissertations by an authorized administrator of ThinkIR: The University of Louisville's Institutional Repository. This title appears here courtesy of the author, who has retained all other copyrights. For more information, please contact thinkir@louisville.edu. 


\title{
AN EXAMINATION OF FACTORS THAT IMPACT PERSISTENCE AMONG ADULT STUDENTS IN A DEGREE COMPLETION PROGRAM AT A FOUR-YEAR UNIVERSITY
}

\author{
By \\ Mathew J. Bergman \\ B.S., Union College, 1999 \\ M.A., Appalachian State University, 2006
}

\begin{abstract}
A Dissertation
Submitted to the Faculty of the

College of Education and Human Development of the University of Louisville in Partial Fulfillment of the Requirements

for the Degree of

Doctor of Philosophy

Department of Education, Leadership and Human Resource Development University of Louisville

Louisville, Kentucky
\end{abstract}

May, 2012 
Copyright 2012 by Mathew J. Bergman

All rights reserved 
AN EXAMINATION OF FACTORS THAT IMPACT PERSISTENCE AMONG ADULT STUDENTS IN A DEGREE COMPLETION PROGRAM AT A FOUR-YEAR UNIVERSITY

By

Mathew J. Bergman

B.S., Union College, 1999

M.A., Appalachian State University, 2006

A Dissertation Approved on

April 14, 2012

By the following Dissertation Committee:

Bridgette Pregliasco, Dissertation Director

Amy Hirschy

Joseph Petrosko

Brad Shuck 


\section{DEDICATION}

This dissertation is dedicated to Jessica, Gus, Delores, and Moe Bergman. I am so thankful for all of your love, support, and patience. I am truly blessed. 


\section{ACKNOWLEDGEMENTS}

When one conducts a study about student persistence, it is impossible not to consider one's own experience during the progression toward degree completion. Like many other adult learners, I have drawn inspiration and counted on the encouragement of so many family, friends, and mentors. They are too many to name individually but I will do my best to acknowledge those that were integral to my success.

It has been an honor and privilege to be guided by a dissertation committee of individuals that I value in so many ways. Dr. Bridgette Pregliasco was a confidant throughout the process providing candid and constructive feedback that pushed me to produce solid thoughtful original research. Dr. Amy Hirschy provided content expertise and positive encouragement as I immersed myself in the literature. Both Drs. Pregliasco and Hirschy challenged me to produce a new survey instrument and theoretical model unique to the population of this study. For that, I am eternally grateful. Dr. Joseph Petrosko was and is a statistical genius. I feel so lucky to have been under his tutelage during the analysis of my data. I am also extremely grateful for having Dr. Brad Shuck as a mentor. He was patient and consistent throughout the process never shrugging me off when I called or emailed with any sort of mini meltdown.

I would be remiss if I didn't mention some of my fellow doctoral students that were instrumental in my degree completion. Dr. Jason Simmons, Katie Partin, Dr. Michael Anthony, Dr. Glenn Gittings, Jonathan Johnson, Megan Church, Dr. Brittany 
Carpenter, Dr. Denise Cumberland, James Atkinson, Natesha Smith, and James Atkinson are valued friends and served as a collective sounding board for ideas, anxiety, and self-doubt. My colleagues and mentors in the Education Advising and Student Services office including Dr. Margaret Pentecost, Betty Hampton, John King, Susan Hildebrand, Sherry Estep, Kirsten Armstrong, Tia Johnson, Kristin Cox, Julie Stout, Tammy Albers, Jody Morkin, Taleia Fisher, Candace Bell, Rita Groves, Aaron Phillips, Sherry McCroskey, Pat Sheffield, Robin Dorsey, Delsie Essig, and others have been incredible sources of encouragement and support. I know that I am very lucky to work with a wonderful group of professionals dedicated to students' success. My colleagues and mentors in the ELFH department including Kelly Ising, Sherry Duffy, Rod Githens, Ann Herd, and others served as an inspiration to finish this degree. My friends Sunny Townes, Joe Trainer, and Jeff Crane were influential in my progress. Sunny was an excellent editor and Jeff and Joe were perpetually pushing me forward to complete the degree with their consistent and loving encouragement. Finally, Dr. Dale Billingsley and Dr. Gale Rhodes were my mentors from the beginning of the program. They embody professionalism and dedication to higher education that I aspire to in my career in higher education. I could not have finished without this long list and many others that will go unmentioned. I am very lucky to work with such incredible mentors, colleagues, and peers. Thank you just doesn't seem enough for the love and support that you have provided. 


\begin{abstract}
AN EXAMINATION OF FACTORS THAT IMPACT PERSISTENCE AMONG ADULT STUDENTS IN A DEGREE COMPLETION PROGRAM AT A FOUR-YEAR UNIVERSITY

Mathew John Bergman

April 11, 2012
\end{abstract}

For more than 100 years, nearly half of all undergraduate students have failed to persist to degree completion (ACT, 2010; Tinto, 1993; U.S. Department of Education, 2008). To make matters worse, adult students have consistently been victims of higher levels of attrition than their traditional student counterparts (Justice \& Dornan, 2001; National Adult Attitudes Report, 2008).

This study utilized the theoretical underpinnings from the Bean and Metzner (1985) Conceptual Model of Nontraditional Undergraduate Student Attrition and Braxton, Hirschy, and McClendon's (2004) Theory of Student Departure in Commuter College and Universities model to create a new model to examine variables that impact persistence among adult students over the age of twenty-five in a degree-completion program at the bachelor's level.

An internet-based self-report survey was constructed to measure variables from three constructs including student entry variables, internal campus/academic variables, and external environment variables. The sample came from the Bachelor of Science in 
Workforce Leadership program at the University of Louisville which includes adults ranging from ages 25-67. Hypotheses were tested through correlational and logistic regression analytic procedures.

Educational goal, finances, and active learning were all significant predictors of persistence, controlling for all other variables in the equation and accounted for $35.4 \%$ of the variance among all variables. Students who reported higher educational goals, sufficient finances to pay for school, and content relevant active learning were more likely to persist. Implications for theory, research, and practice are highlighted as possible strategic leverage points for creating policies and procedures that will aid in adult student retention in degree completion programs at four-year universities. 


\section{TABLE OF CONTENTS}

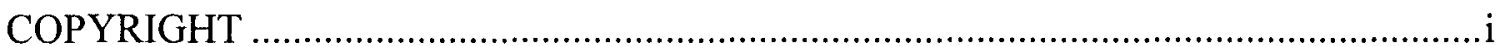

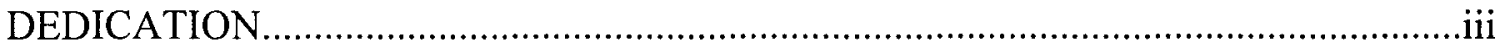

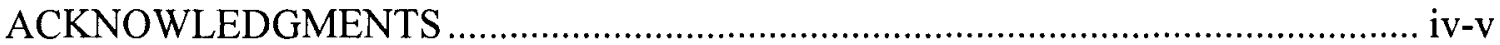

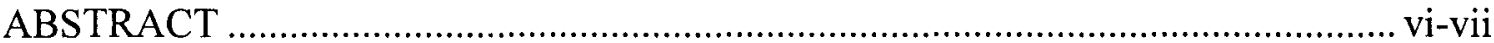

CHAPTER 1 INTRODUCTION ........................................................................ 1

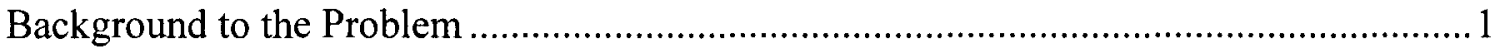

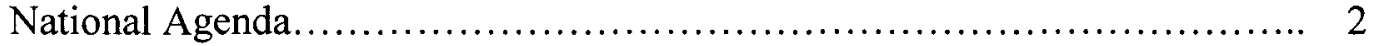

State Agenda........................................................ 3

Regional Agenda................................................. 5

Degree Completion Programs...................................... 6

Adult Student Retention................................................ 8

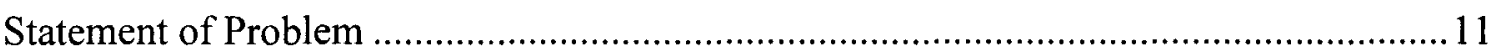

Purpose of Study ................................................ 13

Research Questions..................................................14

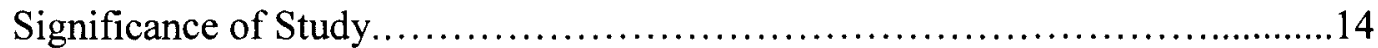

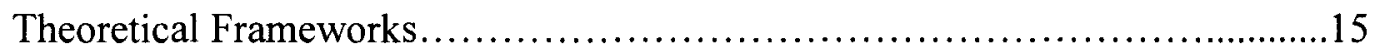

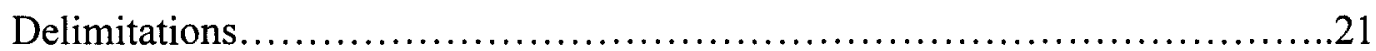

Limitations......................................................... 21

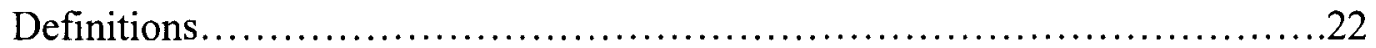

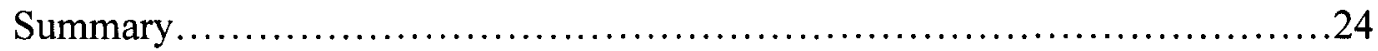

viii 
CHAPTER 2 LITERATURE REVIEW ............................................................... 27

Adult Learners in U.S. Colleges and Universities...................................................28

Nontraditional and Adult Student Distinctions................................29

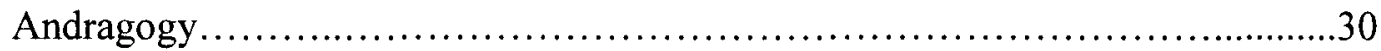

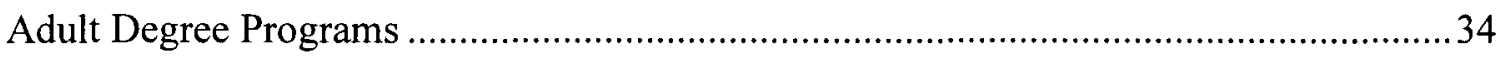

History of Retention and Persistence Literature........................................................ 34

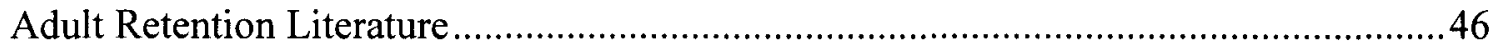

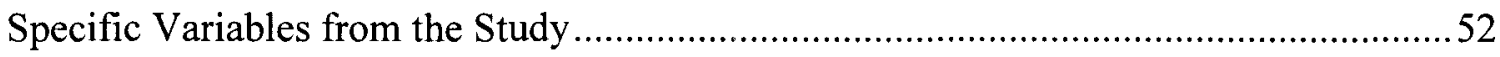

Student Entry Characteristics ...................................... 52

Internal Campus/Academic Environment.................................................60

External Environment Variables........................................72

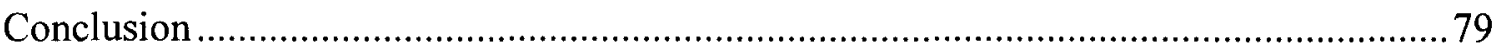

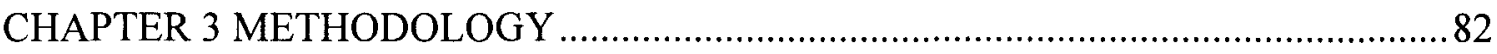

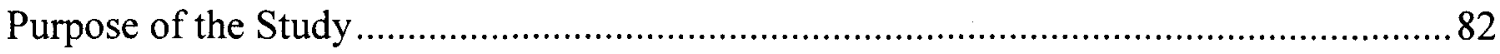

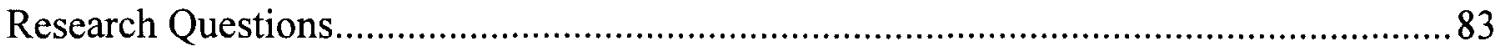

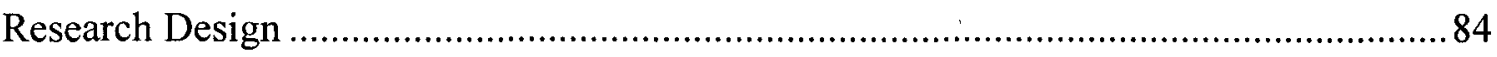

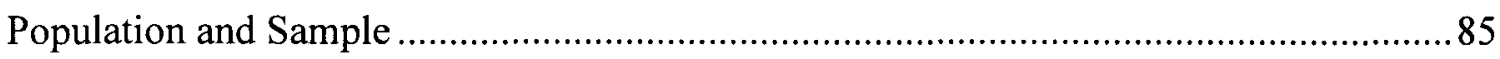

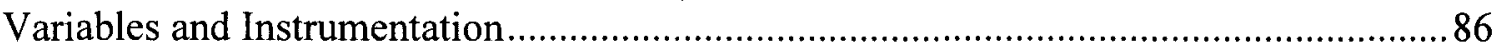

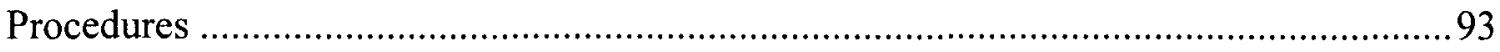

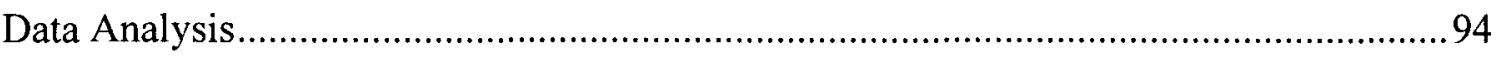

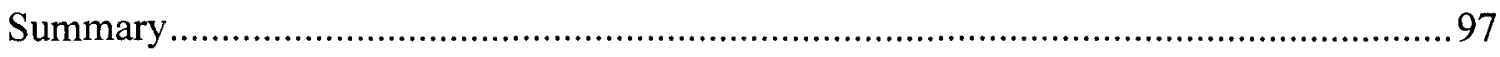

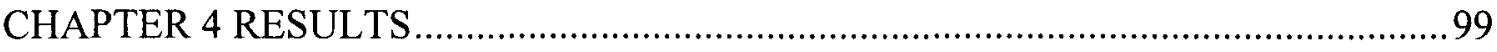

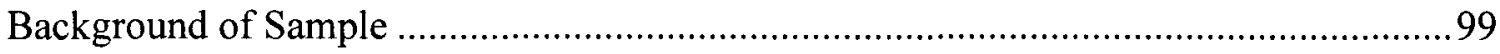




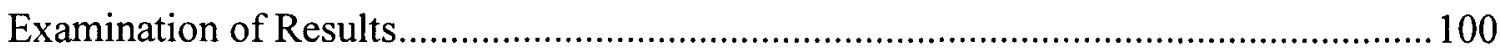

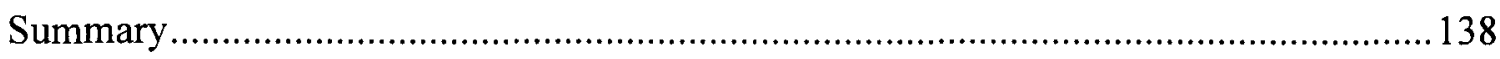

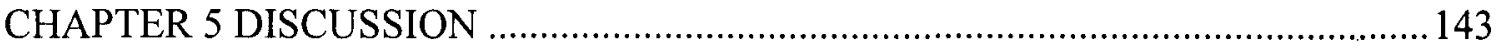

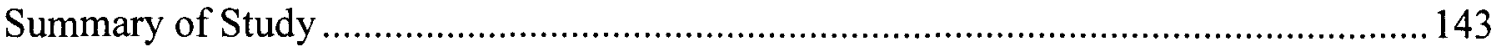

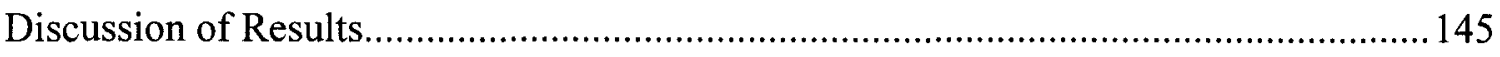

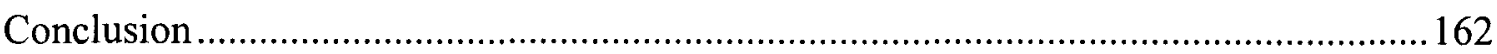

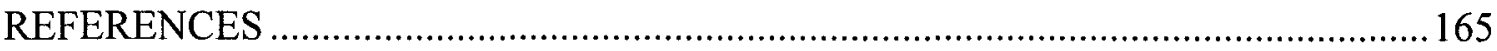

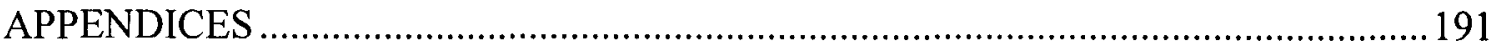

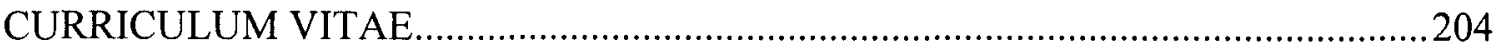




\section{LIST OF TABLES}

TABLE

PAGE

1. Comparison Between Traditional and Adult Learners $31-32$

2. Summary of Key Retention and Persistence Literature

3. Description of Variables

4. Frequency Distribution of Current Enrollment Status. 101

5. Frequency Distribution for Highest Level of Education Completed. 104

6. Frequency Distribution of Household Income During Initial Enrollment 107

7. Frequency Distribution of Importance of Bachelor's Degree Completion 107

8. Summary of Facts Related to Student Entry Characteristics 109

9. Frequency Distribution of Extent the University Provided Resources for Success ...111

10. Frequency Distribution of Number of Academic Advising Meetings .112

11. Frequency Distribution of Number of Outside Instructor Meetings 113

12. Frequency Distribution of Four Types of Experiences in Active Learning 116

13. Summary of Facts Related to Internal Campus/Academic Environment

14. Frequency Distribution of Extent Family Members Encouraged Studies 119 
15. Summary of Facts Related to External Environment

16. Correlations Between Persistence and Student Entry Characteristics

17. Correlations Between Persistence and Internal Campus/Academic Environment .... 126

18. Correlations Between Persistence and External Environment

19. Omnibus Tests of Model Coefficients for Step 1 Logistic Regression

20. Model Summary for Step 1 of Logistic Regression

21. Regression Coefficients for Step 1 of Logistic Regression

22. Omnibus Tests of Model Coefficients for Step 2 Logistic Regression

23. Model Summary for Step 2 of Logistic Regression 134

24. Variables in the Equation for Step 2 of Logistic Regression 134

25. Omnibus Tests of Model Coefficients for Step 3 Logistic Regression 135

26. Model Summary for Step 3 of Logistic Regression 136

27. Variables in the Equation for Step 3 of Logistic Regression 138

28. Summary of Three-Step Logistic Regression Analyses 139 


\section{LIST OF FIGURES}

FIGURE PAGE

1. Adapted Theory of Student Departure in Commuter Colleges and Universities .........17

2. Conceptual Model of Undergraduate Nontraditional Student Attrition ...............18 \& 40

3. Theory of Adult Learner Persistence in Degree Completion Programs ........................20

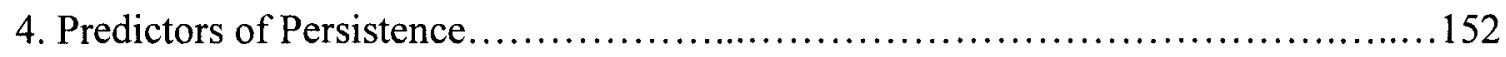




\section{APPENDICES}

$\begin{array}{ll}\text { APPENDIX PAGE } & \text { PAX }\end{array}$

1. Adult Learner Persistence Survey (ALPS) .................................................. 193

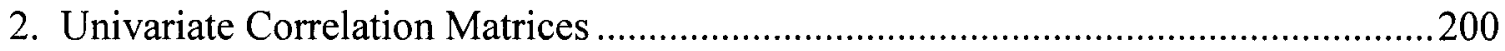




\section{CHAPTER I}

\section{INTRODUCTION}

This chapter begins with background to the problem examined in this study, followed by the problem statement, purpose of the study, and significance of the study. The research questions, theoretical frameworks, definitions of relevant terms, assumptions, delimitations, and limitations follow. Finally, the organization of this study is presented.

\section{Background to the Problem}

Among the most pressing concerns for colleges and universities across the United States is student retention. While most research on the topic has focused on traditional students, labor statistics indicate that adult education programs, which typically have low retention rates, are an essential part of the stability and growth of the nation's economy. There are more than 145 million people in the United States workforce (Bureau of Labor Statistics, 2009). Thirty-eight million of those people are adult working age individuals (ages 25 and older) that have some college but no degree (Adult Learning in Focus CAEL, 2008). The U.S. labor market now requires postsecondary education for most entry-level positions and virtually all mid-level occupations and by $2018,63 \%$ of jobs will require some form of postsecondary training (Carnevale, Smith, \& Strohl, 2010). The U.S. economy will have jobs for 22 million workers with college degrees, but a shortage of nearly 3 million college graduates (Carnevale et al., 2010). These statistics show that 
there is a growing need for the nation's workforce to acquire more postsecondary credentials. To that end, colleges and universities must work to better understand why so many adults fail to reach graduation during their initial or subsequent enrollment in college.

Past generations were able to secure any number of jobs in the public sector with a high school diploma; in today's marketplace, however, possession of a high school diploma alone will not provide the qualifications for entry-level jobs and limit the possibilities of acquiring highly skilled jobs (Klein-Collins, Sherman, \& Soares, 2010; Kratzer, 2009). In the nation's changing economy, baccalaureate-level education is a necessity for a number of jobs that have never before required it (Bragg, Townsend, \& Rudd, 2009). According to Cabrera, Burkum, and LaNasa (2005) "a bachelor's degree is no longer considered a potential stepping-stone to a better life; it is fully acknowledged as the gatekeeper to a myriad of social and individual benefits" (p. 2). Statistics show that college graduates earn roughly $\$ 1$ million more over their lifetimes, earning on average $\$ 48,800$ annually compared to $\$ 30,800$ for workers without a degree (Kazis, Vargas, $\&$ Hoffman, 2007). Their unemployment rates are also $30 \%$ lower than that of high school graduates with an unemployment rate of $5.5 \%$ in 2009 , compared with all other persons at $9.3 \%$ (Turner \& Krumenauer, 2010). College graduates also provide at least $\$ 300,000$ more over a lifetime in federal taxes (Adult Learning in Focus CAEL, 2008).

\section{National Agenda}

Nationally, the percentage of adults with a baccalaureate degree or higher is as low as $18 \%$ in some low-performing states and only as high as $41 \%$ in the best National 
Center for Public Policy and Higher Education, 2009). As part of the fiscal 2010 budget proposal, the current presidential administration included $\$ 2.5$ billion for the creation of the College Access and Completion Fund to help states implement initiatives to boost college completion rates over the next five years. A portion of these funds were slated to be used for programs targeting adult learners returning to U.S. colleges and universities. Expanding postsecondary education for adult learners and those already in the labor force is vital to the United States' workforce and economy (Pusser et al., 2007). The attainment of higher education degree credentials leads to decreases in long-term poverty, higher personal per capita income, a higher-state tax base, and a stronger economy (McMahon, 2000). Therefore, it is important for American colleges and universities to recruit and retain adult learners at a higher level than in previous years.

\section{State Agenda}

Kentucky has eight public four-year institutions and 16 public two-year institutions, along with 27 non-profit and 49 for-profit institutions. In comparison, the Commonwealth of Kentucky currently ranks $48^{\text {th }}$ in bachelor's degree attainment in the United States (Atkinson \& Correa, 2007). Approximately $27.5 \%$ of people in the U.S. ages 25 or older hold a bachelor degree compared to only $20.03 \%$ in Kentucky (Chronicle of Higher Education, 2010; Kentucky Council for Postsecondary Education, 2005). This is not a new problem in the Commonwealth of Kentucky. In 1997 the state legislature passed the Kentucky Postsecondary Improvement Act, which articulated a clear goal that this state reach a higher national bachelor attainment level by the year 2020 (Kentucky Council for Postsecondary Education, 2005). The Kentucky Council for 
Postsecondary Education (CPE, 2005) identified specific goals related to adult degree attainment in its "Double the Numbers" 2020 initiative including more matriculations from associate degree holders to bachelor programs, more returning adult learners, and better retention rates of existing students. However, bachelor degree attainment remains respectively low in the Commonwealth of Kentucky when compared with national averages (U.S. Census Bureau, 2008).

Between 2007 and 2008, nearly 9,000 students did not return for a second year at the schools they enrolled in as freshmen, according to the most recent figures available from the Kentucky Council on Postsecondary Education (2010). Kentucky institutions have made substantial enrollment gains since the 1997 education reform act. In 20092010 academic year, Kentucky schools awarded 19,369 baccalaureate degrees, compared to 6,320 in 2001 . While graduation rates from four-year institutions have shown improvement, they remain lower than the national average, with an overall six-year graduation rate of $45.1 \%$ compared to $59.7 \%$ for the national average (CPE, 2010). Although there are positive signs of improvement, degree attainment still lags when compared with national averages, which in turn has negative economic implications.

Since 1995 the economic impact associated with the annual earning power of more than 12,000 additional graduates who reside in Kentucky equals more than $\$ 200$ million annually in direct payroll to the state's economy and more than $\$ 6$ million annually in state income taxes (CPE, 2009). Based upon economic projections from the Council on Postsecondary Education, doubling the number college graduates in Kentucky would bring Kentuckians an additional $\$ 139.5$ billion in personal income and add $\$ 9$ 
billion in revenues to Kentucky's general fund. Thus, the economic impact of additional college graduates has significant financial implications for the state's tax base.

\section{Regional Agenda}

Louisville has nearly 90,000 working-age adults who have started college but have not finished (Ash \& Landes, 2010). In the Greater Louisville region, the Competitive City Report (2010) highlighted measurements of performance and competitive standing which stressed the importance of raising the region's persistently low levels of education attainment as a "deep driver of change" to advance Louisville's standing among its peer cities (p.3).

As part of the effort to increase graduation rates, the Greater Louisville's Commitment to Educational Attainment established "55,000 Degrees," a public-private partnership that is designed to increase education attainment in the Greater Louisville area (Greater Louisville Inc, 2010). The initiative unites education, business, faith, civic, and community leaders and organizations in support of a common goal to increase education attainment and thus the quality of life of Louisville residents. The goal is for $40 \%$ of working-age adults in the region to hold a bachelor's degree and $10 \%$ to hold an associate's degree by the year 2020, an increase of 55,000 degrees (40,000 bachelor's and 15,000 associate's) among the 31 participating colleges and universities in the Greater Louisville area (Greater Louisville Inc, 2010). This achievement would move Louisville into the top tier among its peer cities.

The size of its enrollment makes the University of Louisville (UofL) the leader in this endeavor. UofL has the largest enrollment in the area and, therefore, has the capacity 
to make a significant contribution to the " 55,000 Degrees" initiative. As such, boosting the number of college graduates is an integral part of the University's accountability mission. By 2020, the University of Louisville aims to achieve a $60 \%$ graduation rate (an

increase from the current rate of 51\%). The University of Louisville's six-year graduation rate has risen to $51 \%$ from $31 \%$ in 2000 , which is a tangible indicator of progress (UofL, 2011). The rate of adult degree attainment has mirrored that of the traditional-age population at the University of Louisville, in part, because of flexible programs offering adult-friendly evening and online course options.

Degree-Completion Programs

Adult degree-completion programs are becoming increasingly relevant within the higher education community and are growing at a rapid pace across the nation (Taylor, 2000). Offering adult students the opportunity to complete a bachelor's degree promises to be one of the fastest ways to raise baccalaureate attainment rates (Bragg, Townsend, \& Ruud, 2009). In 2004, Kentucky's Council on Postsecondary Education endorsed the requirement that all public four-year institutions implement programs that allow for transfer of credit for all associate degree programs (CPE, 2005). At present, all four-year public universities in the state are pursuing or have implemented these types of degreecompletion programs designed to provide working adults with significant college credit an opportunity to finish a baccalaureate degree with convenient and flexible course offerings, including online, evening, and weekend courses.

In the summer of 2007, the University of Louisville introduced a Workforce Leadership major, a revision of a major previously titled Occupational Training and 
Development to address the Council on Postsecondary Education's "Double the Numbers" goal by the year 2020 . The program curriculum was redesigned and implemented in coordination with the state and local graduation initiatives. The Bachelor of Science in Workforce Leadership is a degree-completion program designed for working professionals with previous college credit and five or more years of work experience in various career fields related to training and development, human resources, and workforce development occupations. A unique feature of the program offers adult learners the ability to earn college credit for workplace experiential learning, military training, certifications, licenses, and other experiential learning through a Prior Learning Assessment portfolio. The curriculum, which is offered both online and in classrooms in Louisville and Fort Knox, focuses on content areas such as leadership, human resources, needs assessment, and design and delivery of educational or training curriculum and strives to develop intrapersonal (self-concept) and interpersonal (relationship) dimensions of a student. The introduction of this program resulted in a surge of enrollment, tripling the number of adult learners enrolled from 123 in fall 2007 to its current enrollment of 374 in spring 2012.

This growth in adult-friendly programs is a national trend despite the reluctance of the academy as a whole. Many of the most respected institutions in higher education, including Duke, Harvard, Cornell, and New York universities, now offer online and hybrid programs (Cronin \& Bachorz, 2006). The Bachelor of Science in Workforce Leadership at the University of Louisville is part of this growing movement to embrace the needs of a diverse and ever-changing American labor market. Nevertheless, attracting 
adult learners back to the academic setting is not the final step. Comprehensive policies and procedures aimed at retaining this growing population is an essential piece of making a substantial economic and societal impact.

\section{Adult Student Retention}

Retention is a much-discussed issue in higher education (Bean \& Metzner, 1985; Kuh, 2008; Tinto, 2006). Over the past 100 years, half of all undergraduate students have consistently failed to persist to degree completion (ACT, 2010; Tinto, 1993; U.S. Department of Education, 2008). Yet, even as more emphasis is placed on retaining students, retention rates have remained flat for the past century (ACT, 2010; Tinto, 1993). Retention is a complex issue involving a variety of academic, social, environmental, and behavioral factors that are difficult to define and even harder to control (Astin, 1975, 1993; McGivney, 2004; Tinto, 1993, 2006).

The vast majority of literature in this field is focused on traditional-age students. Seminal authors including Tinto, Spady, Pascarella, and Terenzini conceptualized much of their theoretical frameworks around students between 18 and 21 years of age. Adult and nontraditional learners, however, are subject to a significantly different set of circumstances as they pursue academic degrees. Further, these circumstances present variables that exhibit dynamic characteristics over time as the needs, expectations, and life circumstances of students change (Tinto, 2006). Since higher education has become much more market-oriented, the complexity of this problem calls for more accountability in higher education and has heightened the need for institutions to improve retention 
(Bonk, 2009). As Tinto (2006) aptly stated, retention "matters now more than ever" (p. $5)$.

Adult students persist at much lower rates than that of traditional age students (Justice \& Dornan, 2001; National Adult Attitudes Report, 2008). Information on persistence in adult-focused programs is very limited and there have been numerous calls for research on the subject (Kratzer, 2009; Wlodkowski, Mauldin, \& Gahn, 2001). This research study addressed this gap by measuring retention rates and examining variables that contribute to and detract from adult degree completion. For the purposes of this study, the definition of "dropout" is understood according to the Bean and Metzner (1985) model: "A dropout is considered to be any student who enrolls at an institution one semester but does not enroll the next semester and has not completed his or her formerly declared program of study" (p. 489). The obvious limitation of this definition is that the institutional perspective of dropout is used rather than a considering the possibility of nonlinear enrollment patterns including students that stop in and out over the course of their degree progression. However, this study utilized a one shot survey that does not consider longitudinal departure.

Noel Levitz (2007) used their "College Student Inventory, Form B" to survey 8,867 nontraditional students at 235 institutions including both private and public twoyear and four-year colleges and universities about retention rates. Data from the adult population were compared to data from traditional-aged students who had completed the same survey (National Adult Attitudes Report, 2008). Findings revealed nontraditional students are harder to retain in all categories. The dropout rate for nontraditional students 
was $56.5 \%$ compared to $43.2 \%$ for traditional students at two-year institutions, and $49.9 \%$ for nontraditional students compared to $28.2 \%$ for traditional students at four-year institutions. Despite these statistics, other findings show that nontraditional students study harder, even for courses they dislike, than traditional students, enjoy reading more, and are considerably more stressed and distracted by financial problems (National Adult Attitudes Report, 2008).

Much of the literature on retention and persistence behavior is focused on the negative outcome of dropout and stopout behavior. This study asserts that the examination of both successful and dropout students is a useful way to develop successful retention strategies. It must be noted that students who graduate have experienced any variety of threats to their eventual success in the classroom. Analyzing the confluence of factors that promote and detract from the ability of adult learners to persist at a four-year institution addressed a gap in the current literature.

The adult learners who made up this study were all classified as stopout students. In other words, these students were not starting with zero credits. They have experienced some form of postsecondary schooling and stopped-out for any number of reasons only to return later in life. These adult learners that often enter degree-completion programs are recruited based on their significant college credit. This is an especially salient topic in light of the current economic downturn. Thousands of adults that have been able to excel in the workforce based on their years of experience alone are now being turned down for promotions and raises as a result of their lack of academic credentials (Kolowich, 2011). Thus, higher education has the benefit of attracting highly competent adult learners back 
into the classroom to finish their degrees. The next step is exploring the positive and negative influences on student persistence to graduation because institutions are being held accountable for this outcome.

Public perception of the quality of an institution hinges on graduation rates, which in turn, affects recruitment, tuition revenue, external funding, accreditation/reaccreditation, and fund-raising. Continuous retention problems also increase the reliance on the recruitment of new students to replace the victims of attrition. In Kentucky, colleges and universities seek to become more aware of the reasons behind student departure because the state legislature currently distributes funding according to graduation rates rather than enrollment. While no single strategy will fix everything, one should always consider the possibility that there are a much smaller number of underlying constructs that will account for most of the variance on the original set of variables (Stevens, 2009). In spite of this optimism, current and past research leaves many unresolved questions, primarily in understanding the interaction of the multitude of variables that may have an impact on learner choices.

\section{Statement of Problem}

There is an expansive base of literature on the retention of students at colleges and universities throughout the United States. However, there is only a small base of literature focused on adult learner persistence. Furthermore, there is a significant gap in the literature concerning the retention and persistence behavior related to adult learners in a growing number of degree-completion programs at four-year colleges. While 
universities are scrambling to increase retention, they are experiencing little success. Retention rates are remaining flat or even declining, indicating that there is a need for further investigation of the problem (ACT, 2010). Adult students, in particular, indicate they want more flexible delivery options including online, evening, and weekend courses. The U.S. economy has moved away from the strong manufacturing labor market that existed 30 years ago. Today the workplace is a technologically focused environment, where knowledge-based jobs are driving the demand for a new kind of skilled laborer (Atkinson \& Correa, 2007; Carey, 2004; Childress et al., 2008; Kratzer, 2009). Atkinson and Correa (2007) have identified these knowledge-based workers as the engine driving the economic and technological futures of most organizations, allowing them to compete in the global economy. Consequently, higher education can play an integral role in developing knowledge-based workers for knowledge-based jobs in a more technologybased workplace (Kratzer, 2009).

Adult learners are encompassing an increasing percentage of the total enrollment in today's colleges and universities, however, they continue to be the least understood (Bean \& Metzner, 1985; Kasworm, 2005), the most difficult to recruit (Hadfield, 2003), and the least likely to persist (Donaldson \& Graham, 1990; Justice \& Dornan, 2001; National Adult Attitudes Report, 2008). While the complexities of traditional student departure decisions have been studied extensively, the same cannot be said for adult student retention. Even less research can be found on student retention in adult degree completion programs (Tweedell, 2000; Wlodkowski, 2002). Understanding how entry/background, internal campus/academic environment, and external environment 
variables interact can assist colleges and universities identify at-risk students and implement interventions that support adult students, who are more likely to leave an institution. Additional research can also help local and state officials identify new policies that promote adult student persistence to improve bachelor degree attainment rates in Kentucky and other states. As changes in the global marketplace drive adult students back into the classroom, it is necessary that institutions of higher learning provide appropriate services and resources to ensure these adults attain a baccalaureate degree (Hoffman \& Reindl, 2011).

\section{Purpose of Study}

The purpose of this study was to examine the relationship of student entry characteristics, internal campus/academic environment, and external environment variables to the outcome variable of student persistence in an adult degree completion program at the bachelor's level. The Braxton, Hirschy and McClendon's (2004) Theory of Student Departure in Commuter College and Universities alongside Bean and Metzner's (1985) Conceptual Model of Undergraduate Nontraditional Student Attrition model served as empirically tested conceptual frameworks from which to develop a specific model salient to degree completion programs at a four-year research university. This adapted model was used to test factors that predict undergraduate degree completion for adult learners. Student entry characteristics, internal campus/academic environment variables, and external environment variables were examined in this study. The understanding of how these variables impact student retention is very beneficial to college and university administrators. The cost of recruiting, enrolling, and graduating 
students becomes exceedingly high when only $40-60 \%$ of the student body is retained to graduation. Identifying factors that increase and decrease the likelihood of persistence will arm administrators of adult degree-completion programs with the knowledge to improve graduation rates through policy and procedures that assist adult learners.

Research Questions

1. What are the relationships between (a) student entry variables, (b) internal campus environment variables, and (c) external influences variables and the outcome variable student persistence in an adult degree completion program at the bachelor's level?

2. What is the multivariate predictive relationship between student entry variables, internal campus environment variables, and external influence variables and the outcome variable student persistence?

\section{Significance of Study}

While other studies have explored student and academic characteristics, a study of the University of Louisville's Bachelor of Science in Workforce Leadership is uniquely positioned to add to the body of research on programmatic and policy factors. This study examined differences in adult students in a degree completion program at a state university in a major metropolitan area. Some students in the program are unemployed, trying to regain access to the workforce with additional credentials, while others are taking advantage of workplace initiatives to expand their education. The program offers a variety of course types to accommodate the varying schedules. Classes are offered both 
online and in classrooms both at the University of Louisville and at off-campus locations in the local community. With workplace-relevant curriculum designed to help students teach, train, and manage in non-school settings, the degree in Workforce Leadership aligns academic rigor with real-world practice. Little empirical research has been produced examining this topic and this study examined the combination of variables that significantly impact attrition/retention behavior among adult students. This study advances the theory and research base on degree completion programs. Although there is a small base of literature on adult student persistence, even less exists on adults in degree completion programs. Therefore, the variables isolated for measurement in this study add to understanding of what helps and hinders adult students seeking bachelor's degrees.

\section{Theoretical Frameworks}

Student retention and persistence have been studied for more than 75 years, but the most valuable empirical research concerning this challenging issue has been accomplished in the last 30 years. One of the most authoritative voices in the field, Vincent Tinto, expanded Spady's (1970) work, which was delineated from Durkheim's (1951) seminal theory of suicide. Consequently, Tinto's (1975) interactionalist theory of college student departure provides a comprehensive framework for identification of reliable knowledge of the field. More than 775 citations have been the object of this theory index displaying its predominance in the field (Braxton, Hirschy, \& McClendon, 2004). Tinto's (1975) framework illuminates the connections among the factors deemed as empirically reliable (Braxton \& Hirschy, 2005). Tinto posited that various entry characteristics directly influence a student's ability to persist to graduation and 
highlighted the importance of institutional commitment as a crucial factor influencing one's ability to integrate into the social systems within the university. Academic, institutional, and social integration are key elements of student assimilation. These three factors influence the students' subsequent commitment to the institution and often promote higher levels of persistence to graduation.

While Tinto (1975 \& 1993) was primarily concerned with what goes on inside the institution, he later acknowledged the impact of the external community on persistence. With this model, he argues that "when external communities are strong... their action may serve to condition if not counter events within the college" (p. 116). Braxton, Hirschy, and McClendon (2004) drew important distinctions between residential and commuter colleges and universities constructing their theory from an inductive view of empirical findings. They posit that more adult and nontraditional students attend commuter institutions and that most of these students attend college "in addition" to other involvements and obligations such as family and work (Braxton, Hirschy, \& McClendon, 2004). Hence, the influence of the external environments in commuter colleges and universities differ from those of residential institutions. Although student entry characteristics, internal campus interaction, and academic integration are included in both conceptual models, the external environment is a larger factor in the commuter model adapted by Braxton, Hirschy, \& McClendon (2004). 


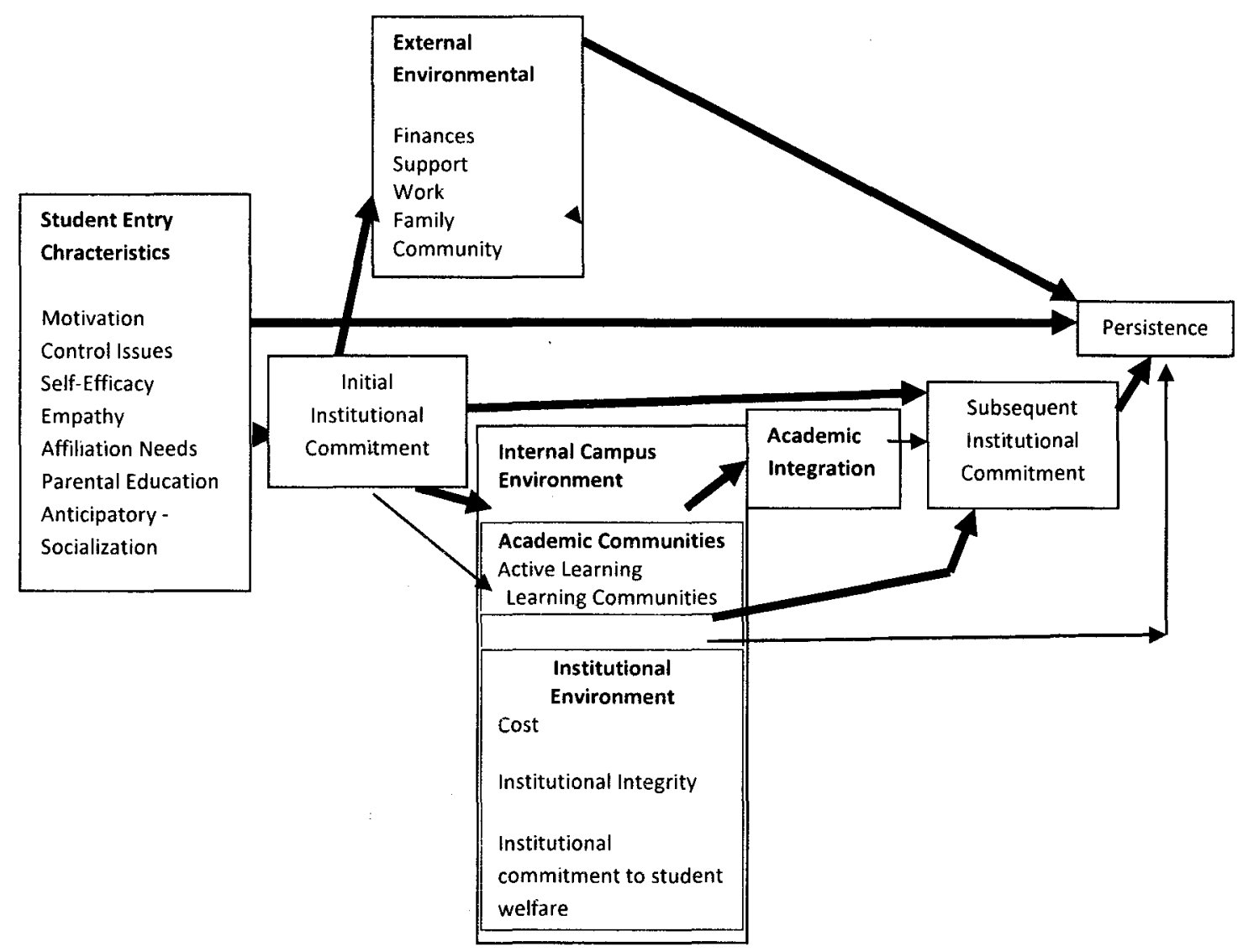

Figure 1: Braxton, Hirschy, and McClendon (2004) adapted Theory of Student Departure in Commuter Colleges and Universities

Bean and Metzner (1985) also theorized that Tinto's model over-stated the impact of socialization on nontraditional and adult students as referenced in Figure 2. They highlighted the fact that characteristics of nontraditional students including living offcampus, working, part-time enrollment, and their advanced age of 25 or older lessen the significance of social interactions with other students and faculty. As seen in Figure 2, the model emphasizes environmental factors such as finances, occupational goals, and external encouragement as a directly impact on retention. However, Bean and Metzner do 
not ignore the importance of academic variables such as study habits, academic advising, and availability of courses.

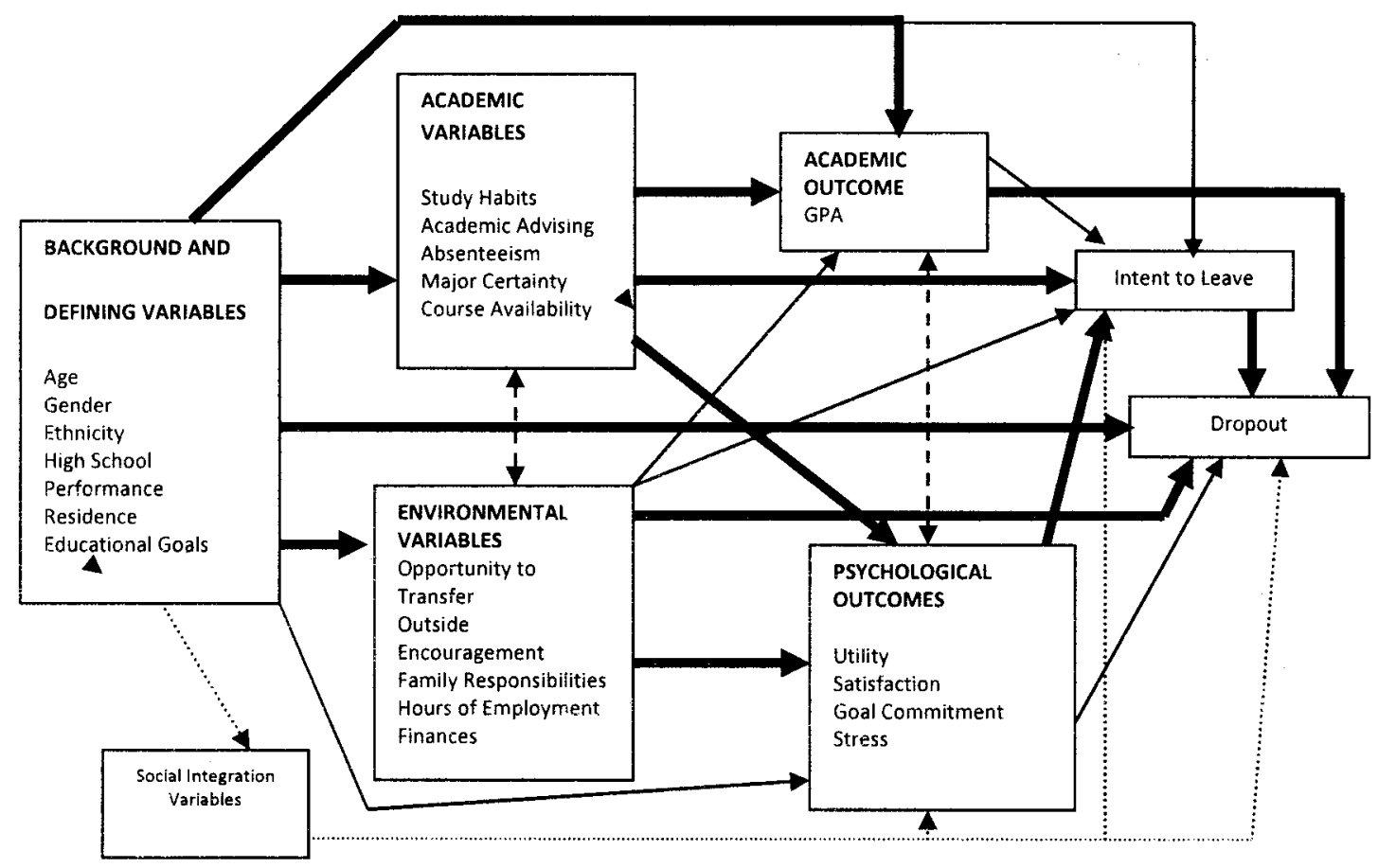

\begin{tabular}{lll}
\hline Key: & Direct effects & Compensatory interaction effects \\
& Direct effects presumed most important & Possible effects
\end{tabular}

Figure 2: Bean and Metzner (1985) Conceptual Model of Undergraduate

Nontraditional Student Attrition

Bean and Metzner's (1985) model distinguishes between variables with direct and indirect influence on dropout. It predicted that four variables that have the most impact on the decision to dropout. The first was prior academic performance. Students who performed poorly in prior academic settings including high school were likely to drop 
out. The second is intent to leave, which is strongly influenced by psychological factors, such as goal commitment, stress, and satisfaction with the academic program, and by academic factors, such as study habits, academic advising, and course availability. The third variable, background and defining goals, again highlight the significance of prior academic performance and the importance of the educational goal to the student. The fourth was environmental factors, including the number of hours worked, outside encouragement, finances, family responsibilities, and opportunities to transfer the credit hours earned.

The Bean and Metzner model (1985) along with Braxton, Hirschy, and McClendon's (2004) Theory of Student Departure in Commuter College and Universities provide the framework to understand adult learners in degree completion programs in greater depth. Therefore, the acknowledgement that adults pursue degrees in addition to a multitude of other responsibilities is essential to understanding the nuances that both encourage and discourage persistence to graduation. These two conceptual models were adapted for the purposes of this study to create a new model that examined the confluence of events that promote and deter adult learners from persisting in adult degree-completion programs at four-year colleges. Significant factors were isolated and examined to understand the variance explained by each variable. Further, statistically significant univariate variables were used in a logistic regression to examine the multivariate predictive relationship between student entry variables, internal campus environment variables, and external influence variables and the outcome variable student persistence. The ultimate objective of logistic regression was to predict a case's group 
membership on the dependent variable by calculating the probability that a case will belong to the 1 (event occurring) category (Myers, Gamst \& Guarino, 2006).

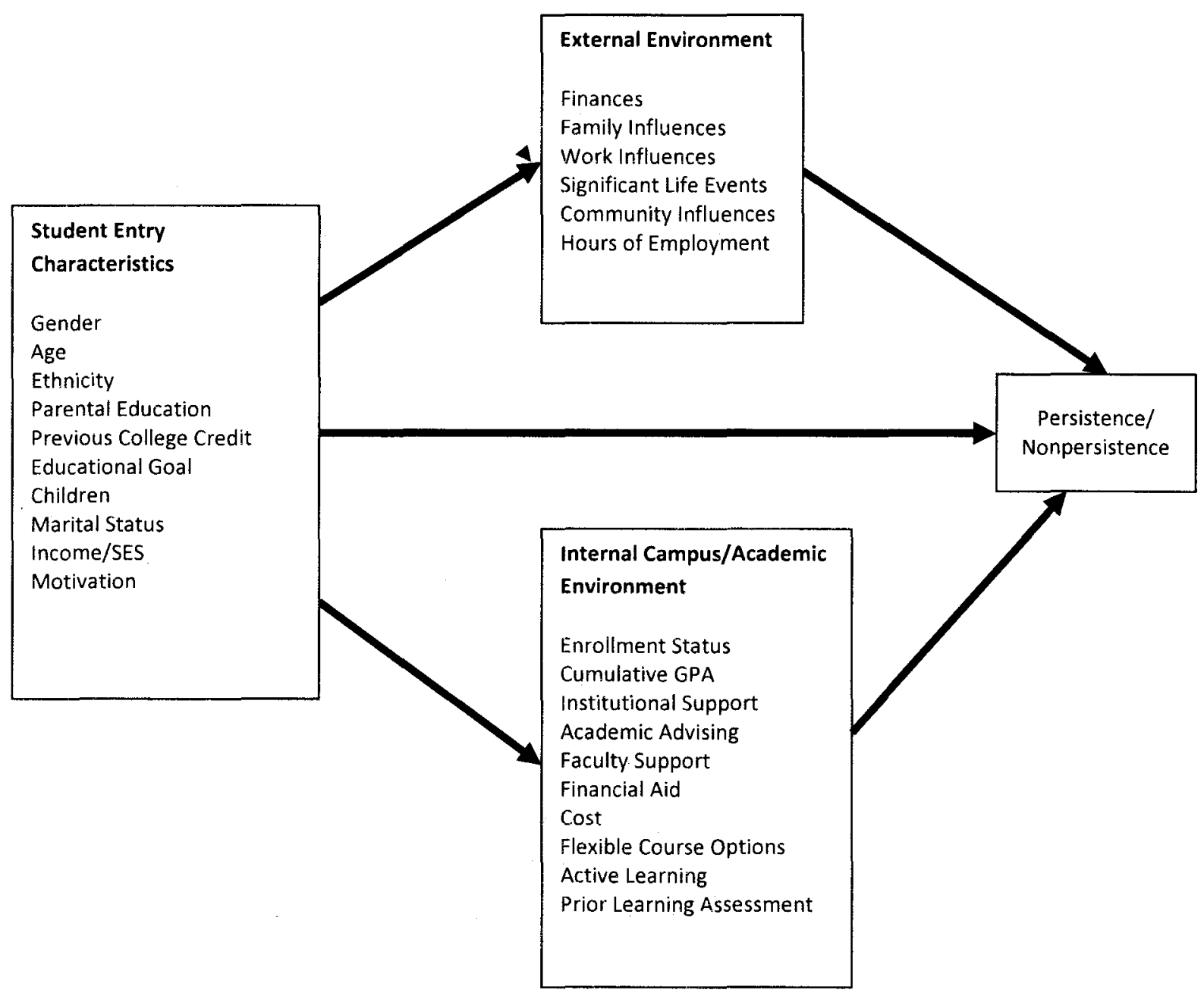

Figure 3: Proposed model: Theory of Adult Learner Persistence in Degree Completion Programs 


\section{Assumptions \& Delimitations}

This study considered only adult ( 25 or older) undergraduate students. It addressed only short-term drop out, continued enrollment, and degree completion and did not account for longitudinal results of students that may stop in and stop out for years beyond the timeframe of this study. The study also did not consider issues of instructional design or program curriculum. In other words, it did not assess the quality of instruction or content. The greatest benefits for explaining attrition behavior and departure decisions among adult students is best explained through longitudinal data that tracks long term persistence, stopout behavior, and dropout (Ishitani, 2006). However, this study only investigated differences in ability to persist through a one-time cross sectional survey instrument to measure interaction of factors that impact retention and persistence due to lack of time and resources available to this investigator. These were all delimitations of the study.

\section{Limitations}

Since this was a single institution study, it is considered a limitation to national generalizability. A multiple institution or national study would net more comprehensive results from which to draw inferences. Further, given that this study is confined to undergraduate courses, the results should not be applied to graduate students. The findings of this study can be generalized only to the adult learner population in Kentucky or regions with similar demographics in similarly structured degree-completion programs. This dissertation focused on persistence for adult learners who were enrolled in a degree-completion program focused on graduation as the overarching goal. 
Therefore, it did not examine students taking courses for professional development. Rather, this study focused on students seeking degree completion. Also this study was focused on limited variables from three constructs so all variables related to persistence were not included. Only significant variables that were included in the adapted theory of adult learner persistence in degree completion programs were examined. Other variables that have been found to be significant predictors of persistence were not included because of their lack of relevance to this adult student population.

\section{Definitions}

The following are definitions that will be used throughout this study:

1. Accelerated program: Completion of a college program of study in fewer than the usual number of years, most often by attending summer sessions, obtaining prior learning assessment credits, and/or carrying extra courses during the regular academic term.

2. Adult learner: Nontraditional students (ages 25 or older) in postsecondary education. In this study, adult learners have attended some college but have not completed a bachelor's degree. Adult learner will be used interchangeable with "adult students."

3. Degree-completion program: One designed especially to meet the needs of the working adult who has acquired sixty or more college credit hours during previous enrollments, and is returning to the school after an extended period of absence to complete a baccalaureate degree. The institution's promise that the student will be able to complete the program in fewer than two years of 
continuous study is realized through provisions such as establishing alternative class schedules, truncating the traditional semester/quarter time frame, organizing student cohorts, and awarding credit for prior learning experiences equivalent to approximately $25 \%$ of the bachelor's degree credit hour total (Taylor, 2000). There are more than 284 such programs as of the Task Force on Adult Degree Completion's analysis in 1993 (Taylor, 2000).

4. Attrition: Student departure or withdrawal from higher education for any reason. Attrition includes both dropouts and stopouts, often called "non-persisters," in that they failed to complete a degree program (Anderson, 1981; Bradburn, 2002).

5. Commuter: A student who lives off campus in housing that is not owned by, operated by, or affiliated with the college. This category includes students who commute from their own homes.

6. Degree completion: Satisfaction of the requirements for a bachelor's degree.

7. Degree-seeking student: Students enrolled in courses for credit that are recognized by the institution as degree seeking.

8. Distance education or online learning: Teaching and learning activities that occur when the learners and the instructors are separated at a distance. Courses may be taught using video teleconferencing, computer-based systems, the internet, or correspondence (Sikora, 2002).

9. Full-time student: A student enrolled in 12 or more credits per semester.

10. Hybrid programs: Programs that offer courses with blended delivery of content both in-class and online over the internet in individual courses. 
11. Nontraditional student: Higher education students that exhibit one of seven attributes: delayed enrollment, part-time attendance, financial independence, dependents to support, single parent, full-time employment, or GED or high school equivalent status (Horn, 1996). Although age was not an attribute in Horn's research, for the purposes of this study, the terms Nontraditional and Adult student will be used synonymously.

12. Part-time student: A student enrolled in fewer than 12 credits per semester.

13. Persistence: Relates to a student's continued progress through a course or program, ultimately resulting in a completed degree (OToole, Stratton, \& Wetzel, 2003).

14. Retention: Often synonymous with persistence, however it differs in that it is better defined as the year-to-year participation of a student at the same institution or program (Barefoot, 2004).

15. Stopout: Individuals who begin postsecondary education, either immediately after high school or later in life, and then interrupt their enrollment for a period of time, typically for more than one year (Horn, 1998). Students are thought to be a stopout until they are no longer capable of returning to the academic setting.

\section{Summary}

Few issues in higher education have received as much attention as persistence and retention (Bean 1990; Braxton, Hirschy, \& McClendon 2004; Cope \& Hannah, 1974; Iffert, 1956; Lang and Ford 1988; McNeely, 1938; Pantages \& Creedon, 1978; Raimst 1981; Spady 1970, 1971; Summerskill, 1962; Tinto, 1975, 1993). Prior research has 
shown that adults persist at lower rates than that of their traditional counterparts. Also, little is known about factors that increase rates of persistence among an increasingly broad base of flexible and convenient degree-completion programs at four-year colleges. With the advent of Prior Learning Assessment (college credit for work related competency) and offerings that include evening, online, and weekend options, one would assume that nontraditional students might persist to graduation at much higher rates. Accurate modeling of nontraditional student attrition behavior, however, is difficult due to the heterogeneity of the population (Metzner \& Bean, 1987).

More students in the United States attain degrees of higher education than anywhere else in the world. However, degree-attainment levels are increasing in every industrialized or post-industrial country in the world except the United States (Lumina Foundation, 2011). The Commonwealth of Kentucky, in particular, has low graduation rates. Only $20 \%$ of Kentucky residents have a bachelor's degree. The University of Louisville, along with other four-year institutions across the state are now focused on increasing number of baccalaureate degrees granted annually. The Commonwealth of Kentucky is determined to become economically attractive to businesses outside of the state and higher education administrators are charged with increasing the number of adults, military, and transfer students annually. Simply waiting for youth to fill the workforce needs, however, will not meet the demands of this rapidly changing economic landscape (Merriam, Caffarrela, \& Baumgartner, 2007).

Thus, it is important to understand the obstacles faced by adult students who return to the academic setting to pursue bachelor's degrees. Various work, family, 
financial, and community responsibilities have been shown to impact attrition and persistence behavior of adult learners. This study will examine these factors and how they interact to increase or decrease likelihood of persistence to graduation among adult learners in a single institution's four-year degree completion program. This study is designed to add to the small body of literature aimed at improving interventions both at a programmatic and policy level within the local and state context for adult degree programming.

\section{Organization of Study}

This chapter included the background to the problem, problem statement, purpose of the study, theoretical framework, significance of the study, definitions, assumptions, limitations, and delimitations. Chapter 2 provides a review of the literature that supports this single-institution study. Chapter 3 describes the research method used to conduct the study. Chapter 4 presents the findings of the study and chapter 5 concludes with a discussion of the results and implications for theory, research, and practice of this salient topic. 


\section{CHAPTER II}

\section{REVIEW OF THE LITERATURE}

Introduction

This study examined the relationship between adult student background/entry characteristics, internal campus/academic environment variables, and external environment variables related to persistence among returning adult students enrolled in degree completion programs at a four-year institution. The study utilized the main theoretical underpinnings of the conceptual model of nontraditional undergraduate student attrition first described by Bean and Metzner (1985) and the Braxton, Hirschy, and McClendon (2004) Theory of Student Departure in Commuter College and Universities.

This chapter begins with an introduction to the adult learner and an exploration of the makeup of this growing and underserved subpopulation of students. A discussion of their diverse and unique characteristics is also included. Next, an overview of the evolution of empirical literature on retention and persistence is presented along with an exploration of the variables associated with stopout and drop out behaviors among adult learners. Third, relevant literature around each of the predictor and outcome variables is examined. The chapter concludes with a discussion of the most significant isolated variables taken from two relevant conceptual frameworks including Braxton, Hirschy, 
and McClendon's (2004) Theory of Student Departure in Commuter College and Universities and the Bean and Metzner (1985) conceptual model of nontraditional undergraduate student attrition. Finally, a brief summary and an overview of the next chapters are presented.

Adult Learners in U.S. Colleges and Universities

Adult learners now comprise more than $45 \%$ of higher education enrollment (Bash, 2003). Wlodkowski (1999) pointed out that even defining the word "adult" results in cultural and historical differences. Dinmore (1997) argued that adult learners might be better defined by their level of experience instead of just chronological age. However, the most widely accepted criteria for identifying this subpopulation of students is age. Consequently, the most consistently recognized criteria for establishing one's classification as an adult learner is the age of 25 and older (Horn \& Berger, 2004). Although a small number of studies use the age of 24, the majority identify the age of 25 as the standard, Thus, this study will utilize the age of 25 as the cutoff for adult learners. With the decline in birth rates in all major developed countries, it is active older adults who must continue the workforce by being trained and retrained (Canja, 2002). Yet, Snyder and Dillow (2007) reported that only $28 \%$ of the 191.9 million adults over age 25 in the U.S. have attained a bachelor's degree or higher. This statistic leaves more than 138 million adults, or $72 \%$ of the adult population, without a bachelor's degree. Although adult learners currently make up nearly half of the U.S. college and university overall enrollment, millions more could potentially seek further postsecondary education. The changing global economy requires a more knowledge-based workforce, which elicits 
the need for a more educated citizenry. Hence, it is essential that this population be further researched and better understood.

Although all adult learners are at least 25 years old, this subpopulation of students is a widely diverse group that cannot be differentiated by age alone. A 25 year-old with five years of work experience is much different from a 65 year-old returning to school after working for the same company for 48 years. Although adults generally demonstrate greater levels of urgency and higher motivation than younger students, it is important to disaggregate the differences represented by this heterogeneous student population. Common characteristics were explored and age distinctions were further extrapolated to distinguish this widely diverse group of students.

\section{Nontraditional and Adult Student Distinctions}

Horn (1996) defined nontraditional students as individuals that meet one of seven characteristics: delaying enrollment after high school, being a part time student, working more than 35 hours a week, being financially independent, having dependents (other than a spouse), being a single parent, or lacking a high school diploma. Horn (1996) further differentiated these traits by categorizing nontraditional students as minimally nontraditional (having one of the characteristics), moderately nontraditional (two to three characteristics), or highly nontraditional (four or more characteristics). Choy (2002) concluded that more than $73 \%$ of the undergraduate student population can be classified as nontraditional (having one of the nontraditional characteristics) and most adult learners have at least one or more characteristic of nontraditional status. Therefore, one can 
conclude that all adults are nontraditional students but not all nontraditional students are adult learners.

The background, educational goals, and learning style of adult and nontraditional students differentiate them from their traditional counterparts. Many adult students have various responsibilities including marriage, children, employment, civic, and social responsibilities (Kasworm, 2003; Wlodkowski et al., 2001) that limit their ability to engage in academic degree programs. They often return to higher education to improve the prospect of advancing their career or increasing earning potential in the workforce. With the decline of the economy and the reduction of manufacturing jobs, more adults are returning to the academic setting to learn specialized technical, business, and professional skills. By $2018,63 \%$ of jobs will require some form of postsecondary training (Carnevale et al., 2010). Thus, it is especially important for institutions of higher education to understand the unique needs and characteristics that shape this growing student base in order to recruit, retain, and graduate more adult learners.

\section{Andragogy}

Houle (1961) found that adult learners were motivated to participate because they were goal, activity, or learning oriented. He postulated that adult learners must be motivated by a specific reason or purpose. Adults, unlike traditional students, are primarily in charge of their major life decisions. They arrive in the classroom with a plethora of previous work experiences, knowledge, interests, competencies, and clearly defined future goals, which make them more able to effectively synthesize information and achieve deeper learning outcomes than traditional students. For adult learners to 
achieve academic success, however, they need direct, facilitated discussions in which they can practically apply their new knowledge in to their prior experience (Knowels, Holton, \& Swanson, 2011). Adult students need to move beyond understanding onto application, analysis, synthesis, and evaluation in a workplace setting.

Knowles (1980) supported these innovative points when he presented the idea that adults pursue education in a problem-centered or performance-centered frame of mind. He is known as the father of Andragogy, a theory of adult education focused on the different learning styles of older learners. Knowles et al. (2011) posited that adult students seek to learn in order to deal with a current (problem-centered) or desired (performance-centered) situation. Table one illustrates the five assumptions defining characteristics of adult learners and their optimal environment: self-directed, experiential, desire or readiness, problem-centered, and internally motivated (Knowles, 1980; Merriam \& Cafferella, 2001).

Table 1: Comparison Between Traditional and Adult Learners (Knowles, 1980)

Traditional Learner

Dependent personality

Teacher is fully

responsible for (what,

how, when, whether).

Little valuable experience; The Learner's Experience
Adult Learner

The Learner

Self-directed learning

Anxious to learn by demonstrating they are taking responsibility for themselves Assumes greater volume 
rely on transmission

techniques via lectures,

readings, and audiovisuals

Students become ready to

learn what they are told

they have to learn

Subject-centered:

Learning as a process of

acquiring prescribed

subject matter

External: pressures come

from parents or teachers
Readiness to Learn

Orientation to Learning

Life-centered, task-

centered, or problem-

centered orientation

(curriculum should focus

on life situations rather

than subject matter units)

Motivation to Learn

Internal: self-esteem,

recognition, better quality

of life, greater self-

confidence 
The process elements of andragogy include; preparing learners, establishing a mutually respectful climate, mutual planning by students and facilitator, diagnosing needs, setting objectives, designing learning plans, facilitating activities, and evaluating performance (Knowles et al. 2011).The andragogical framework utilizes the teacher as a facilitator rather than authority figure by promoting a safe, caring, trusting, respectful, and understanding classroom environment. Although Knowles never intended for andragogy to be a theory of the discipline of adult education, it is a widely accepted theoretical approach to adult learning recognizing the diversity, commonalities, and unique learning needs of adult students (Merriam \& Cafferella, 2001).

\section{Reasons for return}

Job progression among all persons in the workforce is no longer linear as in decades past. Job and career changes are experienced both voluntarily and involuntarily. Corporations, government, non-profit sector, and the military have increased their educational requirements for even entry-level positions (Klein-Collins et al., 2010). Organizational restructuring and technological change has created a greater need for formal education that is often degree seeking (GLI, 2011). Mergers, acquisitions, downsizing, outsourcing, restructuring have companies and organizations interested in new knowledge bases that may be fulfilled by specific academic programming. Early retirement is no longer as prevalent an option as in years past. Thus, educational programs necessary to reach a desired employment level often fill the gap for older adults as well. With an aging population and ever-present economic difficulties, it is evident that adults will seek out additional postsecondary education for the foreseeable future. 


\section{Adult Degree Programs}

While adult learners occupy a growing percentage of total enrollment at U.S. colleges and universities, they continue to represent a much smaller segment of the literature published in the academy. Despite this, the relevance of adult learners to the viability of many institutions of higher learning is becoming increasingly evident. New degree programs and institutions that offer convenient and flexible degree programs have been established to serve the influx of this often neglected subpopulation students. The response, however, has not been sufficient. The gap in literature suggests that academics, practitioners, and policy-makers must examine how the academy attracts and retains adult learners. Institutions that develop meaningful professional partnerships to facilitate the educational needs of the workforce strengthen their ability to complete in the marketplace (Feldman, 2004). Relevant partnerships with the community increase access to the university, while simultaneously embedding the university in the community (Feldman, 2004). Well-planned, convenient, and flexible programs offering excellent instruction and high-level student services are the most effective in their ability to successfully deliver degree-granting programs, thus addressing the age old problem of student retention (Wlodkowski, 2001).

History of Retention and Persistence Literature Few problems in higher education have received as much attention as retention and persistence (Astin 1971 1985; Bean 1980, 1990; Braxton, Hirschy, \& McClendon, 2004; McNeely 1937; Spady 1970, 1971; Summerskill 1962; Tinto 1975, 1993). Currently, only $56 \%$ of students at four-year institutions and $28 \%$ of those at two-year 
colleges earn a degree within six years (College Board, 2009). The importance placed on graduation rates and a more college-educated workforce has led colleges and universities to investigate why students are not persisting at higher levels. The first studies of college student retention emerged in the 1930s (Seidman, 2005). McNeely's (1937) pioneer study of "College Student Mortality" used data from sixty institutions to examine attrition rate, time to degree, impact of institutional size, reasons for departure, and points during academic career of highest rates of attrition. This work was considered highly comprehensive and ahead of its time in a new field of study in higher education. The Great Depression and World War II interrupted retention research, but at the end of the war the United States again began to focus on education, as scores of veterans returned to the classroom.

In another classic study of early sociology, Durkheim (1951) examined suicide rates of different countries over time. Durkheim distinguished four types of suicide: altruistic, anomic, fatalistic, and egotistical (Tinto, 1993). Spady (1971) and Tinto (1975) produced seminal works that were directly influenced by Durkheim's theory of egotistical suicide which highlighted the ways in which social and intellectual societies integrate into communities. According to Tinto (1993), "egotistical suicide provides the analogue for our thinking about institutional departure from higher education" (p. 100). Summerskill (1962) made a significant contribution with his findings that personality attributes of students were the main reasons for persistence and departure decisions. Spady's (1971) model then advanced a movement to understand retention for greater development of theory, research, policy, and practice for the improvement of the 
American higher education system. His model emphasized the interaction between individual student characteristics and key aspects of the campus environment. Spady (1971) provided a synthesis and produced one of the first conceptual frameworks that served as a precursor to Tinto's (1975) model.

Astin (1984) later developed the "Theory of Involvement" which posited that a more involved college student will persist to graduation at a higher rate than one that are less involved. He and his colleagues at the University of California at Los Angeles studied national databases from hundreds of colleges and concluded that student investment in both the social and academic endeavors directly impacts their likelihood of persisting to graduation. Astin (1971), Tinto (1975), and Spady $(1970,1971)$ led the charge to establish a reliable base of theory in the 1970's that became the driving force to conduct empirical studies that produced a more systematic understanding of student retention than any time before in the history of higher education (Seidman, 2005). Subsequently, Pascarella and Terenzini $(1979,1983,1991,2004)$ completed numerous empirical studies that developed operational measures from the core constructs of the various theoretical models presented by these seminal authors. Specifically, Pascarella and Terenzini (1983) attributed the interaction between student and faculty as a major influence on student integration into higher education, resulting in increased student persistence. They found that interaction between the student, peers, and faculty substantially increases the social and academic integration, potentially resulting in increased persistence. 
Establishing himself as the foremost authority in the field, Tinto's (1975) interactionalist theory of student departure became the best-known and most cited theories in the field (Seidman, 2005). The first premise of Tinto's $(1975,1993)$ model was that students come to higher education with a variety of pre-established characteristics, including academic preparation, gender, family background, and race/ethnicity. He posited that based on these characteristics, students possess specific levels of commitment, both to the institution and to the goal of degree completion. Under Tinto's framework, students become part of the educational community where they may participate in a variety of academic and social experiences that may or may not lead to their social and/or academic integration into the institution. The level of integration further influences the students' commitments to the institution and goal attainment, which in turn influence the decision to persist or withdraw from college (Tinto, 1993).

Theoretically, Tinto's derived his theory from Van Gennep's assessment of the three distinct rites of passage of tribal communities (Tinto, 1993). The first is separation, which "requires individuals to disassociate themselves, in varying degrees, from membership in the communities of the past, most typically those associated with the family, the local high school, and local areas of residence" (Tinto, 1993, p. 95). Virtually all students experience some level of stress and isolation during this stage, even adult and nontraditional commuter students. While adult and nontraditional students may not feel a sense of loss from the separation from the prior community, they may also not experience the full sense of reward of integration into the higher education community. 
The second stage of separation is transition. Again, virtually all students experience stress in making the transition to college. Tinto (1993) stated that "the scope of the transition stage depends on a number of factors, among them degree of difference between the norms and patterns of behavior associated with membership in past communities and those required for integration in to the life of the college" (p. 97). Finally, the third stage is the process of becoming integrated into the communities of the college.

Tinto's (1993) longitudinal theory of student persistence is the most widely referenced retention model in higher education. Researchers have tested it against a wide variety of populations and institution types, and it has been consistently validated since it was first introduced in 1973. But it is not the only model of student persistence nor is it universally accepted. Astin (1993), Bean (1980), and Spady (1970, 1971), among others have also proposed widely cited models. Numerous scholars have questioned the applicability of Tinto's theory to all student populations, noting that since it was based on research at traditional residential campuses, minority and nontraditional students may not be fully represented by the model (Cabrera, Nora, \& Castaneda, 1993; Nora, 2001; Tierney, 2001). Specifically, critics suggest Tinto under-estimates the role of significant others and the extended community in the decision-making of those who are minority, nontraditional, and/or commuter students (Cabrera et al., 1993; Nora, 2001; Tierney, 2001). Cabrera et al. (1993) proposed an alternative retention model that synthesized Tinto's emphasis on interactions within the academic institution with Bean and Metzner's (1985) emphasis on the external environment. 
To explore nontraditional retention patterns Bean $(1980,1983)$ adapted a model of employee turnover in work organizations to the problem of student attrition. He examined how organizational attributes and reward structures affected student satisfaction and subsequent persistence. Bean (1980) used ten exogenous variables that influence student satisfaction including participation, routinization, instrumental communication, integration, distributive justice, grades, practical value, development, courses, and membership in campus organizations. He found that all of the variables except routinization had a positive effect on satisfaction, which in turn influences a student's intent to leave prior to graduation.

Bean and Metzner (1985) later teamed up to hypothesize that Tinto's model overstated the impact of socialization on nontraditional students. They highlighted three primary characteristics of nontraditional students: off-campus residents, often with dependent family members; age of 24 or older; (future research highlights the age of 25 as the standard for adult learners) and part-time enrollment status. These three factors lessen the importance and significance of social interactions with both other students and faculty for the nontraditional student. Their model emphasizes environmental factors such as finances, occupational goals, and external encouragement as directly impacting retention. Equally important are academic variables such as study habits, academic advising, and availability of courses. In this theory, socialization is only a marginal influence on the decision to persist or leave the institutions.

Bean and Metzner (1985) reported some aspect of work, related to time or money, was a factor in persistence in all socioeconomic classes. For many students, working 
during college is necessary to survive, despite the research that has established a negative correlation between work and academic persistence, resulting in student drop-out behaviors.

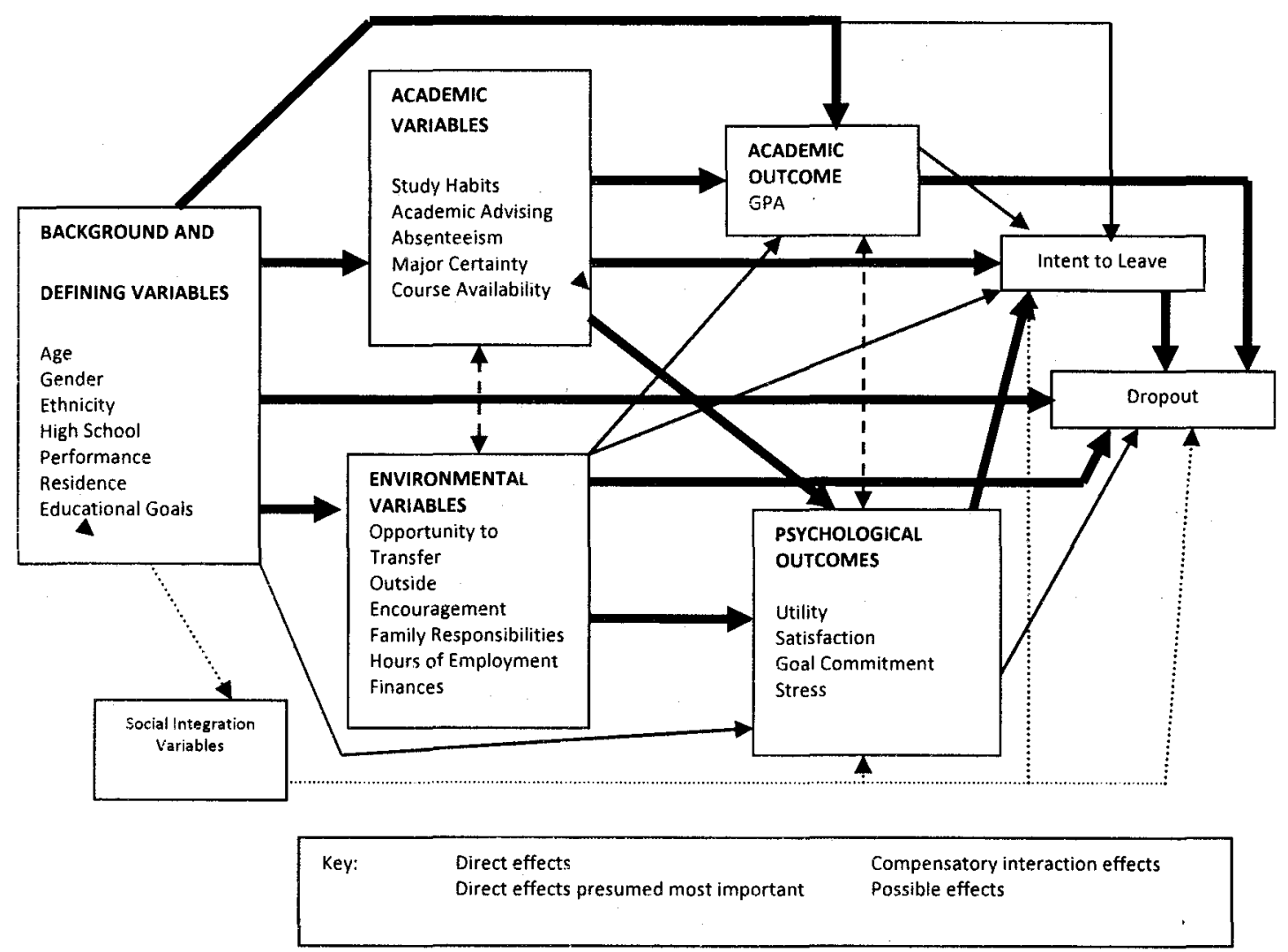

Figure 2: Bean and Metzner's conceptual model of nontraditional student attrition (Bean \& Metzner,1985, p. 491)

Bean and Metzner's (1985) model distinguished between direct and indirect variables that influence dropout as references in figure 2 . It predicted that four variables would have the most influential impact on the decision to dropout. The first was prior academic performance. Students who performed poorly in prior academic settings 
including high school were more likely to drop out. The second was intent to leave, which is strongly influenced by psychological factors such as goal commitment, stress, and satisfaction with the academic program, and by academic factors such as study habits, academic advising, and course availability. This category includes students who intend to transfer to another institution. The third category, background and defining goals, again highlights the significance of prior academic performance and the importance of the educational goal to the student. The fourth was environmental factors and includes number of hours worked, outside encouragement, finances, family responsibilities and opportunities to transfer the credit hours earned.

The Bean and Metzner model (1985) also highlights factors that may have an indirect impact on retention. For example, in and of itself age is not a predictor of retention. However, older students may have more non-academic responsibilities and the responsibilities may influence the decision to drop out. Thus, it is not specifically age but the responsibilities that tend to accompany age that influence persistence. Bean and Metzner (1985) also listed social integration as a variable that may have an indirect effect on nontraditional dropout, noting:

The model posits that social integration variables should have only minimal effects on retention, partly due to the way nontraditional students were defined and partly because social variables from the outside environment are expected to be of greater importance than college social integration variables. In addition, other environmental variables, such as family responsibilities, can play a significant role in the attrition process for nontraditional students (p.530). 
Metzner and Bean's (1987) Conceptual Model of Nontraditional Student Attrition further delineated the model including: enrollment status, residency status, educational goals, high school performance, ethnicity, and gender; academic variables such as study habits, academic advising, absenteeism, major certainty, and course availability; environmental variables such as finances, hours of employment, outside encouragement, family responsibilities, and transfers; and social integration variables, such as memberships, faculty contact, school friends. The variables used in this empirical study accounted for $29 \%$ of the variance in dropout, which compares well with other studies in the area of attrition. Significant effects were confirmed in 11 of 12 areas of the path model originally developed by Bean and Metzner (1985). The only contradictory finding related directly to the impact of environmental variables on dropout. Metzner and Bean (1987) found that external/environmental variables failed to affect dropout directly and three significant effects on intent to leave that were not originally anticipated. Also, the psychological outcome variables, goal commitment, and stress were not directly related to intent to leave or dropout in the 1987 study. Thus, the findings suggest a need to revise the model to understand direct and indirect variables on older students at a deeper level.

Cabrerea, Castaneda, Nora, and Hengstler (1992) summarized Tinto's student integration model by indicating that persistence is a function of the match between a student's motivation and academic ability and the institution's academic and social characteristics. They posited that strong goal and institutional commitment are linked to higher persistence to graduation. This study defined and contrasted the effect of variables 
identified by Tinto (1982) from the social integration construct and Bean and Metzner (1985) inclusion of family and outside influences on student persistence.

More recently, Braxton, Hirschy, and McClendon (2004) constructed an updated path model for commuter institutions based on Tinto's interactionalist theory. This revision is based upon the unique differences between students that attend commuter institutions and those that attend residential institutions. Adult learners make up a larger percentage of students at commuter institutions, and therefore, students who select commuter schools exhibit many more attributes and college is merely one of many priorities in their lives.

For that reason, it is necessary to draw distinctions between students that attend different types of universities to understand the unique characteristics that interact to impact student persistence. The average student's family background, academic ability, and age may vary greatly from a residential to a commuter college or university. The same goes for external environmental impacts for students at each type of institution. Commuter college students are much more likely to attend part-time and live away from the college campus than those at a residential campus. These important distinctions confirm the need for the adapted model presented by Braxton, Hirschy, and McClendon (2004). 
Table 2:

Summary of Key Retention and Persistence Literature (Center for the Study of College

Student Retention)

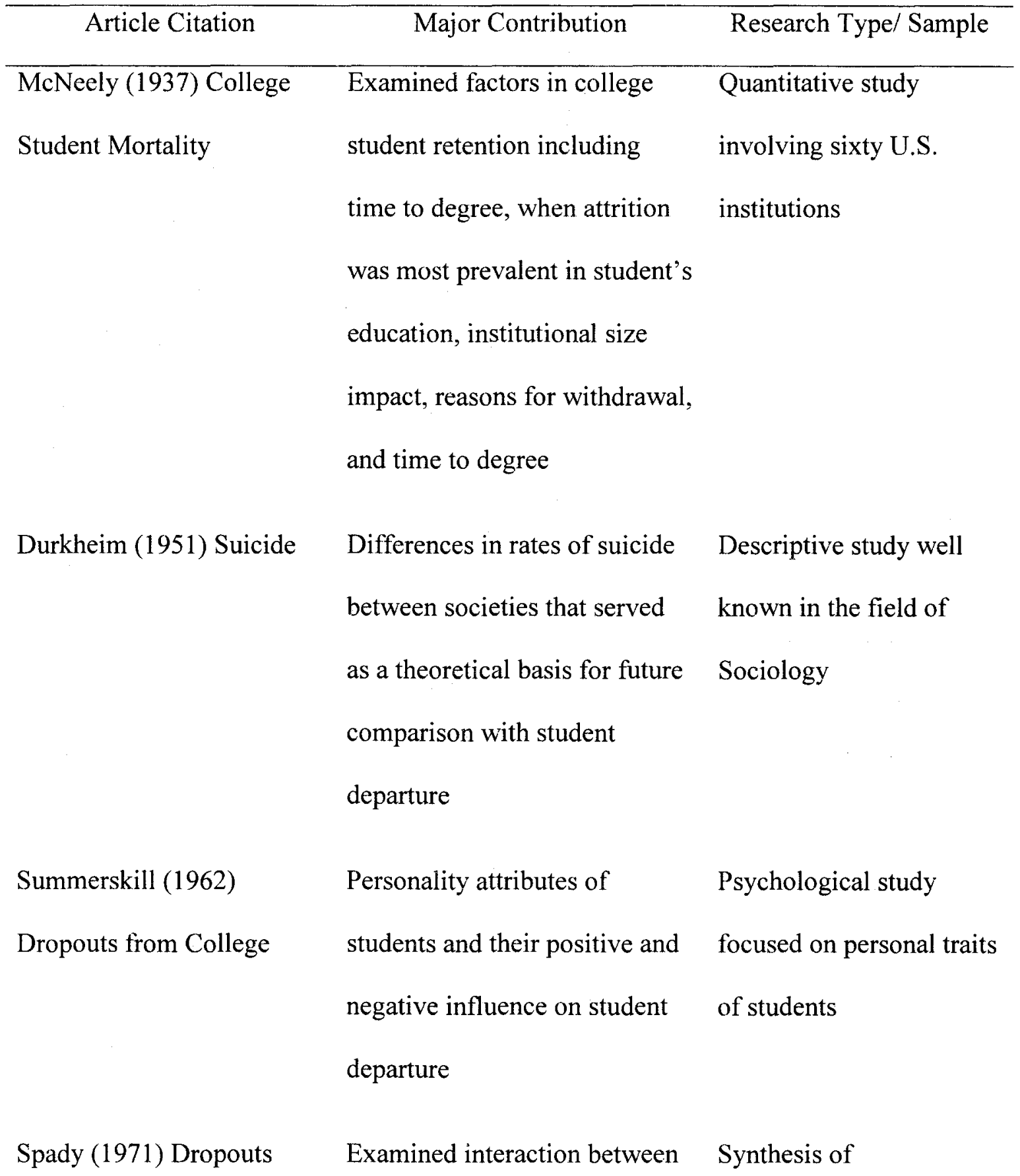




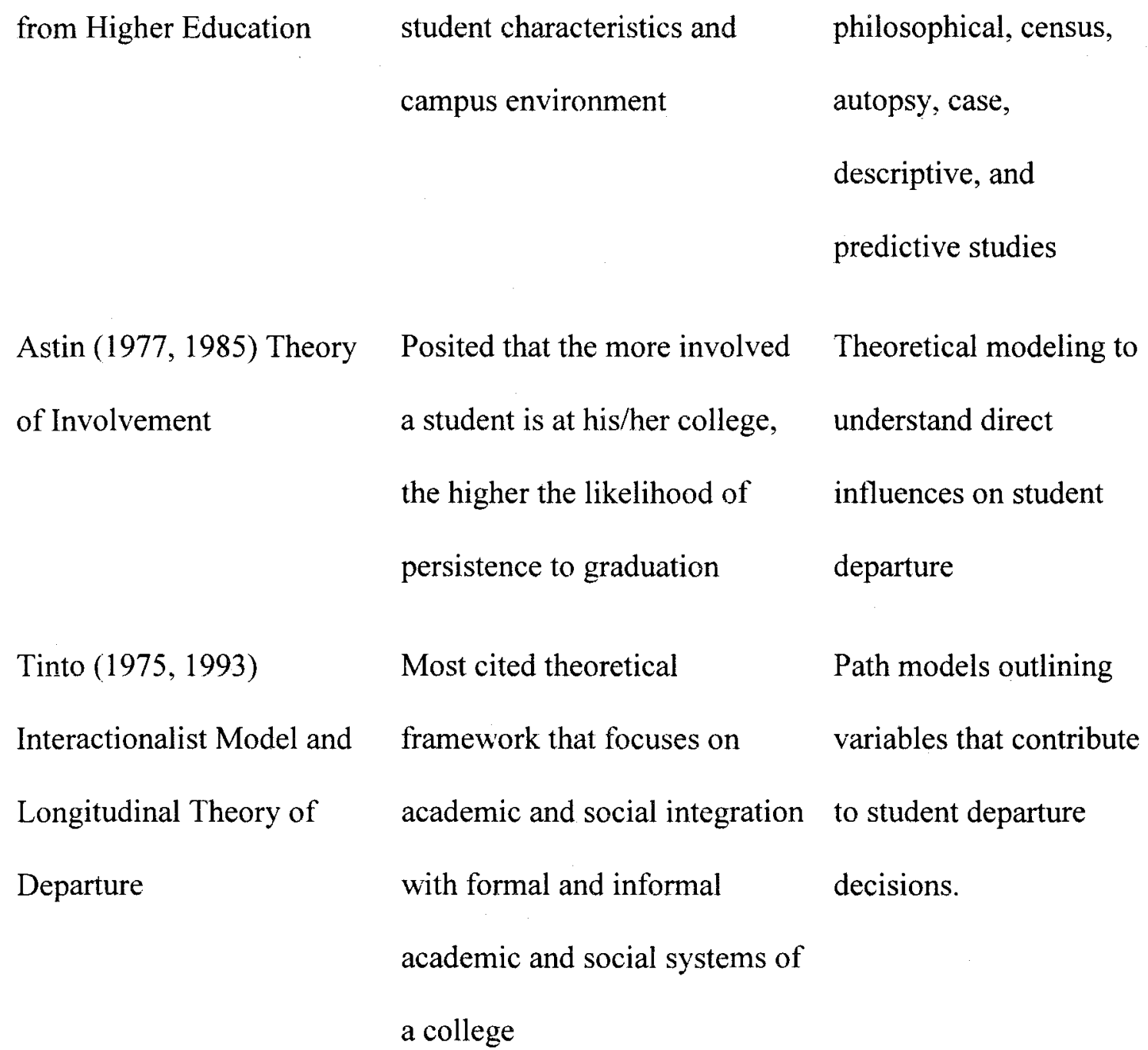

Pascarella \& Terenzini Found that interaction between Numerous empirical $(1977,1978,1980,1981, \quad$ the student, peers, and faculty studies throughout the 1983) How Collge Impacts substantially increases the 70 's and 80 's Students social and academic integration

Bean $(1980,1983)$ Model Used concepts from Theoretical model 
of Work Turnover to

Student Attrition

Bean \& Metzner (1985)

Nontraditional Student

Attrition

Braxton, Hirschy, \&

McClendon (2004)

Adapted Interactionalist

Model for Commuter organizational studies of work adapted from Price and

turnover to equate to student Mueller's (1981)

satisfaction and persistence Employee Turnover

Model

Path model showing

interaction of direct and

decisions in nontraditional indirect variables on

students more than academic student departure

variables

Theory of student departure in Path Model displaying

commuter colleges and

factors that impact

universities

student commitment and

persistence behavior

Schools

\section{Adult Retention Literature}

Despite the important research on adult and nontraditional attrition, scholars have failed to study this subpopulation closely enough. No single group is more important to the viability of higher education as an industry and the reasons for adult student attrition stem from complex and diverse intervening variables (Tweedell, 2000). Moreover, Tinto (1993) posited that much of what we think we know about student retention is wrong or 
at least misleading and a good deal of literature is filled with stereotypical portraits of those student dropouts. Institutions of higher education are still unable to make sense of student departure because so much remains unknown about its longitudinal character and the complex interplay of forces that lead students to drop out (Tinto, 1993). As the number of traditional students continues to decrease, the need for a better understanding of adult students has deepened.

It is important to take the type of institution into consideration when studying retention. Highly selective institutions have more full-time residential students with higher academic aptitude than less-selective institutions. Thus, students at prestigious institutions are retained at greater rates than that of open enrollment, two-year, and forprofit institutions. Along this line of thought, adult learners make up a miniscule percentage of the populations at highly selective institutions. Nontraditional students often enroll in college during a period of transition, e.g., during a divorce, change in job or career, pregnancy or recent birth of a child, young children becoming more independent, or older children leaving the home (Kasworm, 2003). Adults do not have the luxury of attending highly selective schools or progressing through the academic experience in a linear fashion. Although prestigious private institutions boast strong enrollment growth and high academic standards, other less selective, tuition-driven institutions struggle to make budgetary goals each year and teeter on the brink of closing their doors.

In addition, this body of research highlights the importance of categorizing student withdrawal classifications more precisely, with descriptors such as transfer-out, 
stop-out, and drop-out. While most studies on adult learners focus on student characteristics or retention strategies, very few address the decision-making process adults engage when they consider reentering higher education (Donaldson \& Townsend, 2007). Mishler's (1983) study of older students who had entered college and completed a bachelor's degree found the two most important reasons for returning were to develop skills for a new career (26\%), and the satisfaction of having the degree (18\%). Additionally, the participants indicated earning a degree (58\%) and developing job skills (54\%) were very important to them. These findings highlight the fundamental value adult learners place on earning a degree. Older individ hals have a stronger learning goal orientation, whereas younger learners exhibit a greater performance orientation (Eppler \& Harju, 1997). Thus, empirical studies focused on relevant and applicable course content that relates directly to the workforce in the form of degree completion programming will add value to this field of study.

\section{Degree-Completion Programs}

Adult degree completion programs are become increasingly relevant within the higher education community and they are growing at a rapid pace across the nation (Taylor, 2000). According to the North Central Association's Higher Learning Commission Task Force on Adult Degree-Completion Programs (2000), an adult-degree completion program is one designed especially to meet the needs of the working adult who, having acquired sixty or more college credit hours during previous enrollments, is returning to school after an extended period of absence to obtain a baccalaureate degree. The institution's promise that the student will be able to complete the program in fewer 
than two years of continuous study is realized through provisions such as establishing alternative class schedules, truncating the traditional semester/quarter time frame, organizing student cohorts, and awarding credit for prior learning experiences equivalent to approximately $25 \%$ of the bachelor's degree credit total (Task Force, 2000). Adult degree programs share common characteristics including but not limited to: distance (online) options, evening course options, weekend course options, test-out (CLEP and DSST) options, and college credit for prior learning in the workplace.

Educational programs for adults are conducted for five primary purposes: to encourage continuous growth and development of individuals, to assist people in responding to practical problems and issues of adult life, to prepare people for current and future work opportunities, to assist organizations in achieving desired results and adapting to change, and to provide opportunities to examine community and societal issues (Merriam, Caffarella, \& Baumgartner, 2007). Closing the gap between theory and practice in undergraduate education is essential to ensuring the well-being of individuals and the future of our society (Kuh, 2008). Among the best practices for both traditional and adult learners include outreach, financing, life and career planning, assessment of learning outcomes, teaching-learning process, student support systems, technology, and strategic partnership.

Changes in demographics are forcing colleges and universities to consider more adult-friendly practices in order to keep their doors open (Crouch, 2002). Between 1970 and 1991, adult participation in higher education rose at a meteoric rate of $171.4 \%$. Adult learners have steadily increased over the past three decades, to more than $45 \%$ of the total 
student population (Choy, 2002; Kasworm, 2003a). The U.S. Census Bureau (2008) reported that $53.8 \%$ of men and $61.1 \%$ of women between 25 and 29 years old have some college but no degree.

This significant number of adults with some college and no degree has created an adult degree completion program phenomenon and it is impacting thousands of institutions. Within the next twenty years, estimates show that $25 \%$ of adult students will be enrolled in accelerated degree-completion programs (Wlodkowski, 2002). As such, institutions cannot afford to let adult degree completion programs operate on the periphery of their traditional curricula.

Many adults can enhance their lives through the completion of these programs, which are an attractive option because of the reduced barriers to degree completion. Flexible evening and weekend courses alongside online course offerings accommodate the otherwise busy life schedules of adult learners. Nevertheless, barriers still remain and recent studies showed that accelerated degree programs produced a $40 \%$ six-year graduation rate (Wlodkowski et al, 2001). Therefore, $60 \%$ of adults still withdraw prior to graduation. These statistics rival the national average of degree completion among traditional-age students. If adults persist at the same or lower rate than their traditional counterparts, how much do degree completion programs actually help remove barriers to adult student success?

The following is an overview of the Principles of Good Practice for Alternative and External Degree Programs for Adults (Adult Education Alliance, 1998): 
1. The program has a mission statement that reflects an educational philosophy, goals, purposes, and general intent and clearly complements the institutional mission.

2. Faculty and academic professionals working in alternative and external degree programs share a commitment to serve adult learners and have the attitudes, knowledge, and skills required to reach, advise, counsel, and assist such students.

3. Clearly articulated programmatic learning outcomes frame the comprehensive curriculum as well as specific learning experiences; in developing these outcomes, the program incorporates general student goals.

4. The program is designed to provide diverse learning experiences that respond to the characteristics and contexts of adult learners while meeting established academic standards.

5. The assessment of a student's learning is used to determine the achievement of comprehensive and specific learning outcomes (pp. 6-8).

The statements referenced in the list above are taken from the document, Principles of Good Practice for Alternative and External Degree Programs for Adults, published by the American Council on Education and the Alliance: An Association for Alternative Degree Programs for Aduits (1990). The organizational name of the Alliance was changed to the Adult Higher Education Alliance in 1998.

Adult degree completion programs prepare individuals for responsibilities in vocational, business, services, governmental, and industrial occupations, as well as other related fields. They are targeted towards a variety of individuals, including those who are already employed; desire to change their employment; strive for advancement and do not have a "needed" bachelor's degree; planning careers in mid-management in business, banking, and industry plan; to advance in public service (such as legal assistance employment); intend to move into administrative positions in local, state or federal 
governmental positions (i.e. customs, border patrol, legal or court systems) or health professions; or intend to manage or open their own business or workshop (Taylor, 2000).

One unifying assumption held by most scholars is the fact that adult learners are highly pragmatic in their approach to educational attainment (Thomas \& Chickering, 1984). They hold more real-world experience to contribute to their own learning process, and they have well-defined needs that place a utilitarian approach into much of their academic decision-making (Knowles, et al., 2011).

Specific Variables Examined in This Study

There are many factors that affect students' progress to graduation. Adult students pose a unique challenge to researchers because they do not persist to graduation in the same manner or at the same rates as traditional-age students. Adult students come to higher education with a variety of academic backgrounds. Some return to college after a gap of several years well prepared for any academic challenge they face. Others require remedial or developmental education to increase academic preparedness.

\section{Entry characteristics}

Background variables include parents' education, socioeconomic status and income, ethnicity, age, gender, marital status including number of children, total previous college credit earned and goal commitment. Other entry characteristics include high school class rank, standardized test scores, college prep curriculum, and high school friends attending college but they were excluded because they pertain to traditional-age students rather than adult learners. 


\section{Gender}

The strength of association between gender and completion varies in the studies, but gender is a factor in most published studies that have adequate sample size and statistical techniques (Choy, 2002; Farabaugh-Dorkins, 1991; Horn, 1998; McCormick,

Geis, Vergun, \& Carroll, 1995). An analysis of data from the Integrated Postsecondary Education Data System reported that $62 \%$ of women adult students graduate from twoyear institutions and $57.2 \%$ of women adult student graduate from four-year institutions; and men graduate at rates of $38 \%$ and $42.8 \%$ respectively (Knapp et al., 2005). Thus, women graduated at higher rates than men at both the two and four-year levels. On the contrary, the Metzner and Bean (1987) study did not find a significant association between persistence and gender. Horn and Berger (2005) also did not find a significant difference in the gap in the graduation rates between women and men. Shields (1994) found no effect from gender, although total sample size may have had an influence on this conclusion $(\mathrm{N}=97)$. Woosley (2004) also found no significant differences related to gender. Therefore, it is posited that no gender differences are likely to exist in a degreecompletion program composed of adults ages 25 and older.

$$
\text { Age }
$$

Scholars do not agree on whether or not age positively or negatively affects persistence or if it has any influence at all. It is true that as the age of the student increases, it is less likely that the parents attained a college degree and older students may have more non-academic responsibilities that influence the drop-out decision. Simply being older does not mean an individual will have less time to participate in higher 
education. Adult learners often make a pledge to balancing other life commitments and have great success in their degree pursuits. Bean and Metzner (1985) highlighted age as one indirect effect on nontraditional student persistence. However, in and of itself, age was not a predictor of retention. Older students may have more non-academic responsibilities and the responsibilities may influence the drop-out decision. Thus, it is not age but the associated responsibilities that tend to accompany age that influence persistence.

Conversely, age has been found to be a significant factor associated with persistence in a number of other studies. In general, these studies found that younger students are more likely to complete their studies and that older students were more likely to achieve higher grades (Kasworm, 1990). Multiple researchers found that younger students are more likely to finish (McGivney, 1996; Webb, 1989). The longitudinal study by Horn (1998) also found that dropouts tended to be older. While a higher grade point average (GPA) is a factor positively associated with persistence (Kasworm, 1990), older students challenge this theory as they tend to have higher grades but drop out more often. Theoretically, one would expect that because older student tend to have higher GPAs, they would be more likely to persist, but some studies suggest otherwise. It was hypothesized that age would not be a significant predictor of student persistence.

\section{Ethnicity}

This variable appears as a factor in persistence in many education studies. However, the studies that have considered the impact of ethnic origin among adult students have produced contradictory results. Many studies including Byrd (1990), Horn 
(1998), and Webb (1989) found ethnicity to be a statistically significant factor in persistence. Conversely, Bean and Metzner (1985) predicted ethnic origin to be a factor in nontraditional persistence but their 1987 study did not find this variable statistically significant after controlling for other factors. Choy (2002) and St. John and Starkey (1995) also found no ethnic background variable significant when controlling for other factors. For the purposes of this study, it seemed unlikely that ethnic origin would be, by itself, a significant factor in adult student persistence.

\section{Parent's Educational Attainment}

Students with parents and other close family members or friends who have graduated from postsecondary institutions are more likely to desire to attain similar educational goals and persist to graduation at a higher rate (Tinto, 1993). Those whose parents or family members have not achieved such educational credentials are less likely to be interested or aware of the opportunities that are afforded to those with postsecondary degrees. Older students are far more likely than traditional age students to be "first generation" students who are less conscious of all of the nuances related to entry and assimilation into colleges and universities. These students, both adult and traditional are more likely to leave before completing their studies (Choy, 2002; Horn, 1998). Therefore, this variable was considered important to analyze based upon the findings of previous studies. It seemed likely that parent's educational attainment would be influential on adults within this study. 


\section{Previous College Credit}

Students who have more prior college credits are more likely to persist to graduation (Christensen, 1991; Hanniford \& Sagaria, 1994; Harrington, 1993; Martin 1990; \& Simmons, 1995). St. John and Starkey (1995) also found an association between number of credits completed and persistence except at the senior class level. Wlodkowski (2001) noted that adult students benefit from having significant prior college experience before enrolling in four-year colleges, whether in accelerated or in conventional programs. The most important finding of Wlodkowski's (2001) study was that adult learners benefit from having significant prior college experience before enrolling in fouryear colleges. In other words, those with more college credit often have less course work to reach their goal of a baccalaureate degree thus increasing the likelihood of program completion. Persistence for nontraditional transfer students can be enhanced when states encourage four-year colleges to form agreements with community colleges about accepting transfer credits and guaranteeing admission to qualified students (Calcagno, Jenkins, Bailey, \& Crosta, 2006). Institutions aim to improve adult learner persistence by offering multiple learning options, such as off-campus learning centers, distance-learning technologies, online material, and flexible course offerings at nontraditional times (like evenings and weekends). An institution's acceptance of adult learners' transfer credits has been shown to influence student persistence (Simmons, 1995). Therefore, it was believed that more previous college credit would improve a returning adult student's chances of persisting to graduation. 


\section{Educational Goal}

Kasworm (2005) posited that many adult students have a wavering self-image and limited self-confidence. Their sense of self is tested in the collegiate environment, as well as challenged by their external world as they participate in college. Often negative messages, as well as self-doubt, lead to limited energies and productivity in college. Further, initial goals and motives may be weak or unrealistic and may be quickly challenged by participation in a competitive collegiate environment. Some adults selfdestruct when faced with challenges and do not follow through on their initial enrollment application or stop out from further college enrollment when difficulties are presented. However, those adults that have a higher level of commitment to educational attainment often persist at much higher rate than others with lower educational attainment goals (Cabrera, Nora, \& Castaneda, 1993). Consequently, it was believed that higher educational goals would positively influence adult learners' ability to persist.

\section{Marital Status and Children}

Marital status and number of children can be factors in persistence but their effect may be mediated through the age and gender. The number of parents seeking a bachelor's degree peaked in 1989 and declined in 1992 (NCES, 2000). However, due to the economic decline, a resurgence of working parents are now pursuing baccalaureate degrees. The prerequisite of a bachelor's education for most job criteria is driving working adults with children back to American Colleges and Universities (Cabrera et al., 2005). Unfortunately, much of the literature has found that the presence of children is negatively associated with persistence (Horn, 1998; McCaffrey, 1989; McGivney, 1996; 
Mercer, 1993; \& Shields, 1994) and marital status was positively associated with persistence (Mercer, 1993). An early study by Weidman (1985) found that students who report less trouble with children were more likely to persist. Conversely, Byrd (1990) found that students with three or more children experienced more barriers to completion. Another study (Mercer, 1993), however, found no difference in persistence based on marital status or the presence of children when controlling for other factors. Hanniford and Sagaria (1994) found that women who had children were more likely to complete their degree. They also found that school age children were more of a barrier than older children. Older children and marriage apparently slow down but do not stop progress toward the degree. According to Scott, Burn, and Cooney (1996) younger moms reported more maternal role conflicts. Therefore, children can be a factor in persistence but their effect may be mediated through the age of the parent, age of the children, gender, and marital status. Thus, it was hypothesized that children and marital status are not likely significant predictors of persistence among this population of adult learners.

\section{Income/Socioeconomic Status}

Income and socioeconomic status (SES) also play a complex role in the persistence of adult students. One National Center for Education Statistics (2000) study defines SES as a "composite variable combining parents' education and occupation, dependent student's family income, and the existence of material possessions in respondent's home. Horn (1998) included all beginning U.S. higher education students from a national database and SES was not found to be statistically significant when other variables were controlled. However, this study finding did not isolate adult students. 
Scott, Burns, and Cooney (1996) found that SES, as measured by spousal and parental income, was a significant factor in the persistence of female adult students. Adults have more financial commitments and SES/income has been shown to have a direct effect on persistence among adult students (Ashar \& Skenes, 1993). Increased financial assistance made available to adult learners increases access to higher rates of degree completion (Hunt \& Tierney, 2006). Therefore, a student with fewer concerns regarding their basic living expenses experiences less stress that could lead to departure decisions.

\section{Motivation}

There are two roots of voluntary departure: intention and commitment. Individual intentions can change and are not always clear even to the individual. Commitment takes two forms: goal commitment (usually occupational in nature) and institutional commitment. Tinto (1993) found the existence of occupational goals proportionate to the likelihood of completing a degree and that goal commitment "becomes a motivating force" (p. 38) even for students who were marginally academically prepared. In fact, Tinto found that students with high academic preparation but weak goal commitment and motivation were less likely to persist than students with weak academic ability and strong goal commitment. Additional research has supported this assertion that motivation and commitment is a strong predictor of college students' ability to persist (Braxton, Milem, \& Sullivan, 2000; Cabrera, Nora, \& Castaneda, 1993; Sandler, Cohen, \& Kockesen, 2000). The intent and/or motivation to leave or stay is often the best predictor of actual student departure (Bean, 1990). One cause of early withdrawal is a gap between learner expectations and reality. Returning students are motivated enough to enroll in degree- 
seeking programs and many clearly value education, but negative past experiences of school may be too strong (Quigley \& Uhland, 2000). It was hypothesized that motivation and education goals were closely linked and likely to be significant predictors of student persistence.

\section{Internal Campus/Academic Environment}

Internal environment variables include, but are not limited to, financial aid, grade point average, part-time enrollment status, counseling, evening and weekend scheduling, instructor/advisor support, and prior learning assessment. This study does not include several internal campus factors because they pertain more to traditional age students, such as housing policies, membership in student organizations, dining services, and student government involvement. Adult education researchers have also investigated the problematic relationship between the adult student and the university environment, noting lack of sufficient policies, procedures, and services to adequately support the success of adult undergraduates (Kasworm, Sandmann, \& Sissel, 2000). Therefore this study sought to explore a better understanding of adult students' perceptions of their relationship to the internal campus environment and its impact on their progression to degree attainment.

\section{Enrollment status}

Part-time enrollment in higher education has grown dramatically since 1970 in absolute terms and relative to full-time enrollment. Between 1970 and 1990, the share of part-time students grew from $28 \%$ of the total to $42 \%$ and there were five million parttime students in 1990 which meant that two of every three students aged 30 and above were part-time (McCormick, 1995). Part-time attendance meets the needs of a wide range 
of students for whom full-time attendance may not be practical or feasible, thereby permitting postsecondary institutions to be accessible to the widest possible array of students. For example, the part-time student population includes students who are casual course takers, taking only one or two courses for personal enrichment, but not seeking a degree; returning students who want to complete a degree or upgrade their skills, but who cannot afford to give up their jobs to do so; teachers who take courses for professional development, concurrent with full-time employment; high-school graduates seeking a degree but who are restricted by employment or family circumstances; previously fulltime students whose remaining degree requirements constitute less than a full load; and, finally, students who are unsure about their educational plans and want to try out postsecondary education at a lower cost and with less disruption than full-time attendance would require. By allowing students to attend part-time, institutions meet a variety of needs and extend educational opportunity to students who otherwise might be dissuaded from participation or shut out of the system entirely (McCormick, 1995) The movement back and forth between full-time and part-time status occurs frequently as students who near graduation accelerate a job search or as part-time teacher education students move into a full-time status as they engage in student teaching.

Part-time status has become much more common but its effect on persistence is generally negative. Adult students who are able to enroll on a full-time basis persist at much higher levels than do part-time students. The model proposed by Bean and Metzner (1985) included enrollment status as a factor in persistence which was supported by substantial evidence. The more hours the student takes per term, the more likely they are 
to persist (Bean \& Metzner, 1987; Choy et al., 1995; Cuccaro-Alamin et al., 1998; Horn \& Carroll, 1997; McCormick et al., 1995; McGivney, 1996; Mercer, 1993; St. John \& Starkey, 1995).

Taniguchi and Kaufman (2005) reported similar findings for both part-time enrollment and number of women enrolling in postsecondary education. They investigated nontraditional student graduation rates from four-year institutions. The outcome variable was whether or not the adult student completed a four-year degree program. The primary independent variable was part-time enrollment. The study found that part-time students are significantly less likely to complete a degree than those enrolled full-time. Ahson, Gentemann, and Phelps (1998) also found a negative correlation $(r=-.357)$ between the number of hours worked to the credit hours taken, indicating that as the number of hours worked goes up the number of credit hours taken goes down. Less hours per semester is particularly relevant to this population because over $80 \%$ of adults in this program are working full-time. Consequently, it is hypothesized that part-time enrollment will not be statistically significant to the outcome variable of persistence for this particular group under study.

\section{Cumulative GPA}

The cumulative grade point average (GPA) of students is positively correlated with persistence. The Bean and Metzner (1985) model hypothesized that GPA would be a factor in persistence, which they confirmed in their 1987 study. Many other studies also support their conclusion (Farabaugh-Dorkins, 1991; Horn, 1998; Kasworm, 1990; McCaffrey, 1989; Mercer, 1993; St. John \& Starkey, 1995). Cuccaro-Alamin, Choy, and 
Carroll (1998) conducted a study of students of all ages and found that a high GPA was positively associated with persistence. Conversely, Shields (1994) found no effect from GPA on persistence among adult students. Since adults have been shown throughout the literature to have a stronger commitment to learning, it was hypothesized that higher GPAs would not likely be a significant predictor of adult student persistence. In other words, cumulative GPA was important to measure but not likely substantial among the variables measured.

Institutional Support, Academic Advising, and Faculty Support

Traditional American colleges and universities are not known for their extensive adult learner friendliness. However, Kuh (2007) found academic advising and faculty interaction to be an integral part of any retention, persistence, and student-success initiative. Both help students navigate the resources available to them in and around the campus and classroom. Wlodkowski (2002) found adult learners desired better advising services. Adults view advising and faculty support as customer service that needs to be prompt and efficient in the dissemination of quality information that assists students to efficiently move toward a baccalaureate degree. Effective academic advisors, instructors, counselors, and adult support services all influence adult-student persistence. Beal and Noel (1980) posited that inadequate academic and faculty advising was one of the largest impediments to student retention; however, Habley and Morales (1998) found that only $29 \%$ of postsecondary institutions have some form of advisor effectiveness evaluation. Therefore, it was hypothesized that institutional, advising, and faculty support would be significant predictors of adult student persistence. 


\section{Financial Aid and Cost}

Cuts to tuition assistance and revision of policies on state and federally funded loans and grants may weigh heavily in adults' intent to persist. The variety of responsibilities and competing demands for money from adult students' budgets is often cited as a reason for leaving college (Aslanian, 2001; Kasworm, 1990; McCormick et al., 1995). Unfortunately, adult, part-time, and independent students are less likely to receive grants and what funding they do receive is smaller than traditional students (Lumina Foundation, 2011).

Aslanian (2001) found that most adult undergraduates rely on personal funds to cover college costs. Only $20 \%$ use loans, $19 \%$ receive grants or scholarships, and $18 \%$ receive tuition reimbursement (NCES, 2010). However, when tuition reimbursement is available, $70 \%$ of adults use this benefit. Financial sources including federal aid, foundation support, and tuition discounts provide avenues to assist adult students, whether they are in accelerated learning programs or in conventional learning formats. Unfortunately, adult students receive much less financial aid than that of their traditional counterparts.

Astin's (1993) work suggested that, for traditional students, state and federal need-based financial aid displays "no discernible impact on traditional student development" (p. 368). This study overturned his earlier finding (1975) that grants and scholarships were positive and loans were negative. Astin's later work concluded that merit-based awards have a significant effect for nontraditional students. The role of financial aid for adult students is also complex. Receiving financial aid is generally 
positive for persistence among adult students (Cuccaro-Alamin, 1997; Kasworm, 1990; McCormick et al., 1995). For full-time adult students, financial aid is consistently positive (McCormick et al., 1995) but for part-time adult students, the type of aid is crucial (grants were positive, loans more negative). As mentioned previously, adult students do not receive aid as often as traditional students, in spite of broad eligibility (St. John \& Starkey, 1995). For part-time students, the primary form of aid is employer tuition reimbursement (McCormick et al., 1995). To counter the effects of rising tuition costs and offer equal opportunities to adult students, especially those of low socioeconomic status, student aid needs to be increased to that group (Lumina Foundation, 2011). The Lumina Foundation (2011) hypothesized that grant aid (from the employer, the college, or the government) would play a positive role in persistence. Thus, taking on college debt is positively associated with persistence (Cuccaro-Alamin, 1997) for most adult students but a negative factor for adult part-time students in public colleges (St. John and Starkey, 1995). Adult students are particularly willing to borrow money if they are entering a major with a high starting salary (Zito, 1991). Therefore, it is hypothesized that financial aid and scholarships will be a positive predictor of adult student persistence in this study.

\section{Flexible Course Options}

Distance education is becoming a more vital part of the higher education system. Today, nearly every major American university offers these courses, which reach a broader student audience, better addresses student needs, save money, and more importantly use the principles of modern learning pedagogy (Fitzpatrick, 2001). Public as 
well as political interest in distance education is especially high in geographic regions where the student population is widely distributed (Sherry, 1996). In fact, public policy leaders, in some states, are recommending the use of distance education as opposed to traditional learning (Sherry, 1996).

Adult learners are engaging in work and education, particularly distance education, at an unparalleled rate and higher education professionals need to understand the unique challenges nontraditional students face in order to facilitate a positive learning environment. Sikora (2002) postulated that the flexibility of distance education attracted nontraditional students because it allowed them the ability to manage their studies around their life commitments. She further implied that the flexibility and mobility of the online environment will become increasingly more appealing to adult learners who are trying to balance work, family, and education.

Adult learners' increased utilization of online learning is further supported by Ashby's (2002) Government Accounting Office (GAO) report on adult learners and distance education. In an analysis of the National 2002 Postsecondary Student Aid Study (NPSAS), Ashby reported the average age for distance learning students was 30 , and students were more likely to be married, working full-time and studying part-time, with women comprising $65 \%$ of the online undergraduate population. Ashburn (2010) noted that simply offering more online courses is not sufficient to attract and retain the growing adult student population. Evening and weekend courses are also preferred by adult learners with numerous life and familial commitments. 
Active Learning

Active engagement and learning applies to the individual and to the particular sub-community of which a student engages in to become a member (Tinto, 1993). Students can be connected to a sub-group, either social or academic, without being connected to the entire institution. Tinto (1993) posited that students who are connected intellectually but not socially are just as likely to depart as the students who are connected socially but not intellectually. However, adult student retention studies have refuted this claim indicating that intellectual engagement and relevance of course content provide the connection to the university that adults strive to achieve. Ahson et al. (1998) provided further evidence that many students leave college voluntarily, rather than as a result of involuntary reasons such as academic performance. In a sample composed of both traditional and nontraditional students Horn and Carroll (1998) found that academic integration and active learning were positively associated with persistence. To measure active learning and skills development, they used student responses to questions about how often they participated in the following activities: "attend career-related lectures, participate in study groups with other students, talk over academic matters with faculty, and meet with advisor concerning academic plans" (p. 52). In summary, students who were isolated both from the resources of the college and from other students are less likely to persist. Adult students, in particular, exhibit a more problem-centered or skills development focus in the formal academic environment. This population seeks out more active learning because they are self-directed, experiential, problem-centered, and internally motivated (Knowles et al. 2011). 
Research findings from other studies confirm that positive involvement with peers and faculty encourages adult students to persist (New England Adult Research Network, 1999; Tinto, 1998). The study of persistence among traditional age students has stressed the importance of social integration in persistence (Tinto, 1993). Traditional age students who become involved on campus and make friends, join clubs, and participate in activities are far more likely to persist. It is important to re-work this concept to address the persistence of adult students.

For adults, integration and active learning may be better defined as how one integrates pursuit of education into one's overall life (Kerka, 1997). In a study of job training participants by Vann and Hinton (1994), members of in-class cliques were more likely to indicated greater learning outcomes while those who are socially isolated were more likely to drop out. From this framework for adult students, it is possible that social integration and connection of content to real-world application is positively associated with persistence.

Tinto (2006) posited that students tend to succeed in universities that are committed to student success, hold high expectations for student success, and provide needed academic, social, and financial supportive structures and policies on campus. Providing frequent and timely feedback and active involvement and engagement with the university faculty and staff have been linked with greater levels of institutional commitment and improved active learning. Faculty can have a negative or positive influence on student's sense of fitting in, loyalty, perception of institutional quality, satisfaction with content, self-development, self-confidence and self-efficacy, connection 
between course content and workforce practice, and stress (Tinto, 2006). Thus, both student and institutional experiences shape subsequent learning outcomes and overall engagement.

\section{Prior Learning Assessment}

Prior Learning Assessment (PLA) is a process that colleges use to evaluate college-level knowledge, skills, and abilities gained outside the confines of the classroom for academic credit (CAEL, 2010). There are two primary forms of prior learning assessment (PLA): course-specific PLA and the broader portfolio form. In coursespecific PLA, adult learners can test-out of courses via challenge exams or take CLEP or DSST tests that are universally accepted as the equivalent of various core courses. If students are able to demonstrate mastery of any of a number of content areas, they are exempted from those courses and awarded college credit for that requisite knowledge. The second form of prior learning assessment is the portfolio compilation. Students eligible for elective portfolio credit assemble documents to demonstrate competency in a specific area of knowledge that is deemed college-level equivalency. Knowledge acquired in non-college instructional programs, military training, travel, civic engagement, volunteer service, and employment is evaluated through a structured PLA class that documents college-learning outcomes achieved outside the confines of university walls. This PLA credit might include a computer programmer who demonstrates competence in a programming by writing a reflective essay outlining his knowledge in conjunction with the validating documents including certificates for various programming certifications in his or her specialty. Another example would be the police 
officer who serves as the departmental spokesperson is thus able to test-out of a course in oral communication by completing a challenge exam and assembling examples of television appearances that demonstrate mastery of this core content area. The coursespecific PLA portfolio and test-out options help experienced adult students avoid taking a course that would be redundant. This process allows students to convert mastery of a subject into academic credits and provides an opportunity to increase the pace and likelihood of graduating. PLA recognizes and legitimizes significant learning in which adults have engaged in many parts of their lives (CAEL, 2000).

The Council on Adult and Experiential Learning (CAEL, 2010) collected data from 62,475 students at 48 postsecondary institutions and found PLA students had better academic outcomes, particularly in terms of graduation rates and persistence, than other non-PLA students. More than 56\% of PLA students earned a postsecondary degree, while only $21 \%$ of non-PLA students did so (CAEL, 2010). The CAEL study also revealed that many PLA students also graduate sooner than other non PLA students. Another study by the College Board (2009) of 1500 adults rated "credit for prior learning policy" as more important than "small class size" or "availability of financial aid." Smith and McCormick (1992) suggest that learning from experience can often be equivalent, if not superior, to college-level learning. Snyder (1990) found that community college students who applied for PLA credits after one year of study persisted at higher rates and this was a significant factor in the logistic regression equation. When compared to students who earned credit through introductory college course work, students who earn CLEP credit had higher overall GPAs at the end of their undergraduate education (Scammacca \& Dodd, 2005). 
Also, a recent Greater Louisville Inc. (2010) survey indicated that the opportunity to earn credit for prior learning is one of three motivators for adults with some college but no degree who wish to complete their postsecondary education.

Prior Learning Assessment - (CAEL) standards.

1. Credit should be awarded only for learning and not for experience.

2. College credit should be awarded only for college-level learning.

3. Credit should be awarded only for learning that has a balance, appropriate to the subject, between theory and practical application.

4. Competence levels and credit awards must be made by subject matter/academic experts.

5. Credit should be appropriate to the academic context in which it is accepted.

6. Credit awards and transcript entries should be monitored to avoid duplicate credit.

7. Policies and procedures (including appeals) should be fully disclosed and prominently available.

8. Fees charged for assessment should be based on services, not amount of credit.

9. Personnel involved in assessment should receive adequate training.

10. Assessment programs should be regularly monitored, reviewed, evaluated, and revised (CAEL, 2011 p. 1).

The portfolio process is underutilized because of ambivalence toward PLA from faculty and administration, some of whom believe the process lacks academic integrity, a lack of publicity, and low levels of support for students while in the portfolio assembly phase (Fisher, 1991; Topping, 1996). Students who chose not to utilize the process felt it required too much work or did not believe their experience was worthy of credit. 
Students who complete the portfolio report feelings of satisfaction, pride, and accomplishment, as well as the appreciation for saving time and money (Dagavrian \& Walters, 1993; Fisher, 1991). Burris (1997) found that adult students who complete the portfolio process find it strengthens core values, like independence, freedom, learning, tenacity, hard work, nonconformity, pride, aspiration, and goal commitment. A wellstructured PLA process changes students' thinking not only about their pasts, but about the present and their futures (McGinley, 1995). Adult students suggest that the PLA portfolio preparation is "full of revelations" (Burris, 1997, p. 116). Students who finish the process are usually quite proud and speak of the portfolio as something they are excited to share with children and other family members. One of the students in the Burris study explained: "The person I am is now coming out... [the person] that I always was has surfaced" (p. 127). Another reflected: "What I did there was assess my whole life and...realized my capabilities" (p. 121).

Students gain academic and organizational skills in the portfolio development and writing process (Burris, 1997). The PLA portfolio process certifies readiness for further learning and gives students a forum to investigate the structure of college-level learning through its requirement that they equate their learning from experience to the structure of the curriculum (Dagavrian \& Walters, 1993).

External Environment Variables

Some of the major environmental factors include finances, family support, employer support (tuition, flex-time, work hours), significant life events. Environmental factors, including family problems, lack of child care, and job demands are often cited as 
factors for withdrawal or stop-out behaviors of adult students. The balancing act of managing family, work, community, and academic responsibilities can pose great challenges for adult students.

Adults have to cope with a variety of work, life, and academic roles. In addition, negative experiences from the past may impact adults' confidence. Kasworm (2001) stated that "being an adult student is fraught with time and resource issues related to actively pursuing homework assignments and final projects, getting to and from courses and the library, typing papers, collaborating with study groups, and engaging in other activities to support academic success" (p. 33). Many adult learners need more time to dedicate to their academic life than they have available. In these circumstances the academic responsibilities shift to the bottom of the priority list, and the guilt and frustration related to this balancing act often leads to departure decisions. The competing demands of life make it very challenging for adult learners to strike a balance that helps them reach their academic goal of completing a baccalaureate degree. These learners experience a wide variety of life circumstances, such as - work, family, financial pressures, and community responsibilities that weigh heavily on their intentions to return and persist in degree programs (Kasworm, 2003; Kazis, et al, 2007). The ability to juggle multiple roles and responsibilities can often lead to a level of stress that produces higher rates of attrition than that of traditional-aged learners.

\section{Finances}

Bean and Metzner (1985) suggested in their model that finances would be a significant factor in departure decisions only to find that it was not statistically significant 
in their subsequent 1987 study. However, many studies have suggested that finances or low income were a significant factor in persistence to graduation (Christensen, 1991; Hall, 1997; Horn and Caroll, 1997; Losty \& Kreilick, 1982; McCaffrey, 1989; Mercer, 1993; Zajkowski, 1997). In exit surveys, adult students who leave college often say they cannot afford it any longer. The cost of enrollment, tuition, books, and child-care can prevent adults from completing a degree. Some employers have tuition assistance, however there may be caps on the amount available based upon federal government regulation. Others must shoulder the entire financial burden, viewing it as to monumental to overcome on their own.

It is possible that departing students fail to mention other obstacles that might be contributing to the dropout decision. For these students, the challenges add to the overall financial and emotional cost of the program and thus decide to abandon their educational pursuits. A related set of studies also support the idea that adult students persisted at higher rates if they reported higher income (Choy \& Premo, 1995; Losty, 1982), more financial security (Cabrera, et al. 1992), or that finances were not much of a problem (Mercer, 1993). However, men generally express fewer financial problems than women, but they do not persist as often as women (Ryder et al., 1994). Money certainly has an impact on adult students, however, the influence of money may be overstated in persistence studies unless money crises (such as the loss of a job) occur after studies have been initiated. The student's expression of financial difficulty can be very real financial difficulty, but it can also be an expression of declining commitment to education attainment. 


\section{Family and Community Influences}

For their adult learner study, Hammer, Grigsy, and Woods (1998) examined three sets of variables; work and family, enrollment status, and gender and age. The dependent variable was the degree of conflict between work, family, and school. They found a statistically significant correlation between the dependent and independent variables including credit hours, hours of employment, perceived effectiveness of support services, and satisfaction with the academic environment. Kimmel and McNeese (2006) reported family care and financing issues as primary deterrents for nontraditional students $(n=$ 646). Wldokowski (2001) noted that lack of time was the dominant theme for leaving college. He found that adult students repeatedly and emphatically cite competing priorities and not having enough time to meet the demands of family, community, work, and school as a deterrent to completion of their academic degree program. Wldokowski (2001) found that among adults in the school with an accelerated program, the top two reasons for leaving college indicated were conflict between job and studies (60\%) and home and community responsibilities too great $(59 \%)$.

\section{Work Influences and Hours of Employment}

Employment, like age, has been found to have both motivational and detrimental influence on adult student participation (Kasworm, 2003). Bradburn (2002) reported that nontraditional students were "less likely than traditional students to cite academic problems or the need to work as the reason for leaving" (p. 55). Many adults have a stronger tie to career culture than to academic culture. Adult learners often re-enter an academic setting to achieve advanced positions and higher wages. However, the same 
factor that has driven many adults back to the classroom is often the greatest barrier to their completion of the degree. Wlodkowski et. al (2002) found that lack of time was the dominant theme among all adult learners leaving college. The various competing priorities, including job responsibilities, are often cited as generating a feeling of being overwhelmed to the point of not being effective as a student.

As Berker and Horn (2003) reported, $76 \%$ of adult students who work full-time are enrolled in school part-time. Only $19 \%$ of the students were working full-time and taking classes full-time. In general, adult students are generally less likely to persist than their traditionally aged non-working counterparts (NCES 2002). Kirby, Biever, Martinez, and Gomez (2004) examined the influence of school responsibilities on family, work, and social interactions for students in a nontraditional weekend college program. In this study, students who indicated they had support from work reported significantly lower stress levels. However, even with work and family support, full-time employment was a significant predictor of school-related stress. Berker and Horn (2003) also examined the relationship between work and school, finding that adult students who classified themselves as employees who were attending school were less likely to persist than those who classified themselves as students who chose to work. In other words, if a person identifies as an employee or a student, that identity becomes the priority and receives more attention. However, Pascarella et al. (1998) controlled for 15 student background characteristics and college experiences and considered both on- and off-campus employment and found only modest and inconsistent evidence to suggest that either form of work seriously inhibits students' learning or cognitive development. There was, 
however, some evidence in the third year of the study to suggest that reasonable amounts of part-time on- or off-campus work actually facilitated learning.

Researchers have found that support systems are important in helping adult learners succeed (Elkins, Braxton, \& James, 1998). In addition to support of family and friends, adult working students may also receive support for continuing their education from their employers, often in the form of tuition reimbursement and/or time away from work. Studies show that this kind of support increases the likelihood of adult student degree completion (Aslanian, 2001). Many human resources managers believe tuition benefits play an important role in boosting on-the-job motivation, retention and productivity (Gunsauley, 2002). However, most companies do not even collect the most basic data about return on investment of employer-sponsored educational programs (CAEL, 2006).

\section{Significant Life Events}

Some significant life events include: health issues, family health issues, death in the family, divorce, marriage, birth of a child, military deployment, and employment changes including job loss, promotion, or relocation because of job. Sometimes a significant life change will trigger a return to college, propelling a student to return to college and finish a long-delayed goal (Aslanian, 1989). Unfortunately, these events can have multiple results. As Mercer (1993), found that while crises compelled adults to return to school, they also often resulted from the return to school. The literature on significant life events is limited and this study sought to expand the understanding of this complex variable that is particularly salient to this population. It was hypothesized that 
significant live events would be a significant predictor of adult student persistence in this study.

\section{Summary}

There are many factors that dissuade adults from engaging in higher education, however, no one variable can be identified as the chief reason. By looking at the variables as a cluster, or typology, there are certain groups of variables that rise to the top as the major reasons adults do not persist to graduation. Malhortra, Shapero, Sizoo, and Munro (2007) reported slightly different findings for the six factors identified as barriers. Lack of resources $(M=3.0)$, such as time or energy, was the leading barrier. Child care $(M=$ 2.5), which included the child care and cost of tuition, was the second highest rated barrier. Woosley (2004) reported that stop-out and drop-out students identified financial concerns, family responsibilities, and job conflict as the leading reasons for not returning the following year. These temporary withdrawal habits increase the difficulty in identifying specific variables that contribute to the interruption or might be used to develop a recruitment or retention strategy.

Most of the above studies found significant indicators related to work and family responsibilities as leading predictors for the withdrawal decisions of students. While some are able to cope with the multiple demands on their time and persist to completion, others resign themselves to not completing an academic program. Numerous researchers have recently advocated further research on the impact of work and family on nontraditional students to create effective retention strategies (Kirby et al. 2004; Riggert, Boyle, Petrosko, Ash, \& Rude-Parkins, 2006). 


\section{Conclusion}

Much of the literature examining retention and persistence has focused solely on traditional-age students. Reporting and funding state subsidies, until recently, have hinged on first-year full-time freshman retention, thus ignoring a large contingent of parttime nontraditional students. Despite all the published research pertaining to retention, it remains difficult to predict. This is particularly true for adult students who shoulder a variety of responsibilities beyond those of traditional-aged students. This study attempted to discover the possible impact of several variables on the likelihood of completing adult bachelor's degree programs and sought knowledge that assists in the creation of interventions to improve adult student persistence. Three categories of variables were considered: demographic/entry characteristics, internal campus/academic environment variables, and external environment variables. The variables and methodology used are explored in more detail in Chapter 3.

There are literally hundreds if not thousands of specific reasons students might leave college prior to graduation. However, researchers have arrived at a broad group of factors that increase or decrease the likelihood of retention including background, academic, and environmental variables. Pascarella and Terenzini (1991) offered a summary of the literature on student retention. Tinto's (1993) updated model addressed the achievement of some level of academic or social integration as the most likely cause of student attrition. Quigley (1995) posited that the most critical attrition point in students' program of study is the first six to eight weeks of a new program. 
Retention efforts geared to traditional students may be counterproductive to adults by failing to address their limited opportunities for social and academic integration (Taylor, 2000). There is always a percentage of attrition that may be necessary and in the best interest of both students and postsecondary institutions because of lack of effort, time, commitment, etc. However, the reality of voluntary stopping out, withdrawing, or dropping out completely is all too common among adult learners in higher education. Counting all students as drop-outs would be misleading. Understanding what impacts the likelihood of persistence is important to many institutions of higher education, which are under increased pressure to retain students to degree completion. Researcher and practitioners alike need to develop additional theories of student departure that clearly explain the longitudinal process of student leaving from institutions of higher learning while capturing the complexity of behaviors that underlie that phenomenon (Tinto, 1993). Departure from human communities generally, reflects both the attributes and actions of the individual and those of the other members of the community in which that person resides (Knowles, 1984). Decisions to withdraw are more a function of what occurs after entry than of what precedes it. They are reflections of the dynamic nature of the social and intellectual life of the communities which are housed in the institution (Tinto 1993). If there is a secret to successful retention, it lies in the willingness of institutions to involve themselves in the social and intellectual development of their students (Tinto, 1993). That institutional commitment often reflects and influences students' commitment to the institution and their involvement in their own learning. 
There is an ever-present need for more students to graduate from American colleges and universities. By 2025, the U.S. workforce will need one million more college graduates than produced (College Board, 2010). Because of declining birth rates. adults will likely make up more and more of the overall percentage of college enrollment. Current research indicates that adult students experience college differently and act on the college experience in ways that differ from those of the traditional college student (Kasworm, 2003). It is important and necessary to understand the nuances of how institutional, personal, and environmental factors impact adult learners' ability to persist to graduation. This study examined how entry, internal campus environment, and external influences impact adults in degree-completion programs at a four-year university. 


\section{CHAPTER III}

\section{METHODOLOGY}

This chapter begins with a review of the purpose of the study and research questions from Chapter 1. Next, a description of the research design, population and sampling, variables and instrumentation, data management, validity and reliability, and data analysis follow. This chapter concludes with a summary.

\section{Purpose of the Study}

The purpose of this study was to examine Braxton, Hirschy and McClendon's (2004) Theory of Student Departure in Commuter Colleges and Universities alongside Bean and Metzner's (1985) Conceptual Model of Undergraduate Nontraditional Student Attrition model to create a new model that examines factors that predict undergraduate degree completion for adult learners in degree completion programs at four-year universities. Isolated variables from each path model including student background/entry characteristics, internal campus/academic environment, and external/environmental factors were examined to understand the shared variance among factors. This study explored the relationship among student entry characteristics, academic and institutional factors, and external/environmental influences from the newly proposed Theory of Adult Learner Persistence in Degree Completion Programs on adult student persistence in degree completion programs at four-year urban research universities. These variables 
were derived from Braxton, Hirschy and McClendon's (2004) Theory of Student Departure in Commuter Colleges and Universities and Bean and Metzner's (1985) Conceptual Model of Undergraduate Nontraditional Student Attrition to create a new theoretical model for adult learners in degree completion programs at four-year universities.

\section{Research Questions and Hypotheses}

Two overarching research questions guided this study: (a) what are the relationships between student entry variables, internal campus environment variables, external influences variables and the outcome variable student persistence in an adult degree completion program at the bachelor's level? (b) what is the multivariate predictive relationship between student entry variables, internal campus environment variables, external influence variables and the outcome variable student persistence?

To explore these two research questions, two research hypotheses were tested:

$H_{l}$ : There are bi-variate relationships between student entry variables, internal campus environment variables, external influences variables and the outcome variable adult students' ability to persist to graduation in a degree-completion program at the bachelor's level.

$H_{2}$ : There is a multivariate relationship involving student entry variables, internal campus environment variables, external influences variables and the outcome variable adult students' ability to persist to graduation in a degree-completion program at the bachelor's level. 


\section{Research Design}

The framework for this study was derived from seventy years of evolving theories and concepts in college student retention. The manipulation of variables and randomization of samples are not present, therefore this study uses a non-experimental research design (Pedhazur \& Scmelkin, 1991). A newly constructed survey, Adult Learner Persistence Survey (ALPS), was utilized to measure the variables from this researchers proposed Theory of Adult Learner Persistence in Degree Completion Programs model. The ALPS instrument was created to measure variables from this researchers proposed model and to make inferences about factors that impact adult student retention in degree completion programs at a four-year university. Inferences are generally made by attempting to uncover independent variables by first starting with a dependent variable (Pedhazur \& Scmelkin, 1991).

First, a correlation design was used to examine the first research question. This included descriptive statistics calculating mean, median, range, and standard deviation. The Pearson correlation statistic was used to analyze the relationship between combinations of variables. Next, a logistic regression analysis was used to determine the variance and effect explained by the predictor variables on persistence or nonpersistence of adult learners (Leech, Barrett, \& Morgan, 2005). Logistic regression was specifically chosen because the dependent variable is dichotomous in nature. Ishitani (2006) defined degree completion behavior as having dichotomous values (e.g., whether or not students maintained continuous enrollment to graduation) at discrete points in time. Structural equation modeling has also been one typical statistical technique used in previous studies 
(Bean 1983, Pascarella \& Terenzini, 1991). However, structural equation modeling fails to examine differences in departure or completion behavior that may exist at various times in a student's academic progression (Ishitani, 2006). Therefore, logistic regression was an appropriate approach for this study because of its ability to analyze the dichotomous nature of degree completion behavior at various times in adult students' progression through a single academic program (Ishitani, 2006).

Logistic regression was also used because of the nature of the population in this study. Due to the limited resources and time constraints on the researcher, multiple institutional research and longitudinal analyses were not incorporated for this study. Curtis (2005) posited that "the most valuable research for an institution will be the research conducted on that institution's own population" (p. 17). The predictive component of this study was driven by practical purposes, while the explanatory element of this study was driven by theory and used to uncover relationships between the independent and dependent variables. The focus of this research was to examine variables that have direct and indirect effects on persistence among adult learners in degree completion programs at the four-year college. Therefore, this study utilized both a predictive and explanatory framework.

\section{Population and Sample Size}

The population for this study consisted of individuals from a heterogeneous sample of students enrolled in a single institution enrolled in a degree-completion program at a metropolitan urban research university. The adult learners surveyed range from 25 to 67 in age and are enrolled specifically to attain a bachelor's of science in 
Workforce Leadership from the University of Louisville. The adult learners who make up this study are all classified as stopout students. In other words, these students are not starting with zero credits. They have experienced some form of postsecondary schooling and stopped out for any number of reasons only to return later in life. Adult learners that enter degree-completion programs are often recruited based on their significant college credit. An institutional database was accessed to identify all adult learners enrolled in the Workforce Leadership or Occupational Training and Development programs from 2004 to 2011. To be able to make inferences regarding the characteristics of the population from measures of this sample, the size of the sample was considered (Hinkle, Wiersma, \& Jurs, 2009).

For methods such as correlational analysis, a sample size of at least 5 and up to 50 participants per variable is recommended (Green, 1991). Further, a power analysis of .80 with an effect size of .15 and an alpha of .05 recommended a sample size of at least 260 for this study (Hinkle et al., 2009). The population surveyed consisted of 1240 enrolled students from 2004 to 2011 . However, for the purposes of this study, a sample size of 300 participants (25\%) was sought to strengthen statistical power and reduce the likelihood of a Type II error. Also, because students self-selected to participate in this research, 300 responses (25\%) was considered a realistic expectation for total surveys collected.

Variables and Instrumentation

The following section outlines the variables utilized from the survey instrument. First, the dependent variable will be discussed, followed by each of the predictor variables that are hypothesized to have direct and indirect effects on the dependent 
variable. The survey instrument used a variety of methods of scoring student responses. Multiple questions were answered using a 5 point Likert scale from 1 (strongly disagree) to 5 (strongly agree). Yes or No responses, as well as ( $\mathrm{a}, \mathrm{b}, \mathrm{c}$, or $\mathrm{d})$ answers were used for other questions. All questions were analyzed and examined for direct and indirect effects on the dependent variable. Full versions of each scale and scoring method can be found in Appendix A. Reliability analyses using Cronbach's alpha coefficient were used to justify scales that were formed by averaging survey items.

\section{Persistence or Nonpersistence}

The dependent variable (persistence or nonpersistence) is dichotomous. Therefore, understanding what variables impact continuous enrollment to degree completion or non-degree completion was measured with the statistical research method of univariate correlation and multivariate logistic regression. The predictor variables included items from three constructs including; entry characteristics, internal campus/academic environment variables, and external influences. The variables designated as entry characteristics are gender, age, ethnic background, marital status and number of children, previous college credits accumulated, goal commitment, motivation, and parents' level of educational attainment. The internal campus/academic environment variables selected include financial aid, cumulative GPA, enrollment status, academic advising, availability and convenience of courses, and prior learning assessment. Finally, the external influences included in this study are finances, family support, work/employer support, significant life events, number of hours worked, and community and friend support. The predictor and outcome variables are further delineated in Table 3. 
Table 3:

Description of variables

Variable SPSS variable Definition/ Label (variable type)

Dependent variable

Persistence

NONPERS

GENDER

AGE

Age

Independent variables

Student Entry variables

Gender

PERSIST

Currently enrolled, Graduated

(A - Enrolled = 1, B Graduated $=1$ )

Not enrolled, intend to reenroll - Not enrolled, don't intend to re-enroll $(\mathrm{C}$ Intend to re-enroll $=, \mathrm{D}-$ Don't intend to re-enroll $=0$ )

Student gender (categorical: male $=0$, female $=1$, other $=$ 2)

Age during bachelor's degree enrollment (ordinal: 25-35; $36-45$; $46-55$; 56-65; 66 or older)

Ethnicity
Student ethnic identity (categorical: American Indian; Asian; Pacific Islander; Black or African American; Hispanic or Latino; White or Caucasian; other/multicultural) 
Table 3: Description of variables (continued)

Parent's Education PARENTED

Mother and Father degree attainment (ordinal: grammar school or less; some high school; high school graduate; some college; college degree; some graduate school; graduate degree)

Previous College Credit

Educational Goals

Children

Marital Status

Income/SES

Motivation
CHILDREN

PREVCOLL

EDUCGOAL

MARSTAT

INCOME

MOTIV
Fill in the Blank (interval)

Highest educational goal (ordinal: Certificate, Associate's, Bachelor's, Master's, Doctoral)

Number of children (ordinal: Zero, One, Two, Three, Four or more)

Marital status during enrollment (categorical:

Never married $=0$, Married/Partnered $=1$, Previously Married $=0$, Separated $=1$, Divorced $=0$, Widowed $=0$ )

Annual household income (ordinal: Less than $15 \mathrm{k}, 16 \mathrm{k}$ $25,999,26 \mathrm{k}-40,999,41 \mathrm{k}-$ $60,999,61 \mathrm{k}-75,999,76 \mathrm{k}-$ $99,999,100 \mathrm{k}$ or more)

How important is completing degree (ordinal: Very unimportant, Unimportant, Neither unimportant nor important, Important, Very Important) 
Table 3: Description of variables (continued)

Internal Campus/Academic Environment Variables

\begin{tabular}{|c|c|c|}
\hline Enrollment Status & $\overline{\text { ENROLL }}$ & $\begin{array}{l}\text { Average credits per semester } \\
\text { (ordinal: } 1-3,4-6,7-9,10- \\
12,12 \text { or more) }\end{array}$ \\
\hline Cumulative GPA & GPA & $\begin{array}{l}\text { Overall GPA (ordinal: } 2.09 \\
\text { or less, } 2.10-2.59,2.60-3.09 \text {, } \\
3.10-3.59,3.60-4.00 \text { ) }\end{array}$ \\
\hline Institutional Support & UNIVREC & $\begin{array}{l}\text { Extent to which university } \\
\text { provides resources for } \\
\text { success (ordinal: not at all, to } \\
\text { a small extent, to some } \\
\text { extent, to a great extent, to a } \\
\text { very great extent) }\end{array}$ \\
\hline Academic Advising & NOFADV & $\begin{array}{l}\text { Multiple Questions: Number of } \\
\text { advising meetings of at least } \\
10 \text { minutes (ordinal: } 0,1,2 \text {, } \\
3,4 \text { or more) Q20a \& } 20 \mathrm{~b} \text {. to } \\
\text { what extent was your advisor } \\
\text { knowledgeable and caring } \\
\text { (categorical: not at all, to a } \\
\text { small extent, to some extent, } \\
\text { to a great extent, to a very } \\
\text { great extent) }\end{array}$ \\
\hline Faculty Support & NOFINST & $\begin{array}{l}\text { Multiple Questions: Number } \\
\text { of instructor meetings of at } \\
\text { least } 10 \text { min. outside of class } \\
\text { (ordinal: } 0,1,2,3,4 \text { or more) } \\
\text { Q20c \& } 20 \mathrm{~d} \text {. to what extent } \\
\text { was your instructor } \\
\text { knowledgeable and caring } \\
\text { (categorical: not at all, to a } \\
\text { small extent, to some extent, } \\
\text { to a great extent, to a very } \\
\text { great extent) }\end{array}$ \\
\hline
\end{tabular}

Financial aid

FINAID

Did you receive scholarships or financial aid (categorical: yes or no) 
Table 3: Description of variables (continued)

Cost

Flexible Course Options

Active Learning

Prior Learning Assessment
COST

FLEX

ACTIVE

PLA
Rank order reasons for selecting program (rank: cost, reputation, speed of completion, conveniencelocation, convenience-course delivery options

Multiple Questions: Type of courses enrolled in (ordinal: online only, in-class only, both online and in-class) Q24a-d flexible course options, sufficient classes, convenient enrollment, clear plan (ordinal: not at all, to a small extent, to some extent, to a great extent, to a very great extent)

Multiple Questions: Q25a-d: critical thinking, interperson skills, working with others, problem solving skills (ordinal: not at all, to a small extent, to some extent, to a great extent, to a very great extent) Q26a-d worked in teams, real-world application, combined ideas, connection to outside envir. (ordinal: not at all, to a small extent, to some extent, to a great extent, to a very great extent)

To what extent: time-saving, more likely with PLA, finish faster (ordinal: not at all, to a small extent, to some extent, to a great extent, to a very great extent 
Table 3: Description of variables (continued)

Finances

Family Influences

Work Influences
FINANCE

FAMILY

WORK
To what extent -believe you have the financial resources (ordinal: not at all, to a small extent, to some extent, to a great extent, to a very great extent)

Multiple Questions: Q30b To what extent -experience family/class conflict (ordinal: not at all, to a small extent, to some extent, to a great extent, to a very great extent) Q35a $\& b$ To what extent experience encouragement from spouse or other family (ordinal: not at all, to a small extent, to some extent, to a great extent, to a very great extent)

Multiple Questions: Q30a To what extent -experience work/class conflict (ordinal: not at all, to a small extent, to some extent, to a great extent, to a very great extent) Q33 tuition assistance from employer (dichotomous: yes or no) follow-up Q34 to what extent - how important was employer tuition support (ordinal: not at all, to a small extent, to some extent, to a great extent, to a very great extent) (categorical: not at all, to a small extent, to some extent, to a great extent, to a very great extent) 
Table 3: Description of variables (continued)

\begin{tabular}{lll}
\hline Significant Live Events & SIGNIF & $\begin{array}{l}\text { Q31 experience one or more } \\
\text { significant life event } \\
\text { (categorical: yes or no) }\end{array}$ \\
Community Influences & COMMUN & $\begin{array}{l}\text { Q30c To what extent - } \\
\text { experience community/class } \\
\text { conflict (ordinal: not at all, to } \\
\text { a small extent, to some } \\
\text { extent, to a great extent, to a } \\
\text { very great extent) }\end{array}$ \\
& HOURS & $\begin{array}{l}\text { How many hours worked: } \\
\text { (ordinal: } 0-20,21-30,31-40, \\
41-50,51 \text { or more) }\end{array}$ \\
& &
\end{tabular}

Procedures

An Internet-based self-report survey was used to collect data for this study. Internet-based self-report surveys are utilized in research more often than any other mode of data collection (Dillman, Smyth, \& Christian, 2009) and offer researchers tremendous cost savings and time efficiency as opposed to traditional mail surveys (Dillman, 2000). Because the Internet has become widely used (Dillman, Tortora, \& Bowker, 1999), its use as a data collection tool has grown in interest for both academic and organizational researchers (Dillman et al., 2009; Stanton, 1998). This method of data collection is becoming more common for its convenience and efficiency. Access to the University of Louisville's Peoplesoft database makes the use of an Internet survey a logical choice. Students have been shown to respond more openly and honestly to Internet surveys because of the anonymity that comes with online responses (Dillman, 2002). An Internetbased self-report survey involves a computerized, self-administered questionnaire sent by 
the researcher, which the respondent receives, and completes (Crim, 2006; Simsek \& Veiga, 2001).

\section{Sampling Procedures}

Methods used for conducting the present research study are discussed in the following section. First, permission to conduct the study was sought from the University of Louisville's Human Subjects Review Board (IRB). After permission was granted, the researcher prepared the adult student retention survey instrument for distribution.

Dillman et al. (2009) suggest a four-stage process to provide each member of the defined population an equal chance of being surveyed and to check the wording and appropriateness and wording of questions. The four guidelines followed in this study were: (a) survey content was reviewed by knowledgeable colleagues, (b) interviews were conducted to evaluate cognitive and motivational qualities of content, (c) a pilot study was conducted, and (d) a final check was completed.

\section{Data Analysis}

All quantitative data were entered into the SPSS database and examined for statistically significant relationships using correlational and logistic regression analyses (Aiken \& West, 1991; Hinkle et al., 2009). Characteristics were analyzed using descriptive statistics including frequency, mean, standard deviation, and chi-square tests of homogeneity. Descriptive analyses were conducted on the data set to identify the student composition for each variable. The use of descriptive statistics summarized the study population and helped simplify the data into meaningful categories. Graphic portrayals of the data will also be presented to further illuminate the composition of the 
study population (Gravetter \& Wallnau, 2007; McMillan \& Schumacher, 2001). An alpha level of .05 (one-tailed) was used in both hypothesis tests.

In addition to descriptive statistical analysis, this study employed the use of inferential statistics. The purpose of inferential statistics is to study samples and make generalizations about the population from which they were drawn (Gravetter \& Wallnau, 2007). In this case, inferential statistics were used to analyze factors describing students who enrolled in the Workforce Leadership or Occupational Training and Development major to determine if any of those factors were statistically significant and thus can be confidently applied to all adult students who take undergraduate courses in the Bachelor of Science in Workforce Leadership at University of Louisville. Several inferential statistical approaches have been explored in preparation for this study and are discussed below.

\section{Statistical approaches considered}

Through the literature review, several commonly used statistical approaches to retention studies were noted. The value of each approach to this study is considered below. Specifically, the applicability of logistic regression, and multiple regression were examined. Logistic regression is widely used in higher education and specifically in retention studies (Peng, So, Stage \& St. John, 2002). It is well-suited for retention studies because it uses categorical outcome variables, such as persisting or dropping out from college (Peng et al, 2002). Caison (2006) noted that logistic regression is a "superior" approach for use in higher education because of its "ability to describe the relationship between a categorical dependent variable and a number of both interval and categorical 
independent variables" (p. 439). This study will use a categorical dependent variable (i.e., did the student drop out and not return during the specified cross sectional survey period). Logistic regression was specifically chosen because the dependent variable is dichotomous in nature. Because this study uses multiple independent variables (shown in Table 3), the specific model that would be appropriate would be logistic regression, which is "used whenever researchers are interested in the relationship of several independent variables combined with a dependent variable" (McMillan \& Schumacher, 2001, p. 295).

In multiple regression, each independent variable is tested. This differs from factoral analysis, which combines variables into categories. It is useful when distinction between dependent and independent variables "is not meaningful" (Ferguson, 1981, p. 488). For example, in this study, factoral analysis was considered to group all variables classified as "demographic" variables into one category in order to test the significance of demography on course retention. If a large number of coefficients was computed, it was likely that there was a relationship that was erroneously suggested as true (Gay \& Airasian, 2003). Thus, a smaller number of carefully selected variables are much preferred to a larger number of selected variables (Gay \& Airasian, 2003). Determining how to combine the variables into one factor is difficult, however, and does not seem appropriate in this study, given the wide array of variables in each of the three categories. The value of several statistical approaches was considered for this study including logit and probit analysis; linear, multiple, and stepwise multiple regression; factor analysis; 
and path analysis. The conclusion reached is that logistic regression analyses was the most appropriate inferential statistical methods for this study.

\section{Summary}

This study sought to determine if there were variables that increase or decrease the likelihood of completing the bachelor's degree in an adult degree completion program by utilizing the theoretical underpinnings of Braxton, Hirschy, and McClendon's (2004) Theory of Student Departure in Commuter Colleges and Bean and Metzner's (1985) Conceptual Model of Undergraduate Nontraditional Student Attrition. It relied on data collected from the newly created ALPS survey sent to 1240 undergraduate students enrolled in the Bachelor of Science in Workforce Leadership and Occupational Training and Development majors between 2004 and 2011 at the University of Louisville. Analysis of the relationship between variables was conducted using correlational statistical analysis, and logistic regression techniques. Descriptive statistics were provided to describe the study population in more detail. Inferential statistics were used to address the primary study question - Are there variables that predict the likelihood of completing the degree? - and the main sub-questions, which are: 1) What are the relationships between (a) student entry variables, (b) internal campus environment variables, and (c) external influences variables and the outcome variable student persistence in an adult degree completion program at the bachelor's level? and 2) What is the multivariate predictive relationship between student entry variables, internal campus environment variables, and external influence variables and the outcome variable student persistence? 
Chapter 3 detailed the research processes including the research design, sampling and population, instruments, and procedures used for data collection and analysis in the present study. Chapter 4 presents detailed analysis of findings and is followed by Chapter 5, which includes a discussion of the results and implications for theory, research, and practice. 


\section{CHAPTER IV}

\section{RESULTS}

This chapter presents the results of the study and is organized into three sections: background of the sample, examination of the results, and brief summary of the chapter. Descriptive statistics, correlational analyses, and logistic regression analyses were used to examine the research questions. Prediction methods, such as logistic regression, are helpful in determining which set of variables are most closely linked to a specific outcome (Green, 1991).

\section{Background of the Sample}

This study examined factors that influence adult learners' ability to persist in a degree-completion program at a four-year university. Data were collected from 437 adult students enrolled in the Bachelor of Science degree program in Workforce Leadership and Occupational Training and Development from 2004 through the summer 2011. The outcome variable was persistence and had adult learners dichotomously classified as a persister or nonpersister depending on their enrollment status. The predictor variables were divided into three constructs including student entry characteristics, internal campus/academic environment, and external environment. The student entry characteristics were composed of gender, age, ethnicity, parental education, previous college credit, educational goals, children, marital status, income, and motivation. The predictor variables categorized as internal campus/academic environment were 
enrollment status, cumulative GPA, institutional support, academic advising, faculty support, financial aid, cost, flexible course options, active learning, and prior learning assessment. Finally, the predictor variables classified as external environment included finances, family influences, work influences, significant life events, community influences, and hours of employment.

The population ( $n=1240)$ consisted of individuals, currently or formerly enrolled in the Bachelor of Science degree program in Occupational Training and Development or Workforce Leadership, who were between the ages of 25 to 67 , and had previous college credit but no degree prior to enrollment in this baccalaureate program. Email surveys were sent to all 1,240 current and former students. A total of 157 emails were undeliverable making the total sample $(n=1083)$. Of the total 1083 emailed surveys, 437 current and former students participated, representing a $40 \%$ response rate.

Examination of the Results

\section{Statistical Procedures}

The data analyses were conducted using the Statistical Package for Social Sciences (SPSS), version 20.0, and Survey Monkey online survey software and questionnaire tool. Descriptive and inferential statistics were used to analyze data collected with the Adult Learner Persistence Survey (ALPS). Descriptive statistics, such as frequencies, percentages, and Pearson correlation were used to analyze the demographic, internal campus, and external characteristics related to the first research question. The inferential statistical method included logistic regression, and was used for research question two. Logistic regression is a technique often used when researchers want to predict whether or not something will happen, such as persisting to graduation 
(Field, 2005). The first section in the examination of the results is a representation of the descriptive statistics from the 437 respondents followed by univariate correlation analyses, and then concluded by logistic regression analyses.

\section{Dependent Variable}

Persistence is viewed as dichotomous variable in this study. Therefore, those adult learners that have graduated or maintained continuous enrollment in the program are considered persisters. Students that are not currently enrolled and have not graduated are considered nonpersisters. Approximately 83.3\% $(n=353)$ of the respondents were persisters and $16.7 \%(n=71)$ of respondents were nonpersisters. The program retention from 2008 through 2010 was only $64 \%$ so this sample is not entirely representative of the overall population. This fact will be noted in the limitations section of chapter 5. A total of $2.9 \%(n=13)$ did not indicate their enrollment status and were therefore excluded from further analysis. Although the large majority of respondents were persisters, the $16.7 \%(n=71)$ of nonpersisters were deemed as useful for analyses. While this sample is not perfectly reflective of the overall program, the results are still empirically valuable and were deemed worthy of further analysis. Table 4 displays all variations of enrollment of respondents from the sample.

Table 4

Frequency Distribution of Current Enrollment Status

\begin{tabular}{lrrr}
\hline & $n$ & \multicolumn{1}{c}{$\%$} \\
\hline Currently enrolled & 219 & 51.7 & \\
Not taking classes but intend to return & 56 & 13.2 & \\
Not taking classes do NOT intend to return & 15 & 3.5 & $\vdots$ \\
Graduated from the program & 134 & 31.6 & \\
\hline
\end{tabular}




\section{Student Entry Characteristics}

Gender

Approximately $54.3 \%(n=229)$ of the sample was female and $45.7 \%(n=193)$ of the sample was male. Fifteen students did not report their gender. It is worth noting that the gender distribution for the overall population was the opposite of the sample. Approximately, $44.6 \%(n=553)$ were female and $55.4 \%(n=687)$ were male and from the total population of students from the Bachelor of Science degree program in Occupational Training and Development or Workforce Leadership. Age

A frequency analysis of age indicated that $22.3 \%(n=94)$ of the respondents reported belonging to the $25-35$ group, $34.6 \%(n=146)$ to the $36-45$ group, $35.5 \%(n=$ $150)$ to the $46-55$ group, $6.9 \%(n=29)$ to the $56-65$ group, and finally $0.7 \%(n=3)$ to the 66 or older group. Approximately 3.4\% $(n=15)$ of respondents did not report their age. Over $70 \%$ of respondents were between $36-55$ years of age. Thus, the representatives from this degree completion program were slightly older on average than that of other programs (averaged 34 years of age) focused on adult degree attainment throughout the United States with a mean age of 39 (Wlodkowski et al., 2001).

\section{Ethnicity}

Question five examined students ethnicity and the results indicated that $76.5 \%(n$ $=322)$ of the respondents were White or Caucasian, $20.2 \%(n=85)$ were Black or African American, 2.4\% $(n=10)$ were Hispanic or Latino, $1 \%(n=4)$ were Asian, $1 \%(n$ $=4)$ were American Indian, $0.2 \%(n=1)$ were Pacific Islander, and $0.2 \%(n=1)$ were Other/Multiracial. Approximately 3.6\% percent $(n=16)$ of respondents did not report 
their ethnicity. Therefore, no significant difference exists between this sample and overall adult student enrollment in the United States (National Center for Education Statistics, 2002). It is worth noting that the respondents from the sample were very similar to the overall population from the Bachelor of Science degree program in Occupational Training and Development or Workforce Leadership. Approximately, 70\% $(n=873)$ were White or Caucasian, 21.2\% $(n=264)$ were Black or African American, 3.7\% $(n=$ 47) were Hispanic or Latino, $1 \%(n=12)$ were Asian, and $.03 \%(n=4)$ were American Indian. Approximately $3.2 \%$ percent $(n=40)$ of respondents did not report their ethnicity.

\section{Parental Education}

Table 5 depicts results for the sample related to parents' level of education. As seen in the table, the largest number of students $(n=171)$ reported their mothers' and $(n=$ 174) reported their fathers' highest level of education was completion of a high school degree, followed by the completion of some college by mother $(n=97)$ and by father $(n$ $=71$ ). Together, these two levels made up $63.6 \%$ for mother and $58.9 \%$ for father respectively. Overall, the data indicate that mothers and fathers of the survey respondents were not likely to have completed a college degree. 
Table 5

Frequency Distributions for Highest Level of Education Completed $(n=437)$

\begin{tabular}{|c|c|c|c|c|}
\hline \multirow[b]{2}{*}{ Level of Education } & \multicolumn{2}{|c|}{ Mother } & \multicolumn{2}{|c|}{ Father } \\
\hline & $\%$ & $n$ & $\%$ & $n$ \\
\hline Elementary school or less & 4.5 & 19 & 5.5 & 23 \\
\hline Some high school & 11.4 & 48 & 13.0 & 54 \\
\hline High school graduate & 40.6 & 171 & 41.8 & 174 \\
\hline Some college & 23.0 & 97 & 17.1 & 71 \\
\hline College degree & 11.6 & 49 & 13 & 54 \\
\hline Some graduate school & 1.9 & 8 & 1.0 & 4 \\
\hline Graduate degree & 5.5 & 23 & 5.5 & 23 \\
\hline Don't know & 1.4 & 6 & 3.1 & 13 \\
\hline Missing & 3.6 & 16 & 4.8 & 21 \\
\hline
\end{tabular}

Previous College Credit

Question eight asked respondents to give a best estimate of their total college credits prior to entering the degree completion program. Students were able to type in a numerical value into a response box. Of the 403 responses, students returned to the degree completion program with an average of 67.78 total college credits. The mode of the 403 responses was 60 . This high number of previous college credit is based upon many respondents in the program previously attaining an associate's degree or at least two years of four-year college credit. Not surprisingly, the range of credits was 
expansive. Students indicated as few as 6 and as many as 154 total college credit hours prior to entering their degree completion program. These results match much of the literature which indicates that students with some college and no degree have wide and varied backgrounds although they share the same goal of receiving a baccalaureate degree (Lumina, 2011).

\section{Educational Goal}

Question nine asked respondents to indicate their highest educational goal. A frequency analysis indicated that only $1.4 \%(n=6)$ of the participant's highest educational goal was a certificate, $8.6 \%(n=36)$ reported earning an associate's degree was their highest educational goal, $32.7 \%(n=137)$ reported earning a bachelor's degree was their highest goal, $48.9 \%(n=205)$ reported earning a master's degree was their highest educational goal, and $8.4 \%(n=35)$ reported earning a doctorate was their highest goal. Approximately $4.1 \%(n=18)$ of respondents did not report their highest educational goal. Accordingly, $61.4 \%(n=258)$ of student respondents indicated an educational goal beyond the bachelor's degree.

\section{Children}

Question ten asked respondents to indicate the number of children they had during their enrollment in the bachelor's degree completion program. A frequency analysis indicated that $27.6 \%(n=116)$ had zero children, $15.9 \%(n=67)$ had one child, $32.7 \%(n$ $=146)$ had two children, $13.3 \%(n=56)$ had three children, and $8.6 \%(n=36)$ had four or more children during their enrollment in the program. Approximately $3.6 \%(n=16)$ of respondents did not report their number of children during enrollment. Therefore, over $72 \%$ of student respondents had one or more children in this study with the highest 
percentage having two children, $32.7 \%(n=146)$. It should also be noted that over one quarter of respondents have no children.

\section{Marital Status}

A frequency analysis of marital status during initial enrollment in the program indicated that $14.7 \%(n=62)$ of the respondents were never married, $69.4 \%(n=292)$ were married, $12.2 \%(n=51)$ were divorced or previously married, $2.9 \%(n=12)$ were separated, $11.2 \%(n=47)$ were divorced, and 1.0\% $(n=4)$ were widowed. Approximately $3.6 \%$ percent $(n=16)$ of respondents did not report their marital status during initial enrollment. Almost $70 \%$ of respondents were married so a dichotomous variable of marital status was created $(1=$ Married $\& 0=$ Not married $)$ for better entry into the logistic regression equation. The makeup of this sample included a much higher percentage of married people than the national average of $55 \%$ of males and $52 \%$ of females, age 15 and older (U.S. Census Bureau, 2011).

\section{Income}

Question 12 of the survey examined a frequency analysis of annual household income during initial enrollment. The results indicated that the largest segment of this sample made between $\$ 41,000$ and $\$ 60,999$, which was $22.0 \%(n=91)$. Table 6 displays the distribution of the household income levels of the respondents of this study. Overall, the distribution of income level among students is widely varied and does not cluster around one particular household salary range. Approximately $5.2 \%$ percent $(n=23)$ of respondents did not report their annual household income. Interestingly, the median household income range for this sample $\$ 41,000$ - $\$ 60,999$, is similar to that reported by the U.S. Census Bureau (2009) of $\$ 50,221$. 
Table 6

Frequency Distribution of Household Income During Initial Enrollment

\begin{tabular}{lll}
\hline Income Level & $\%$ & $n$ \\
\hline Less than $\$ 15,000$ & 4.3 & 18 \\
$\$ 15,000-\$ 25,999$ & 8.2 & 34 \\
$\$ 26,000-\$ 40,999$ & 17.9 & 74 \\
$\$ 41,000-\$ 60,999$ & 22.0 & 91 \\
$\$ 61,000-\$ 75,999$ & 14.3 & 59 \\
$\$ 76,000-\$ 99,999$ & 15.2 & 63 \\
$\$ 100,000$ or more & 18.1 & 75 \\
\hline
\end{tabular}

\section{Motivation}

The final student entry characteristic questions examined students' motivation to complete the degree given other possible priorities and alternatives and students' reasons for return to finish a bachelor's degree. The results indicated that the largest section of adults returning to school found completion of a bachelor's degree to be very important $63.5 \%(n=265)$. Table 7 displays the distribution of the respondents' answers to this question. Overall, the distribution of motivation to complete a bachelor's degree among students was concentrated around important and very important encompassing $83.9 \%$ ( $n$ $=350$ ) of the responses. Interestingly, however, fifty-four respondents indicated the importance of receiving a degree was very unimportant. Although this accounts for only $13 \%$ of the sample responses, it is important to note that over fifty adults ranked obtaining the degree as very unimportant. This is likely related to many adults in this program currently maintaining steady employment and pursuing this degree for personal fulfillment rather than work advancement. Approximately $4.5 \%$ percent $(n=20)$ of respondents did not report the importance placed on completing a bachelor's degree. 
Table 7

Frequency Distribution of Importance of Bachelor's Degree Completion

\begin{tabular}{lll}
\hline Level of Importance & $\%$ & $n$ \\
\hline Very unimportant & 12.9 & 54 \\
Unimportant & 0.2 & 1 \\
Neither unimportant or important & 2.9 & 12 \\
Important & 20.4 & 85 \\
Very important & 63.5 & 265 \\
Missing & 4.5 & 20 \\
& & \\
\hline
\end{tabular}

Question 14 was a rank order response regarding the reasons for returning to complete a bachelor's degree ( 1 being highest and 5 being lowest priority). Overall, $50.3 \%(n=172)$ of students identified personal fulfillment as the most important reason for returning to complete a degree, followed by $28.4 \%(n=93)$ who cited work advancement and $25.8 \%(n=92)$ who desired to inspire children/family. The fourthranked response was career change followed by maintaining current employment as the lowest-ranked response. Approximately $3.6 \%$ percent $(n=16)$ of respondents did not rank their reasons for returning to complete a bachelor's degree.

Table 8 provides a summary of the key facts pertaining to background characteristics of the study sample. Not all values of the variables are shown in the table, only the values that represent the majority of the cases. 
Table 8

Summary Facts Related to Student Entry Characteristics

$\underline{\text { Variable }}$

$\underline{\text { Summary }}$

Gender

Male 54\%, Female $46 \%$

Age

Between 36 to 55 : $70 \%$; mean age was 39

Ethnicity

White, Non-Hispanic 77\%; African-American 20\%

Father's Education

High school graduate or Some college $59 \%$

Mother's Education

High school graduate or Some college $64 \%$

Previous college credits

Mean $=68 ;$ Mode $=60$

Highest Education Goal

Associate's degree 9\%; Bachelor's degree 33\%;

Master's degree 49\%

Number of Children

None $28 \%$, One $16 \%$, Two $33 \%$

Marital status

Never married 15\%, Married 69\%, Divorced $12 \%$

Income

$\$ 26 \mathrm{~K}-40 \mathrm{~K} 18 \% ; \$ 41 \mathrm{~K}-60 \mathrm{~K} 22 \% ; \$ 61 \mathrm{~K}-75 \mathrm{~K} \quad 14 \%$

Importance of

Bachelor's degree

Very important $64 \%$, Important $20 \%$

Note. Only the categories with the highest percentages are reported, so percentages do not always total to $100 \%$. 


\section{Internal Campus/Academic Environment}

\section{Enrollment Status}

A frequency analysis of average credit hours per semester during enrollment in the program indicated that $16.4 \%(n=67)$ of the respondents took $1-3$ credit hours per semester, $50.0 \%(n=204)$ took 4-6 credit hours each semester, $11.0 \%(n=45)$ enrolled in $7-9$ credit hours, $15.2 \%(n=62)$ took $10-12$ credit hours, and $7.4 \%(n=30)$ enrolled in more than 12 credit hours per semester. Therefore, approximately $77.4 \%(n=316)$ of students were classified as part-time students and $22.6 \%$ percent $(n=92)$ were classified as full-time during the majority of their enrollment in this degree completion program. Approximately $6.6 \%(n=29)$ of respondents did not report their average credit hours during enrollment.

\section{Cumulative GPA}

Question 16 asked respondents to identify their overall cumulative GPA. A frequency analysis of this variable indicated that $2.9 \%(n=12)$ of the respondents had a 2.09 or less, $5.9 \%(n=24)$ had a 2.10 to $2.59,21.1 \%(n=86)$ had between a 2.60 and $3.09,20.6 \%(n=84)$ had a 3.10 to 3.59 , and $49.4 \%(n=201)$ earned between a 3.60 and 4.0. Therefore, approximately $91.1 \%(n=371)$ of all respondents had a 2.6 cumulative GPA or higher with a mean GPA for the population of 3.54 . Only $6.8 \%(n=30)$ did not elect to respond to this question.

\section{Institutional Support}

Question 17 asked respondents to indicate to what extent support was provided by the university to become a successful student. Students were given a Likert scale ranging 
from 1 (not at all) to 5 (to a very great extent). Approximately $71.4 \%(n=288)$ of students specified that the university provided services to promote student success to a great or very great extent. Conversely, only $1.2 \%(n=5)$ indicated no support at all from the institution. This variable will be paired with academic advising and institutional support to constitute a scaled variable of academic/institutional responsiveness. The combination of the variables is meant to reduce the number of items entering the logistic regression for better explanation of the variance. Table 9 displays the extent to which students felt that the university provided services to promote their success as learners.

Table 9

Frequency Distribution of Extent

the University Provided Resources to Promote Student Success

\begin{tabular}{lll}
\hline Extent & $\%$ & $n$ \\
\hline Not at all & 1.2 & 5 \\
To a small extent & 7.4 & 30 \\
To some extent & 20.6 & 84 \\
To a great extent & 46.7 & 190 \\
To a very great extent & 24.1 & 98 \\
Missing & 6.8 & 30 \\
& & \\
\hline
\end{tabular}

Academic Advising Support

Question 18, the first question measuring the advising support variable, asked students about the amount of meetings with an advisor that lasted ten minutes or more during their entire enrollment in this degree completion program. Students were asked to give their best estimate of all phone contacts, in-person meetings, and email correspondence that lasted longer than ten minutes. This was designed to exclude quick 
informational emails, phone calls, and drop-in visits. The highest percentage of students selected four or more meetings $42.8 \%(n=175)$ as their response. It should be noted that students are required to meet with their advisor only once when they enroll in this program initially. Table 10 reports students' frequency of meetings with their academic advisor.

Table 10

Frequency Distribution of Number of Academic Advising Meetings

\begin{tabular}{lll}
\hline Number of Meetings & $\%$ & $n$ \\
\hline 0 & 3.7 & 15 \\
1 & 12.0 & 49 \\
2 & 23.7 & 97 \\
3 & 17.8 & 73 \\
4 or more & 42.8 & 175 \\
Missing & 6.4 & 28 \\
& & \\
\hline
\end{tabular}

Questions 20a and 20b explored the extent to which students believed their academic advisor was knowledgeable about academic planning and level of care toward the individual student. The results from the question about advisor knowledge indicate that $86.7 \%(n=351)$ felt that their advisor was knowledgeable about the plan toward individual student degree completion to a great extent or higher. Similarly, $77.5 \%(n=$ 313) students indicated that their advisor cared about them personally to a great extent or higher.

Faculty Support

Question 19 asked students about the number of outside meetings with instructors during their enrollment. Specifically, students were asked to give their best estimate of 
the number of meetings outside the classroom or online environment of ten minutes or more. The greatest percentage of responses came from $122(30 \%)$ of students that indicated they did not meet with their instructor outside of the classroom during their enrollment in this program. Approximately, $6.8 \%(n=30)$ did not respond to this question. Table 11 displays the frequency of meetings with instructors among the respondents.

Table 11

Frequency Distribution of Number of Outside Instructor Meetings

\begin{tabular}{llll}
\hline Number of Meetings & $\%$ & $n$ \\
\hline 0 & 30.0 & 122 & \\
1 & 16.5 & 67 & \\
2 & 19.2 & 78 & \\
3 & 10.1 & 41 & \\
4 or more & 24.3 & 99 & $\ldots$ \\
Missing & 6.8 & 30 & \\
\end{tabular}

Question 20c and 20d explored the extent to which students believe their instructors were knowledgeable about course content and the amount of personal care they exhibited. The results from the question about instructor content knowledge indicate that $88.9 \%(n=360)$ believe that their instructor was knowledgeable to a great extent or higher about the course content in each class within the program. Also, 65.1\% $(n=263)$ of students indicated that their instructors cared about them personally to a great extent or higher. 


\section{Financial Aid}

Approximately $84.1 \%(n=328)$ of the sample did not receive scholarships and $57.4 \%(n=230)$ indicated that they did receive financial aid (not scholarships). This percentage of financial aid recipients is due to the prevalence of tuition assistance offered by many employers. Approximately $60.3 \%(n=242)$ indicated that they did receive tuition assistance from their employer in question thirty three. Approximately, $7.3 \%(n=$ 32) students did not report whether or not they received financial aid or scholarships.

\section{Cost}

Question 22 asked a rank order question related to reasons for selecting the degree completion program. Students were instructed to rank ( 1 being the highest and 5 being the lowest) reasons including cost, reputation of the institution, speed of completion, convenience (location), and convenience (course delivery options). Approximately 58.9\% ( $n=206$ ) of the students identified cost as the lowest-ranking of the five selections. On the contrary, $42.6 \%(n=156)$ of the students gave the highest ranking to speed of completing the program.

\section{Flexible Course Options}

Question 23 examined the type of courses students enrolled in throughout their program. The results indicated that $28.0 \%(n=113)$ selected online-only course options during their enrollment. Approximately $16.8 \%(n=68)$ enrolled in in-class only courses during their enrollment and 55.2\% $(n=223)$ enrolled in both online and in-class options throughout their enrollment period. Only $7.5 \%(n=33)$ skipped this question.

Question 24 also sought to examine course flexibility by asking to what extent students were able to choose flexible course options that fit their life circumstances, were 
there sufficient course offerings, were enrollment processes convenient, and did students have a clear plan to meet graduation requirements. All responses from question 24a through $24 \mathrm{~d}$ had a response of to a great extent or higher above $77 \%$ indicating a confidence and comfort with the flexibility of course offerings in this particular program. Active Learning

Questions 25 and 26 explored the students' experience with concepts related to active learning. Question 25 asked students to what extent their experience in the program provided advancement in critical thinking skills, interpersonal skills, working with others, and problem-solving skills. Sixty percent of respondents to this question exhibited that they were advancing these skills to a great extent or higher. Four percent or less indicated that they were experiencing no contribution to their skills in critical thinking, interpersonal skills, working with others, and problem-solving skills.

Similarly, question 26 asked students about the relevance of the course content to real-world practice. More than $74 \%$ of responses indicated experience applying relevant content to real-world practice. Also, nearly $55 \%$ indicated to a great extent or higher that they worked in teams to complete assignments. The high percentage of persisters in this study indicates that content relevance and active learning are influential in one's ability to persist. Table 12 displays the full results from this active learning question. 
Table 12

Frequency Distribution of Four Types of Experiences in Active Learning

\begin{tabular}{|c|c|c|c|c|c|}
\hline & Not at All & $\begin{array}{l}\text { To a Small } \\
\text { Extent }\end{array}$ & $\begin{array}{l}\text { To Some } \\
\text { Extent }\end{array}$ & $\begin{array}{l}\text { To a Great } \\
\text { Extent }\end{array}$ & $\begin{array}{l}\text { To a Very } \\
\text { Great Extent }\end{array}$ \\
\hline $\begin{array}{l}\text { Worked in } \\
\text { teams to } \\
\text { complete } \\
\text { assignments }\end{array}$ & $\begin{array}{l}6.6 \% \\
(27)\end{array}$ & $\begin{array}{l}10.8 \% \\
(44)\end{array}$ & $\begin{array}{l}27.8 \% \\
(113)\end{array}$ & $\begin{array}{l}33.2 \% \\
(135)\end{array}$ & $\begin{array}{l}21.6 \% \\
(88)\end{array}$ \\
\hline $\begin{array}{l}\text { Complete } \\
\text { assignments } \\
\text { that apply to } \\
\text { real-world }\end{array}$ & $\begin{array}{l}2.2 \% \\
(9)\end{array}$ & $\begin{array}{l}4.7 \% \\
(19)\end{array}$ & $\begin{array}{l}18.4 \% \\
(75)\end{array}$ & $\begin{array}{l}38.8 \% \\
(158)\end{array}$ & $\begin{array}{l}35.9 \% \\
(146)\end{array}$ \\
\hline $\begin{array}{l}\text { Put together } \\
\text { ideas from } \\
\text { different } \\
\text { courses }\end{array}$ & $\begin{array}{l}2.7 \% \\
(11)\end{array}$ & $\begin{array}{l}5.9 \% \\
(24)\end{array}$ & $\begin{array}{l}18.7 \% \\
(76)\end{array}$ & $\begin{array}{l}39.6 \% \\
(161)\end{array}$ & $\begin{array}{l}33.2 \% \\
(135)\end{array}$ \\
\hline $\begin{array}{l}\text { Discussed } \\
\text { ideas with } \\
\text { classmates } \\
\text { outside of } \\
\text { class }\end{array}$ & $\begin{array}{l}3.9 \% \\
(16)\end{array}$ & $\begin{array}{l}7.6 \% \\
(31)\end{array}$ & $\begin{array}{l}19.0 \% \\
(77)\end{array}$ & $\begin{array}{l}35.5 \% \\
(144)\end{array}$ & $\begin{array}{l}34.4 \% \\
(138)\end{array}$ \\
\hline
\end{tabular}

Prior Learning Assessment

Questions 27a through 27c examined students' benefit from participation in Prior Learning Assessment (PLA). Approximately 72.9\% $(n=296)$ indicated that they viewed PLA as a time saving avenue for degree completion to a great extent or higher. Likewise, $73.4 \%$ of students indicated that they strongly believed they were more likely to complete the degree because of credits awarded from PLA and $70 \%$ of students indicated that they would finish their degree faster as a result of credit awarded from PLA. Therefore, it was evident that students believed in the value of PLA in their personal pursuit of a baccalaureate degree. 
Table 13 provides a summary of the key facts pertaining to internal campus or academic environment variables. Not all values of the variables are shown in the table, only the values that represent the majority of the cases.

Table 13

Summary Facts Related to Internal Campus/Academic Environment

Variable

Enrollment Status

Cumulative GPA

Institutional Support

Academic Advising

Faculty Support

Financial Aid

Cost

Flexible Course Options

Active Learning
Summary

1-3 16\%; 4-6 50\%; 7-9 11\%; 10-12 15\%; more than $127 \%$

2.60 or higher $91 \%$; mean GPA of 3.54

Resources for success to a great extent or higher $71 \%$

Knowledgeable to a great extent or higher $87 \%$;

Personal care to a great extent or higher $78 \%$

Knowledgeable great extent or higher $89 \%$;

Personal care $65 \%$

Scholarships 16\%; Financial Aid (other) 57\%

Ranked as lowest priority of five options 59\%

Online only $28 \%$; In-class only $17 \%$; Both $55 \%$ Availability of flexible course options to a great extent or higher $78 \%$

To a great extent or higher: Critical thinking 74\%; Interpersonal skills 59\%; Working with others $63 \%$; Problem-solving skills $68 \%$

Prior Learning Assessment Time saver to a great extent or higher 73\%

Note. Only the categories with the highest percentages are reported, so percentages do not always total to $100 \%$. 


\section{External Environment}

Finances

The first variable measured from the external environment construct in this study was finances. Question 30a asked to what extent students believed they have the financial resources to complete their bachelor's degree. Approximately 55.5\% $(n=222)$ of respondents indicated that they believed they had the appropriate finances to complete their degree to a great extent or higher. Conversely, a total of $22.6 \%(n=90)$ indicated that they did not have the financial resources to complete their degrees. Since $83 \%$ of the respondents were persisters and only $17 \%$ were nonpersisters, this distribution of responses is reflective of the overall makeup of the students who responded to this survey. In other words, if one believed that he or she did not have the money to complete the degree they were significantly more likely to dropout or stopout from this degree completion program.

\section{Family Influences}

Question 30b examined whether or not students experienced conflicts between completing class assignments and their family responsibilities. The surveys indicated that $13.6 \%(n=55)$ of the respondents reported no conflict (not at all), 25.6\% $(n=103)$ experienced family/class conflict to a small extent, $35.7 \%(n=144)$ experienced family/class conflict to some extent, $16.6 \%(n=67)$ experienced family/class conflict to a great extent, and $8.4 \%(n=34)$ experienced family/class conflict to a very great extent. Approximately $3.6 \%(n=34)$ did not answer this question. 
Questions $35 \mathrm{a}$ and $35 \mathrm{~b}$ also broached a query related to family influences. It asked students to what extent their spouse or partner and other family members encouraged them to continue their studies in the degree completion program. The findings indicated that $63.5 \%(n=255)$ of students' spouses or partners encouraged them to a great extent or higher and $60.2 \%(n=239)$ of other family members encouraged them to a great extent or higher. Table 14 displays the overall responses related to family encouragement to continue studies in the Bachelor of Science degree completion program.

Table 14

Frequency Distribution of Extent to Which Family Members "Encouraged You to Continue Your Studies"

\begin{tabular}{|c|c|c|c|c|c|c|}
\hline & Not at All & $\begin{array}{l}\text { To a Small } \\
\text { Extent }\end{array}$ & $\begin{array}{l}\text { To Some } \\
\text { Extent }\end{array}$ & $\begin{array}{l}\text { To a Great } \\
\text { Extent }\end{array}$ & $\begin{array}{l}\text { To a Very } \\
\text { Great Extent }\end{array}$ & $\begin{array}{l}\text { Not } \\
\text { Applicable }\end{array}$ \\
\hline $\begin{array}{l}\text { Spouse or } \\
\text { Partner }\end{array}$ & $\begin{array}{l}10.2 \% \\
(41)\end{array}$ & $\begin{array}{l}4.2 \% \\
(17)\end{array}$ & $\begin{array}{l}10.0 \% \\
(40)\end{array}$ & $\begin{array}{l}17.2 \% \\
(69)\end{array}$ & $\begin{array}{l}46.3 \% \\
(186)\end{array}$ & $\begin{array}{l}12.2 \% \\
(49)\end{array}$ \\
\hline Other Family & $\begin{array}{l}7.6 \% \\
(30)\end{array}$ & $\begin{array}{l}10.6 \% \\
(42)\end{array}$ & $\begin{array}{l}18.6 \% \\
(74)\end{array}$ & $\begin{array}{l}21.4 \% \\
(85)\end{array}$ & $\begin{array}{l}38.8 \% \\
(154)\end{array}$ & $\begin{array}{l}3.0 \% \\
(12)\end{array}$ \\
\hline
\end{tabular}

Approximately $7.7 \%(n=34)$ students did not elect to answer the question about familial encouragement.

\section{Work Influences}

Multiple questions were constructed to examine the impact of work on students' ability to persist. The survey asked to what extent the student's employer encouraged them to continue studies in this program. Approximately $20.6 \%(n=81)$ of the respondents indicated no encouragement (not at all), 10.9\% $(n=43)$ received employer encouragement to a small extent, $18.3 \%(n=72)$ received employer encouragement to a 
some extent, $16.8 \%(n=66)$ received employer encouragement to a great extent, $24.6 \%$ $(n=97)$ received employer encouragement to a very great, and $8.9 \%(n=35)$ indicated that employer support was not applicable. Approximately $3.6 \%(n=34)$ did not answer this question.

Approximately $60.3 \%(n=242)$ indicated that they did receive tuition assistance from their employer. Conversely $39.7 \%(n=159)$ students did not receive any tuition assistance from their employer and 8.2\% $(n=36)$ did not answer this question. Of the students who indicated they received employer tuition assistance, $80.6 \%(n=213)$ of indicated that it was important to a great extent or higher. This finding is consistent with the literature that employer tuition is crucial to those that utilize reimbursement funds for their education. When employer support is available, $70 \%$ of adults use the benefit to pursue formal education (NCES, 2010). Thus, the sample is similar to that of other adult learner studies.

Finally, question 30 a posited to what extent students experienced conflicts between completing class assignments and his or her work schedule. The findings indicated that $25.9 \%(n=104)$ of the respondents experienced no work/class conflict (not at all), $20.6 \%$ $(n=83)$ experienced work/class conflict to a small extent, $35.1 \%(n=141)$ experienced work/class conflict to some extent, $10.4 \%(n=42)$ experienced work/class conflict to a great extent, and $8.0 \%(n=30)$ experienced work/class conflict to a very great extent. Approximately $3.6 \%(n=34)$ did not answer this question.

\section{Significant Life Events}

Question-31 asked students if they had experienced one or more significant life events during their enrollment. It provided examples including, but not limited to, 
military deployment, birth of a child, family illness, personal illness, marriage, divorce, and loss of employment. A total of $56.7 \%(n=228)$ respondents answered yes.

Conversely, $43.3 \%(n=174)$ indicated no significant life event during their enrollment in the degree completion program. A total of $8.0 \%(n=35)$ chose not to disclose whether or not they had a significant life event. Those who had experienced significant life events were asked in Question 32 to list specific life events. The 229 students who responded listed events ranging from personal illness to loss of employment. Specifically, the most frequent occurring responses were 75 responses related to illness, 45 related to death of a loved one, 22 mentions of divorce, 21 responses about loss of employment, and 10 respondents indicating a military deployment during enrollment. This may be an opportunity for future study to extrapolate levels of significant life event to see the individual impact on students' ability to persist.

\section{Community Influences}

Question 30c asked students to identify the extent of conflict between community commitments and class assignments. The findings indicated that $37.3 \%(n=150)$ of the respondents experienced no community/class conflict (not at all), 27.6\% $(n=111)$ experienced community/class conflict to a small extent, $23.6 \%(n=95)$ experienced community/class conflict to some extent, $7.7 \%(n=31)$ experienced community/class conflict to a great extent, and only $3.7 \%(n=15)$ experienced work/class conflict to a very great extent. Approximately $3.6 \%(n=34)$ did not answer this question. Overall, students indicated that community commitments had little impact on their ability to complete class assignments. 


\section{Hours of Employment}

The final external environmental variable examined was hours of employment and employment status. Question 28 asked respondents how many hours per week respondents worked while enrolled in the program. A frequency analysis of average hours of work per week during enrollment in the program indicated that $15.1 \%(n=61)$ of the respondents worked $0-20$ hours, $5.0 \%(n=20)$ worked $21-30$ hours per week, $27.5 \%(n=111)$ worked $31-40$ hours per week, $39.4 \%(n=159)$ worked $41-50$ hours per week, and $13.1 \%(n=53)$ worked 51 hours or more per week. Therefore, approximately $80 \%(n=323)$ of students were working 31 or more hours per week and $20.1 \%$ percent ( $n$ $=81$ ) worked 30 hours or less during their enrollment in the program. Also, approximately $7.5 \%(n=33)$ of respondents did not report their per-week work hours during enrollment.

Table 15 provides a summary of the key facts pertaining to external environment variables. Not all values of the variables are shown in the table, only the values that represent the majority of the cases. 
Table 15

Summary Facts Related to External Environment

$\underline{\text { Variable }}$

Finances

Family Influences

Work Influences

Significant Life Events

Community Influences

Hours of Employment
Summary

Believe they have finances to complete to a great extent or higher $56 \%$; To some extent $35 \%$

Experience family conflicts with school to a great extent or higher $25 \%$; To some extent $36 \%$

Experience work conflicts with school to a great extent or higher $18 \%$; To some extent $35 \%$

Yes $56.7 \%$; No $43.3 \%$

Experience community conflicts with school to a great extent or higher $11 \%$; Not at all $37 \%$

$0-2015 \% ; 21-305 \% ; 31-4028 \% ; 41-5039 \% ; 51+13 \%$

Note. Only the categories with the highest percentages are reported, so percentages do not always total to $100 \%$.

\section{Correlation Analyses}

In order to address Research Question 1 and to understand the relationships between the independent student entry variables, internal campus/academic environment variables, and external influences variables and the dependent variable student persistence, bivariate correlation analyses were performed. The correlations were done in separate sets to help determine which variables would enter the logistic regression equation. In other words, the three constructs were separated to examine all variables within each construct during the correlation analyses.

The first set of correlation analyses used all student entry characteristics including gender, age, ethnicity, parental education, previous college credit, educational goal, 
children, marital status, income, and motivation. Table 16, which displays the results of the correlation analysis of all student entry variables, shows that educational goal has a positive significant correlation with the dependent variable persistence. Of the ten correlation coefficients, only one was statistically significant at the .05 alpha level, educational goal $(r=.202)$. Although gender, age, ethnicity, parents' education, previous credits, number of children, marital status, income, and motivation have previously been significant variables in previous studies, none of the ten variables were statistically significant predictors of persistence for this population of adult learners. Most surprisingly, the variable previous college credit was not significant. Prior studies have found a direct link between adult learners' likelihood of persisting to graduation and their previous college credit (Wlodkowski, 2001). The lack of statistical significance for this variable may be due, in large part, to this program's offering of prior learning assessment, flexible course options, and content relevant to workforce development. These adult friendly program practices in the Workforce Leadership Program may offset the need for students to have significant prior education to be more likely to persist. See Appendix B for a full correlation table that shows correlations among the predictor variables. 
Table 16

Correlations Between Persistence and Student Entry Characteristics

\begin{tabular}{|c|c|c|c|c|}
\hline$\underline{\text { Gender }}$ & Age & Ethnicity & $\begin{array}{l}\text { Parents' } \\
\text { Education }\end{array}$ & $\begin{array}{l}\text { Previous } \\
\text { Credits }\end{array}$ \\
\hline .032 & -.046 & -.019 & .042 & .050 \\
\hline $\begin{array}{l}\text { Educational } \\
\text { Goal } \\
\end{array}$ & $\begin{array}{l}\text { Number } \\
\text { Children }\end{array}$ & $\begin{array}{l}\text { Marital } \\
\text { Status } \\
\end{array}$ & Income & Motivation \\
\hline $.202 * *$ & .044 & .035 & -.026 & .081 \\
\hline
\end{tabular}

Next, the internal campus/academic variables were considered. Table 19 includes internal campus/academic environment variables: enrollment status, GPA, institutional support, academic advising, and faculty support. Multiple variables are broken out to test for individual threads of each variable and its direct influence on the outcome variable student persistence. See Appendix B for tables showing intercorrelations among predictors.

The first two rows of correlations presented in table 17 display that nine statistically significant variables exhibited a positive correlation to the criterion variable: credits per semester $(r=.183, p<.001)$, overall GPA $(r=.121, p<.05)$, university resources $(r=.273, p<.001)$, number of advising appointments $(r=.233, p<.001)$, advisor knowledge $(r=.217, p<.001)$, advisor care $(r=.246, p<.001)$, number of instructor appointments $(r=.117, p<.05)$, instructor content knowledge $(r=.144, p<$ $.05)$, and instructor care $(r=.263, p<.001)$. These findings imply that credit hours, GPA, 
university resources, number of advising and instructor appointments, advisor and instructor knowledge, and advisor and instructor care all contribute to higher levels of persistence of the sample in this study. These finding support the use of each variable in the adapted model by the researcher in this study. Each variable was significant at the univariate level so it will be considered useful for the logistic regression equation.

Table 17

Correlations Between Persistence and Internal Campus/Academic Environment Variables

$\begin{array}{lllll}\begin{array}{l}\text { Credits per } \\ \text { Semester }\end{array} & \begin{array}{l}\text { Overall } \\ \text { GPA }\end{array} & \begin{array}{l}\text { Univ. } \\ \text { Resources }\end{array} & \begin{array}{l}\text { N of Advisor } \\ \text { Appoints. }\end{array} & \begin{array}{l}\text { Advisor } \\ \text { Knowledge }\end{array} \\ .183^{* *} & .121^{*} & .273^{* *} & .233^{* *} & .217^{* *} \\ \begin{array}{l}\text { Advisor } \\ \text { Care }\end{array} & \begin{array}{l}\text { N of Instructor } \\ \text { Meetings }\end{array} & \begin{array}{l}\text { Instructor } \\ \text { Content Know. }\end{array} & \begin{array}{l}\text { Instructor } \\ \text { Care }\end{array} \\ .246^{* *} & .117^{*} & .144^{* *} & .263^{* *} \\ & \text { Financial } & \text { Flexible } & \text { Skills } \\ \text { Scholarships } & \underline{\text { Aid }} & \underline{\text { Course options }} & \underline{\text { Development }} \\ .178^{* *} & .161^{* *} & & .317^{* *} & .339^{* *} \\ \text { Active } & \text { PLA } & & \\ \text { Learning } & \underline{\text { Utility }} & & \\ .331^{* *} & .159^{* *} & & \end{array}$

${ }^{*} p<.05^{* *} p<.01$

Table 17 includes internal campus/academic environment variables: financial aid, scaled variable flexible course options, skill development/active learning, and PLA utility. Flexible course options, skill development, active learning and PLA utility are 
scaled variables with sufficiently high Cronbach alpha coefficients to measure their direct influence on the outcome variable student persistence. Several variables were checked to see if the items might constitute a scaled variable for more efficient measurement. This method was examined to improve the analyses of the logistic regression equation. Because independent variables may serve as covariates to allow researchers to hold them constant, entering fewer items into the logistic regression equation better assesses the unique effects of the other independent variables (Myers et al. 2006). Consequently, Items in Questions 24a-d related to flexible course options were tested and the reliability statistics produced a Cronbach's alpha of .80 . Therefore, a scaled variable labeled flexible course options was created to reduce the amount of independent variables that ultimately enter the logistic regression equation. Also, items in Questions 25a-d related to skills development and active learning were tested and the reliability statistics produced a Cronbach's alpha of .92. Therefore, a variable labeled skill development was created. Next, items in question 26a-d related to active learning were tested and the reliability statistics produced a Cronbach's alpha of .83. Therefore, a variable labeled active learning was created. Finally, items in question $27 \mathrm{a}-\mathrm{c}$ related to prior learning assessment were tested and the reliability statistics produced a Cronbach's alpha of .88 . Therefore, a variable labeled $P L A$ utility was created. Table 19 displays all positive correlations to the dependent variable in the study.

The final univariate correlation analysis used all external environment variables including finances, family influences, work influences, significant life events, community influences, and hours of employment. Table 18 shows that finances, encouragement, and 
work influences have a significant correlation with the dependent variable persistence. Work influences were negatively correlated and statistically significant at the .05 alpha level $(r=-138)$. Conversely, finances were positively correlated and statistically significant at the .05 alpha level $(r=.228)$. The scaled variable of encouragement is positively significant at the .05 alpha level $(r=.286)$. The encouragement variable includes spouse, family, employer, and friends support into one single variable for better use in the logistic regression equation. These findings are consistent with the literature.

This study confirms the findings of Horn and Carroll (1997) that finances are directly attributed to higher levels of persistence for adult learners. The study also confirms Wlodkowski's (2002) findings that work creates a lack of time that leads to a negative influénce on working adult learners' ability to persist. Another confirmatory finding is the importance of support systems in helping adult learners succeed (Elkins, Braxton, \& James, 1998). These three significant variables advance the utility of the proposed model from this researcher and confirm the validity of using these variables in future studies. Conversely, hours of employment, family influences, community influences, and significant life events were not statistically significant predictors of persistence in the univariate correlation. Most surprisingly is the lack of significance of the significant life events variable. This researcher has found this to be an overarching reason for much of the attrition among advisees in this program. The lack of statistical significance of this variable could be attributed to the fact that most adult learners are experiencing some form of significant life event throughout much of their adult life. The family additions, personal and family health issues, and other significant events are common place and most, if not all, adults cope with these challenges on a daily basis. To 
summarize, Table 18 displays the complete univariate correlations for the external environment and their correlation to student persistence. See Appendix B for a full correlation table that shows correlations among the predictor variables.

Table 18

Correlations Between Persistence and External Environment Variables

\begin{tabular}{llll}
\hline $\begin{array}{l}\text { Hours } \\
\text { Employed }\end{array}$ & $\begin{array}{l}\text { Work } \\
\text { Influences }\end{array}$ & $\begin{array}{l}\text { Family } \\
\text { Influences }\end{array}$ & $\begin{array}{l}\text { Community } \\
\text { Influences }\end{array}$ \\
-.096 & $-.138^{*}$ & -.077 & -.013 \\
& & Significant & \\
Finances & Barriers & Life event & \\
$.228^{*}$ & -.095 & .073 &
\end{tabular}

Encouragement: Encouragement: Encouragement: Encouragement:

Spouse or part. Other family Employer $\quad$ Friends

$\begin{array}{llll}.200^{*} & .205^{*} & .110^{*} & .233^{*}\end{array}$

Encouragement

$.286^{*}$

${ }^{*} p<.05$

Overall there were multiple variables that both positively and negatively had a direct statistically significant correlation with the outcome variable of persistence. However, none was greater $(r=.339)$ than skills development with $R^{2}=.115$, indicating that $11.5 \%$ of the variance in student persistence can be attributed to Perceived Skill Development. Hence, no single variable outweighs all others to positively or negatively influence persistence behavior. In other words, the cumulative effect of multiple variables 
may better predict students' decisions to continue or withdraw from school. The findings from the univariate correlation guided the specific variables included and excluded from the multivariate logistic regression analyses.

\section{Logistic Regression}

Research question two examined the multivariate predictive relationship between student entry variables, internal campus environment variables, and external influence variables and the outcome variable student persistence. Logistic regression analysis was conducted to determine how much the eleven statistically significant variables predicted the probability of the criterion variable, persistence. The predictor variables selection was guided by the univariate analyses. Only statistically significant variables entered the logistic regression analyses. The predictor variables included in the logistic regression analyses were educational goal, finances, work influences/conflict, enrollment status, cumulative GPA, flexible course options, financial aid, advising and instructor support, active learning, and prior learning assessment. Logistic regression is a viable statistical procedure because the criterion variable must be dichotomous, such as persistence (i.e., 0 $=$ nonpersister, $1=$ persister), and the predictor variables must be continuous or categorical (Field, 2005).

The strategy for entering variables into the logistic regression analyses was driven by the three constructs examined in this study. Three steps or blocks of variables were entered using a hierarchical strategy with eleven total predictors. The model summary was examined first by entering educational goal into the first block. Step two included educational goal, finances, and work influences. Step three included all three constructs 
starting with educational goal followed by finances and work influences, and was rounded out with enrollment status, GPA, flexible course options, financial aid, advising and instructor support, active learning and prior learning assessment.

Step one of entering the student entry characteristic, Educational Goal (the single statistically significant variable from this construct) presents the Omnibus Tests of Model Coefficients. Table 19 displays that the null hypothesis is rejected because the significance is less than .05 (shown by the .000 under the Sig. heading). It is concluded that this independent variable improves prediction of the outcome variable persistence. The other two tests, Block and Step, have the same value as the Model statistic because all the variables were entered in one block.

Table 19

Omnibus Tests of Model Coefficients for Step I of Logistic Regression

\begin{tabular}{|c|c|c|c|}
\hline & Chi-square & $\mathrm{df}$ & Sig. \\
\hline \multicolumn{4}{|l|}{ Step 1} \\
\hline Step & 15.263 & 1 & .000 \\
\hline Block & 15.263 & 1 & .000 \\
\hline Model & 15.263 & 1 & .000 \\
\hline
\end{tabular}

The Model Summary table, shown in Table 20, presents three measures of how well the logistic regression model fits the data. The Nagelkerke pseudo $R^{2}$ is preferred because it can achieve a maximum value of one, unlike the Cox and Snell pseudo $R^{2}$, which cannot (Myers, Gamst, \& Guarino, 2006). The Nagelkerke $R^{2}$ is .068 which indicates that $6.8 \%$ of the variance is accounted for by educational goal. 
Table 20

Model Summary for Step 1 of Logistic Regression

\begin{tabular}{clll}
\hline Step & $\begin{array}{l}-2 \text { Log } \\
\text { likelihood }\end{array}$ & $\begin{array}{l}\text { Cox \& Snell R } \\
\text { Square }\end{array}$ & $\begin{array}{l}\text { Nagelkerke R } \\
\text { Square }\end{array}$ \\
\hline 1 & $316.357^{\mathrm{a}}$ & .040 & .068 \\
\hline
\end{tabular}

The Hosmer and Lemeshow Test table provides a formal test assessing whether the predicted probabilities match the observed probabilities. The nonsignificant $c h i$ square means that the predicted probabilities match the observed probabilities, which is the preferred outcome for a researcher. This occurred for the model with the first predictor variable in the equation, $\chi^{2}(2)=5.78, p=.06$.

The variables in the equation Table 21 presents coefficients, standard errors, Wald statistics, significance, odds ratios, and confidence intervals. The $\beta$ display a positive effect of educational goal on persistence $(\beta=.67, p<.000)$.

Table 21

Regression Coefficients for Step 1 of Logistic Regression

\begin{tabular}{l|cccccc}
\hline \multicolumn{1}{c}{ Step 1 } & \multicolumn{1}{c}{ B } & S.E. & Wald & df & Sig. & Exp(B) \\
\hline $\begin{array}{l}\text { Education } \\
\text { Goal }\end{array}$ & .666 & .173 & 14.863 & 1 & .000 & 1.974 \\
Constant & -.648 & .585 & 1.228 & 1 & .268 & .523 \\
\hline
\end{tabular}


Step two included the entry of educational goal plus the external environment variables finances and work influences. These two external environment variables were selected specifically because they were the only two from the external construct that were statistically significant in the univariate analysis. The second block entry for the logistic regression begins with the Omnibus Tests of Model Coefficients. Table 22 displays that the null hypothesis is rejected because the significance is less than .05 which indicates that the variables entered in step two are statistically significant at the $p<.000$. It is concluded that this group of independent variables improve prediction of the outcome variable persistence.

Table 22

Omnibus Tests of Model Coefficients for Step 2 of Logistic Regression

\begin{tabular}{cccc}
\hline & Chi-square & df & Sig. \\
\hline Step 2 & & & \\
Step & 22.613 & 2 & .000 \\
Block & 22.613 & 2 & .000 \\
Model & 37.876 & 3 & .000 \\
\hline
\end{tabular}

The Model Summary table, shown in Table 23, presents three measures of how well the logistic regression model fits the data from step two. The Nagelkerke $R^{2}$ is .164 which indicates that $16.4 \%$ of the variance is accounted for by variables from step one and step two combined. 
Table 23

Model Summary for Step 2 of Logistic Regression

\begin{tabular}{llll}
\hline Step & $\begin{array}{l}-2 \text { Log } \\
\text { likelihood }\end{array}$ & $\begin{array}{l}\text { Cox \& Snell R } \\
\text { Square }\end{array}$ & $\begin{array}{l}\text { Nagelkerke R } \\
\text { Square }\end{array}$ \\
\hline 2 & $293.744^{\mathrm{a}}$ & .097 & .164 \\
\hline
\end{tabular}

The Hosmer and Lemeshow Test had a nonsignificant value of chi square, $\chi^{2}(8)$ $=9.34, p=.32$. This supported the statistical model.

The Variables in the Equation table 24 presents coefficients, standard errors, Wald statistics, significance, odds ratios, and confidence intervals. The first $\beta$ coefficient displays a positive effect of educational goal on persistence $(\beta=.667, p<.000)$, the second $\beta$ coefficient displays a positive effect of finances on persistence $(\beta=.386, p<$ .000 ), and the third $\beta$ coefficient displays an effect of work influences/conflict on persistence $(\beta=-.394, p=.002)$.

Table 24

Variables in the Equation for Step 2 of Logistic Regression

\begin{tabular}{l|cccccc}
\hline \multicolumn{1}{c}{ Step 2} & S.E. & Wald & df & Sig. & Exp(B) \\
\hline $\begin{array}{l}\text { Education } \\
\text { Goal }\end{array}$ & .666 & .178 & 14.006 & 1 & .000 & 1.947 \\
Finances & .386 & .109 & 12.612 & 1 & .000 & 1.471 \\
$\begin{array}{l}\text { Work } \\
\text { Influences/ }\end{array}$ & -.394 & .125 & 9.983 & 1 & .002 & .674 \\
$\begin{array}{l}\text { Conflict } \\
\text { Constant }\end{array}$ & -.886 & .733 & 1.460 & 1 & .227 & .412 \\
\hline
\end{tabular}


Step three included the entry variable of educational goal plus the external environment variables finances and work influences and finally the significant internal campus variables enrollment status, GPA, flexible course options, scholarships and financial aid, advisor/instructor responsiveness, and prior learning assessment. The third block of internal campus/academic environment variables were selected specifically because they were all statistically significant in the univariate analysis. The third block entry for the logistic regression begins with the Omnibus Tests of Model Coefficients. Table 25 displays that the null hypothesis is rejected because the significance is less than .05 which indicates that the variables entered in step two are statistically significant at the $p<.000$. It is concluded that this group of independent variables improve prediction of the outcome variable persistence.

Table 25

Omnibus Tests of Model Coefficients for Step 3 of Logistic Regression

\begin{tabular}{rlll|l}
\hline & Chi-square & df & Sig. & \\
\hline Step 3 & & & & \\
Step & 48.840 & 8 & .000 & \\
Block & 48.840 & 8 & .000 & \\
Model & 86.716 & 11 & .000 & \\
\hline
\end{tabular}

The Model Summary table, shown in Table 26, presents three measures of how well the logistic regression model fits the data from step three. The Nagelkerke $R^{2}$ is .353 which indicates that $35.3 \%$ of the variance is accounted for by variables from step one, step two, and step three combined. 
Table 26

Model Summary for Step 3 of Logistic Regression

\begin{tabular}{llll}
\hline Step & $\begin{array}{l}-2 \text { Log } \\
\text { likelihood }\end{array}$ & $\begin{array}{l}\text { Cox \& Snell R } \\
\text { Square }\end{array}$ & $\begin{array}{l}\text { Nagelkerke R } \\
\text { Square }\end{array}$ \\
\hline 3 & $244.905^{\mathrm{a}}$ & .208 & .353 \\
\hline
\end{tabular}

The Hosmer and Lemeshow Test had a nonsignificant value of chi square, $\chi^{2}(8)$ $=6.28, p=.62$. This supported the statistical model.

Table 27 illustrates the variables in the equation: coefficients, standard errors, Wald statistics, significance, odds ratios, and confidence intervals. The first $\beta$ coefficient displays a positive significant effect of educational goal on persistence $(\beta=.418, p=$ .044). The second $\beta$ coefficient also displays a positive effect of finances on persistence $(B=.257, p=.043)$. Only one $\beta$ coefficient from the internal campus variables, active learning, displays a significant positive effect on persistence $(\beta=.490, p=.019)$. A closer inspection of the variables in the equation indicates that educational goal $(\beta=.418)$, finances ( $\beta=.257)$, and active learning $(\beta=.490)$ emerged as the significant contributors to predicting the likelihood of persistence while controlling for all other variables in the equation. Specifically, for every level increase in educational goal, likelihood of persistence increased by 1.52 times, for every unit of increase in finances, likelihood of persistence increased by 1.29 times, and for every level increase in active learning, likelihood of persistence increased 1.633 times. It should be noted that although all 11 variables that entered the logistic regression were statistically significant at the univariate 
level, only educational goal, finances, and active learning were significant at the multivariate level in the third step of this logistic regression analysis.

An overall measure of goodness-of-fit was applied to the final logistic model, the area under the receiver operating characteristic curve (ROC) statistic (Hosmer \& Lemeshow, 2000). This statistic indicates how well the logistic equation discriminated between persisters and non-persisters. The area under the ROC curve was .839 . According to Hosmer and Lemeshow, a value for this statistic above .800 "is considered excellent discrimination" (p. 162). Thus, there is evidence the model developed here had utility. 
Table 27

Variables in the Equation for Step 3 of Logistic Regression

\begin{tabular}{|c|c|c|c|c|c|c|}
\hline Step 2 & B & S.E. & Wald & $\mathrm{df}$ & Sig. & $\operatorname{Exp}(B)$ \\
\hline $\begin{array}{l}\text { Education } \\
\text { Goal }\end{array}$ & .418 & .207 & 4.073 & 1 & $.044^{*}$ & 1.520 \\
\hline Finances & .257 & .127 & 4.078 & 1 & $.043^{*}$ & 1.293 \\
\hline $\begin{array}{l}\text { Work } \\
\text { Influences/ } \\
\text { Conflict }\end{array}$ & -.216 & .146 & 2.172 & 1 & .141 & .806 \\
\hline $\begin{array}{l}\text { Enrollment } \\
\text { Status }\end{array}$ & .113 & .180 & .395 & 1 & .530 & 1.120 \\
\hline Cum GPA & .167 & .142 & 1.387 & 1 & .239 & 1.182 \\
\hline $\begin{array}{l}\text { Flexible } \\
\text { Course } \\
\text { Options }\end{array}$ & .446 & .294 & 2.303 & 1 & .129 & 1.563 \\
\hline Scholarships & 18.605 & 5086.823 & .000 & 1 & .997 & 1.203 \\
\hline $\begin{array}{l}\text { Financial } \\
\text { Aid }\end{array}$ & .514 & .354 & 2.113 & 1 & .146 & 1.672 \\
\hline $\begin{array}{l}\text { Advisor! } \\
\text { Instructor } \\
\text { Responsive }\end{array}$ & .196 & .242 & .654 & 1 & .419 & 1.217 \\
\hline $\begin{array}{l}\text { Active } \\
\text { Learning }\end{array}$ & .490 & .208 & 5.543 & 1 & $.019^{*}$ & 1.633 \\
\hline PLA & .142 & .142 & 1.003 & 1 & .317 & 1.153 \\
\hline Constant & -6.257 & 1.455 & 18.493 & 1 & .000 & .002 \\
\hline
\end{tabular}

Table 28 summarizes the results in each of the three step regression analyses. The procedure for entering the logistic regression analyses was completed through a hierarchical entry starting with the single statistically significant student entry 
characteristic, followed by two significant external environment variables, and concluded with eight significant internal campus/academic significant variables from the correlation analyses.

Table 28

Summary of Three Step Logistic Regression Analyses Results

\begin{tabular}{|c|c|c|c|c|c|}
\hline \multirow[t]{2}{*}{ Model } & \multicolumn{2}{|c|}{$\begin{array}{l}\text { Unstandardized } \\
\text { Coefficients }\end{array}$} & \multirow{2}{*}{$\begin{array}{l}\text { Odds Ratio } \\
\text { Exp (B) }\end{array}$} & \multirow[b]{2}{*}{$t$} & \multirow[b]{2}{*}{ Sig } \\
\hline & B & Std. Error & & & \\
\hline 1. (Constant) & -.648 & .585 & .523 & 1.228 & .268 \\
\hline Educational Goal & .666 & .173 & 1.947 & 14.863 & .000 \\
\hline 2. (Constant) & -.886 & .733 & .412 & 1.46 & .227 \\
\hline Educational Goal & .666 & .178 & 1.947 & 14.006 & .000 \\
\hline Finances & .386 & .109 & 1.471 & 12.612 & .000 \\
\hline Work Influences & -.394 & .125 & .674 & 9.983 & .002 \\
\hline 3. (Constant) & -6.257 & 1.455 & .002 & 18.493 & .000 \\
\hline Educational Goal & .418 & .207 & 1.520 & 4.073 & .044 \\
\hline Finances & .257 & .127 & 1.293 & 4.078 & .043 \\
\hline Work Influences & -.216 & .146 & .806 & 2.172 & .141 \\
\hline Enrollment Status & .113 & .180 & 1.120 & .395 & .530 \\
\hline Cum GPA & .167 & .142 & 1.182 & 1.387 & .239 \\
\hline Flex Course Options & .446 & .294 & 1.563 & 2.303 & .129 \\
\hline Scholarships & 18.605 & 5086.82 & 1.203 & .000 & .997 \\
\hline Fin Aid & .514 & .354 & 1.672 & 2.113 & .146 \\
\hline Advisor/Instr Response & .196 & .242 & 1.217 & .654 & .419 \\
\hline Active Learning & .490 & .208 & 1.633 & 5.543 & .019 \\
\hline PLA & .142 & .142 & 1.153 & 1.003 & .317 \\
\hline
\end{tabular}

\section{Summary}

This chapter provided the results of the demographic and inferential statistical analyses conducted on the data collected from adult learners that responded to the Adult Learner Persistence Survey. Frequencies and correlation analyses were used to gain an understanding of the demographic characteristics of the aduit learners in this degree completion program at the University of Louisville. Of those responding, approximately 
$83.3 \%(n=353)$ of the respondents were persisters and $16.7 \%(n=71)$ of respondents were nonpersisters. The significantly larger amount of persisters is common based upon the fact that those with positive attitudes toward education are more likely to respond to a survey about their experience. The age distribution included $70.1 \%(n=296)$ adults aged 36-55 which indicates that middle-aged adults are seeking this degree completion at high rates. The respondents also indicated a high level of interest in advanced levels of formal education. Approximately, $61.4 \%(n=258)$ of the sample indicated an educational goal beyond the bachelor's degree.

Additionally, $50.3 \%(n=172)$ students identified personal fulfillment as the most important reason for returning to complete a degree. Regarding their enrollment patterns, $77.4 \%(n=316)$ of students were classified as part-time students and $22.6 \%$ percent $(n=$ 92) were classified as full-time during the majority of their enrollment in this degree completion program. This is an important point based upon a program retention rate that is over 63\% in the Bachelor of Science in Workforce Leadership between 2008 and 2010. Although the literature indicates that part-time students persist at lower rates than fulltime students, this does not hold true for this large population of part-time students (Choy et al., 1995). Also, $91.1 \%(n=371)$ of all respondents had over a 2.6 cumulative GPA which indicates that, in general, students are not stopping out or dropping out because of poor grades. Student respondents also indicated a high level of favorability toward academic advising and faculty support. Students indicated that $86.7 \%(n=351)$ that their advisor was knowledgeable about the plan toward individual student degree completion to a great extent or higher. Similarly, $88.9 \%(n=360)$ of the sample believed that their 
instructor was knowledgeable to a great extent or higher about the course content in each class within the program.

Generally speaking, external environment descriptive statistics were similar to that of much of the literature on adult students. Approximately $80 \%(n=323)$ of students in this sample were working 31 or more hours per week and $20.1 \%$ percent $(n=81)$ worked 30 hours or less during their enrollment in the program. Also, a total of $56.7 \%$ ( $n$ $=228$ ) respondents indicated that they experienced one or more significant life events during their enrollment. Still, $55.5 \%(n=222)$ respondents indicated that they believed they had the appropriate finances to complete their degree to a great extent or higher. And a total of $22.6 \%(n=90)$ specified to a small extent or not at all did they have the financial resources to complete their degrees. Therefore, external influences appear to be a significant aspect of adults' lives as they pursue bachelor's degree programs.

In relation to the outcome variable of persistence, educational goal $(r=.202)$ was the only statistically significant student entry characteristic. On the contrary, nine internal campus/academic environment variables were statistically significant. The variables that exhibited a positive correlation to the criterion variable were credits per semester $(r=$ $.183, p<.001)$, overall GPA $(r=.121, p<.05)$, university resources $(r=.273, p<.001)$, number of advising appointments $(r=.233, p<.001)$, advisor knowledge $(r=.217, p<$ $.001)$, advisor care $(r=.246, p<.001)$, number of instructor appointments $(r=.117, p<$ $.05)$, instructor content knowledge $(r=.144, p<.05)$, and instructor care $(r=.263, p<$ .001). In addition, financial aid, flexible course options, skill development, active learning, and PLA utility were also statistically significant in the univariate correlation. Finally, from the external environment construct, both finances and work influences had 
a significant correlation with the dependent variable persistence. Work influences were negatively correlated and statistically significant at the .05 alpha level $(r=-.138)$ and finances were positively correlated and statistically significant at the .05 alpha level $(r=$ $.228)$.

Logistic regression analysis was then used to address research question two, which examined the multivariate predictive relationship between student entry variables, internal campus environment variables, external influence variables and the outcome variable student persistence. Logistic regression analyses were conducted to determine how much the eleven statistically significant variables predicted the probability of the criterion variable, persistence. The predictor variables selection was guided by the univariate analyses. Only statistically significant variables entered the logistic regression analyses. The predictor variables included in the logistic regression analyses were educational goal, finances, work influences/conflict, enrollment status, cumulative GPA, flexible course options, financial aid, advising and instructor support, active learning, and prior learning assessment. Overall, educational goal, finances, and active learning were statistically significant predictors of persistence, controlling for all other variables in the equation. The first statistically significant $\beta$ coefficient displayed a positive effect of educational goal on persistence $(\beta=.418, p=.044)$. The second $\beta$ coefficient also displayed a positive effect of finances on persistence $(\beta=.257, p=.043)$. Only one $\beta$ coefficient from the internal campus variables, active learning, displayed a significant positive effect on persistence $(\beta=.490, p=.019)$. Therefore, these findings suggest that educational goal, finances, and active learning were the most important predictors of student persistence in the degree completion program at this four-year university. 
The next part of this research study, Chapter five, is a summary of the findings of the two research questions in this study, along with further discussion, limitations, and future research recommendations. 


\section{CHAPTER V}

\section{DISCUSSION}

Chapter 5 provides a summary of the study, followed by a discussion of results. Implications for theory, research, and practice are offered followed by limitations of the study.

\section{Summary of the Study}

Retention is one of the most researched issues in higher education (Bean \& Metzner, 1985; Kuh, 2008; Tinto, 2006). Over the past 100 years, half of all undergraduate students have consistently failed to persist to degree completion (ACT, 2010; Tinto, 1993; U.S. Department of Education, 2008). Yet, even as more emphasis is placed on retaining students, retention rates have remained flat for the past century (ACT, 2010, Tinto, 1993). Furthermore, despite their increasing importance for universities and the nation's economy, only a small amount of literature is focused on adult learner persistence. Consequently, there is a significant gap in the literature concerning persistence behavior of adult learners in a growing number of degree-completion programs at four-year colleges.

In response to this shortage of focus on adult learners, this study sought to examine further the variables that impact adults in degree completion programs at a fouryear research university. The proposed Theory of Adult Student Persistence in Degree Completion Programs (see Figure 3) suggests that adult learners' ability to persist is 
influenced by variables in three constructs including student entry characteristics, external environment, and internal campus/academic environment. Retention is a complex issue involving a variety of academic, social, environmental, and behavioral factors that are difficult to define and even harder to control (Astin, 1975, 1993; McGivney, 2004; Tinto, 1993, 2006). Therefore, it is necessary to understand the positive and negative influences on adult students and to explore how those factors interact to predict student persistence behavior.

The purpose of this study was to examine the relationship of student entry characteristics, internal campus/academic environment, and external environment variables to the outcome variable of student persistence in an adult degree completion program at the bachelor's level. The Braxton, Hirschy and McClendon's (2004) Theory of Student Departure in Commuter College and Universities alongside Bean and Metzner's (1985) Conceptual Model of Undergraduate Nontraditional Student Attrition model served as empirically tested conceptual frameworks from which to develop a specific model salient to degree completion programs at a four-year research university. The adapted Bergman model (Theory of Adult Student Persistence in Degree Completion Programs, see Figure 3) was used to test factors that predict undergraduate degree completion for adult learners in degree completion programs at a four-year research university. Student entry characteristics, internal campus/academic environment variables, and external environment variables were examined in this study. By identifying empirically tested variables that combine to increase or decrease the likelihood of persistence, administrators of adult degree completion programs can work to improve graduation rates through policy and procedures that promote student success. 
Two overarching research questions guided this study: (a) what are the relationships between student entry variables, internal campus environment variables, and external influences variables and the outcome variable student persistence in an adult degree completion program at the bachelor's level and (b) what is the multivariate predictive relationship between student entry variables, internal campus environment variables, and external influence variables and the outcome variable student persistence?

A survey constructed to investigate the variables from the three constructs against the outcome variable of persistence was issued to $(n=1083)$ students currently or formerly enrolled in the Bachelor of Science in Workforce Leadership and Occupational Training and Development. Existing literature was used to provide the foundation for the study and guide the research. Descriptive statistics, correlational analyses, and logistic regression analyses were used to test the hypothesized model and examine the two research questions.

Results suggested that educational goal, finances, and active learning were the most significant variables while controlling for all other variables in the equation. Therefore, students that had a high level of desire to achieve education beyond the bachelor's level, those that believed they had the means to pay for their education, and those that were engaged in the learning and felt that the course content was connected to real-world application were more likely to persist. The following sections will expand on these findings and then examine the implications for research, theory, and practice.

Discussion of the Results

Guided by theory and research, the following section discusses the results of each research question tested. Results of this study suggested that there were statistically 
significant and meaningful relations to explore among the variables of interest. First, relevant descriptive statistics are explored, followed by univariate and multivariate methods examining both research questions A brief summary closes the section.

\section{Descriptive Statistics}

The descriptive statistics for this study were particularly salient to building the literature because of the increased offerings of degree completion programs throughout the country. Understanding the makeup of this population is almost as important as the multivariate research being conducted in this study. The age, ethnicity, previous college credits, educational goals, marital status, income and many other variables provide a window into the experience and needs of adult learners entering our institutions to finish these types of baccalaureate programs. The following sections discuss some of the most poignant statistics about the makeup of this group.

\section{Student Entry Characteristics}

Approximately $54.3 \%(n=229)$ of the sample was female and $45.7 \%(n=193)$ of the sample was male. This concurs with the expansive base of literature in all fields of the social sciences. Women typically respond at a greater rate than men. The age frequency analysis of age indicated that $22.3 \%(n=94)$ of the respondents reported were $25-35$ years old, $34.6 \%(n=146)$ were $36-45$ years old, $35.5 \%(n=150)$ were $46-55$ years old, $6.9 \%(n=29)$ were $56-65$ years old, and finally $0.7 \%(n=3)$ were 66 or older. Although more than one-fifth of respondents were 25-35 years old, the majority of adults pursuing degrees in these programs are over the age of 35 . This has major implications for practitioners in the field. If middle-aged to older adults are entering institutions that gear 
most, if not all, of their services to traditional-aged students, then these advanced-age adult learners will have to navigate a system that is not geared towards their needs. Much of the literature alludes to this fact, but this and other empirical studies prove the need for more "older-adult friendly" processes and procedures at our traditionally based universities. Some best practices include evening office hours for student and academic services, orientation courses for returning adults, and technology basics courses to help adults that have not been in the academic environment for an extended period of time.

Of the 403 respondents that indicated they had earned previous college credit prior to beginning the degree completion program, the average number of college credits was 67.78. Since all or most general core requirements have often been met, this provides a pathway for students to focus squarely on the remaining degree requirements in the major. Also, over $70 \%$ of students from the sample had one or more children. Therefore, the need for childcare during evening or even online course completion in this program is important to many of these students. At the same time, $69.4 \%(n=292)$ were married during the program so spousal/partner support was likely a benefit completing their degree. The income level of adults in this program varied widely but the results indicated that the largest segment of this sample made between $\$ 41,000$ and $\$ 60,99922.0 \%(n=$ 91), comparable to that reported by the U.S. Census Bureau (2009) of $\$ 50,221$.

\section{Internal Campus/Academic Environment}

Approximately $77.4 \%(n=316)$ of students were classified as part-time students and $22.6 \%$ percent $(n=92)$ were classified as full-time during the majority of their enrollment. Also, $91.1 \%(n=371)$ of all respondents had over a 2.6 cumulative GPA. Hence, the results confirmed the literature that indicates most adults attend part-time but 
perform at a high level in their course work. Students from the sample indicated overwhelming acknowledgement of the support from the institution as a whole, including academic advising and faculty. Approximately $71.4 \%(n=288)$ of students specified that the university provided services to promote student success to a great or very great extent. Similarly, respondents met often with their academic advisor and found their instructors and advisors to be very knowledgeable and caring.

Most of this sample did not receive scholarships but $57.4 \%(n=230)$ did utilize some form of financial aid toward their degree completion. The relatively small amount of financial aid used is indicative of the large portion of employer tuition assistance received by these adult learners. Approximately $60.3 \%(n=242)$ indicated that they did receive tuition assistance from their employer and of those, $80.6 \%(n=213)$ indicated that it was important to a great extent or higher. This is consistent with much of the literature on employer support indicating that grant aid (from the employer) plays a positive role in retention of adult learners (Lumina, 2011).

The survey also revealed interesting data regarding the type of courses that the students chose to pursue their bachelors' degrees. The results indicated that $28.0 \%(n=$ $113)$ selected online-only courses, $16.8 \%(n=68)$ enrolled in in-class only courses, and $55.2 \%(n=223)$ enrolled in both online and in-class courses. Thus, a majority of adults tend to prefer a mixture of in-class and online courses during their progression in a degree completion program. Similarly, students indicated a high level of relevance to real-world application with this particular program. The availability of prior learning assessment and applicable course content to the workforce was valued to a great extent by a majority of this sample. 


\section{External Environment}

The first variable measured from the external environment construct in was finances and $55.5 \%(n=222)$ respondents indicated that they did believe they had the appropriate finances to complete their degree to a great extent or higher. Conversely, $22.6 \%(n=90)$ specified to a small extent or not at all did they have the financial resources to complete their degrees. Therefore, one's perceived ability to afford tuition was an important factor in students' ability to persist. Student respondents also indicated a high level of family support and encouragement in pursuit of their bachelor's degree. To a much smaller extent, respondents indicated some encouragement from their employers. Only $33.5 \%(n=135)$ received employer encouragement to a great extent or higher. Conversely, more than $60 \%$ reported both spouse/partners and other family members encouraged them to complete their degrees at a great extent or higher.

Finally, Question thirty-one asked students if they have experienced one or more significant life events during their enrollment. This question provided examples including, but not limited to, military deployment, birth of a child, family illness, personal illness, marriage, divorce, and loss of employment. A total of $56.7 \%(n=228)$ respondents answered yes. On the other hand, $43.3 \%(n=174)$ indicated no significant life event during their enrollment in the degree completion program. Another question asking respondents to write in responses provided everything from personal illness to death of a family member. The 229 write-in responses could provide rich details of for future qualitative study on life issues confronted by adults seeking degrees. The rich detail provided in the responses could be triangulated to extract common themes indicated by these adult learners. 


\section{Research Question One}

The first research question explored the relationships between student entry variables, internal campus environment variables, and external influences variables and the outcome variable student persistence in an adult degree completion program at the bachelor's level. Results from the correlational analyses indicated there was a significant positive relationship between educational goal and the outcome variable of persistence. The results also showed a significant negative relationship between finances work influences (conflict), and persistence. Other statistically significant univariate variables included finances (money to complete), financial aid, enrollment status, GPA, institutional support, number of advising appointments, advisor knowledge, advisor care, number of instructor meetings, instructor knowledge, and instructor care. Findings support rejecting the null hypothesis. There was a relationship between variables from each construct and the dependent variable of persistence.

\section{Research Question Two}

The second research questions examined the multivariate predictive relationship between student entry variables, internal campus environment variables, and external influence variables and the outcome variable student persistence. Results from a threestep logistic regression analyses indicated that three variables were significant predictors of persistence while controlling for all other variables entering the equation. Specifically, educational goal $(B=.418, p=.044)$, finances $(B=.257, p=.043)$, and active learning $(B$ $=.490, p=.019)$ were all positive and significant predictors of student persistence. It is worth noting that work influences (conflict) was negative and significant $(B=-.394, p=$ 
.002 ) in step two of the logistic regression analysis but was not significant when all variables from each construct were entered into the step three analysis.

In summary, the results are consistent with the hypothesis that there was a multivariate predictive relationship between the three constructs and the outcome variable of persistence. The findings expand on other empirical evidence in the adult student attrition literature. However, further research is needed to better understand the predictive relationship between educational goal, finances, active learning and persistence.

Figure 4: Predictors of Persistence

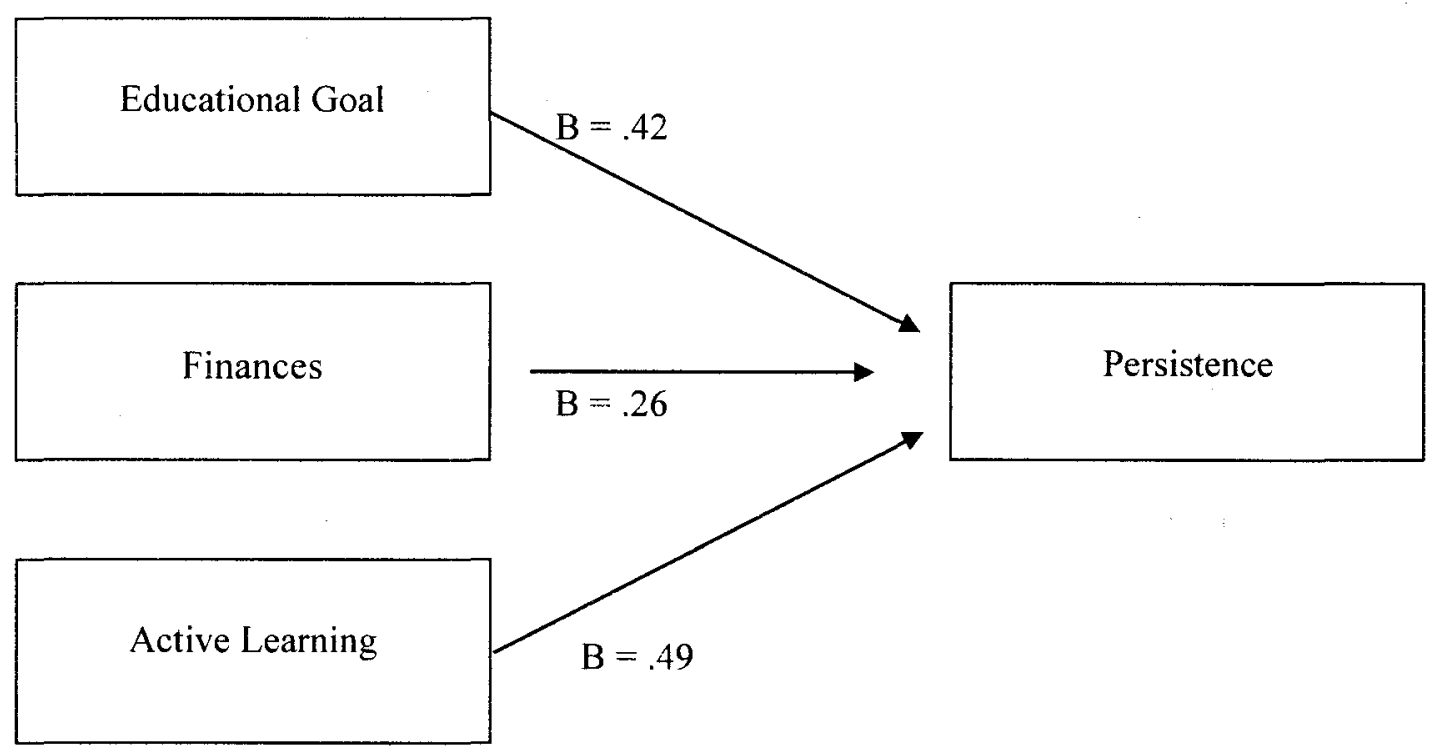


Implications for Theory, Research, and Practice

There was evidence that variables from the three constructs in the model are related to both positive and negative persistence behavior. Having access to a significant base of literature about college student retention provides a wide variety of variables to examine. Understanding multiple conceptual frameworks illuminates the connections among the factors deemed as empirically reliable (Seidman, 2005). While the complexities of traditional student departure decisions have been studied extensively, the same cannot be said for adult student retention. Even less research can be found on student retention in adult degree completion programs (Tweedell, 2000; Wlodkowski, 2002). The following sections examine implications of this study for theory building, research, and practice in the area of adult student retention in degree completion programs at four-year universities.

\section{Implications for Theory}

Substantial evidence from this study supports and extends Knowles (1980) theory of Andragogy. Knowles et al. (2011) presented a comparison of traditional and adult learners centered around the differences exhibited by each. This research supports these points in that adults pursue education in a problem-centered or performance-centered frame of mind. Knowles et al. (2011) posited that adult students seek to learn in order to deal with a current (problem-centered) or desired (performance-centered) situation. This research confirms the self-directed, experiential, problem-centered, and internally motivated nature of adult students in this particular degree completion program (Knowles, 1980, Merriam \& Cafferella, 2001). Adults identified personal fulfillment as 
the number one reason for returning to complete a bachelor's degree, affirming that adults are self-directed and internally motivated in their approach. This self-direction is also displayed in the overall GPA variable within this study in that $70.0 \%(n=285)$ of all respondents had over a 3.10 cumulative GPA.

The findings also confirmed the experiential nature of adult learners. Approximately $72.9 \%(n=296)$ indicated that they viewed prior learning assessment (PLA) as a time saving avenue for degree completion to a great extent or higher. Likewise, $73.4 \%$ of students indicated that they were more likely to complete the degree because of credits awarded from PLA to a great extent or higher and $70 \%$ of students indicated that they strongly felt they would finish their degree faster as a result of credit awarded from experiential PLA. Therefore, it was evident that students believed in the value of experiential learning and credit for that learning. Finally, the androgogical theory was confirmed through the active learning variable in this study. The results revealed that $60 \%$ of the students surveyed valued to a great extent or more the advancement in critical thinking skills, interpersonal skills, working with others, and problem-solving skills within this program. Similarly, $74.7 \%$ of responses indicated a positive experience in the program applying relevant content to real-world practice and 54\% appreciated working in teams to solve problems.

Bean and Metzner's (1985) theory of Adult student persistence and advancement of Braxton, Hirschy, and McClendon's (2004) models were also evident in this study. Specifically, both models hypothesized positive correlation with persistence and specific entry, internal, and external variables used in this study. Braxton, Hirschy, and McClendon (2004) conceptualized an adapted model suited for commuter schools due to 
the unique makeup of these institutions as opposed to that of traditional residential campuses. This model was more closely linked to the population in this study and was validated for its many variables of statistical significance. For example, the entry characteristic of student educational goal/motivation was found to be statistically significant in both univariate and multivariate analyses. Also, finances, academic and institutional support systems were validated as essential elements of any path model related to student persistence. Overall, Bean and Metzner (1985) and Braxton, Hirschy, and McClendon (2004) were well suited as conceptual frameworks that provided the theoretical underpinnings for this study. Furthermore, the model developed for this study, Theory of Adult Learner Persistence in Degree Completion Programs, was also validated as a valuable path model worthy of future analysis.

In conclusion, the findings provided empirical evidence that components of the theory of adult learner persistence in degree completion programs framework have relational and predictive utility. Of particular interest to theory building is the predictive relationship between educational goal, finances, and active learning and the outcome variable of persistence. The present study demonstrates evidence of a relationship between these three variables in the multivariate analysis and a total of 11 variables in the univariate correlation. While more research is needed, this study suggests the importance of strong financial aid structures for adults as well as implementation of rigorous and relevant curriculum in degree completion programs. It is important for researchers and practitioners alike to recognize the value of strong curriculum delivered by quality instructors as well as sufficient assistance to help adults return to the academic setting. Further, adult degree completion programs must maintain proper oversight, rigorous 
content, consistency, relevance, integrity, and support services in order to justify equitable treatment among other more traditional programs within a university. In other words, quantitative and qualitative measures of student learning outcomes to prove a high level of academic rigor are essential to justify integration of degree completion programs.

\section{Implications for Research}

This study has important implications for adult student engagement and adult student persistence research. The descriptive statistics alone provide a window into the makeup of a growing population of students in our colleges and universities.

Understanding that economic factors are pushing older adults back into the academic setting is important knowledge to consider when categorizing adult students. As stated in Chapter one, adult students are, by no means, a homogeneous population. Categorizing all students 25 and older as "adults" limits the understanding of the subpopulations that exist within that broad spectrum of age and adult development pattern. Additional disaggregation of age groups would be an appropriate approach to measuring retention of large-scale national databases.

This study verified in the findings of other adult retention studies and provided some interesting new findings worth highlighting. First, results confirmed that educational goal is a positive predictor of student persistence (Cabrera, Nora, \& Castaneda, 1993). Second, this study displayed that adult student persistence was positively associated with many internal campus/academic influences including: enrollment status, GPA, institutional support, academic advising support, faculty support, financial aid, flexible course options, active learning, and prior learning assessment. Many of these variables have been shown individually to be positively correlated with persistence of 
adults in degree completion programs but they have never been measured collectively. Further study of the variables from the model could provide insight into the validity of the proposed Theory of Adult Learner Persistence in Degree Completion Programs. This study also displays the power of campus and academic resources in assisting adult learners to reach their goal of completing a bachelor's degree. Although the magnitude of the internal campus/academic variables should be considered, there was statistical significance among all variables from this construct at the univariate level. On the other hand, active learning was found to be a positive indicator of student success in the multivariate analyses. While Tinto (1993) found social integration to be a key element of student assimilation and eventual persistence to graduation, this study identifies a new conceptualization of student engagement/assimilation. The active learning variable in this study acknowledges the importance of student engagement but considers it from a unique and more suitable perspective. Social engagement is often considered one of the most important variables in retaining traditional age students (Horn \& Caroll, 1998; New England Adult Research Network, 1999; Tinto, 1998), but for adults, social integration may be better defined as how one integrates pursuit of education into one's overall life (Kerka, 1997). This study on active learning indicates the importance of making realworld connections with the curriculum to the individual's work and personal life. Adult persisters in this study indicated a high level of interest in completing assignments that applied to real-world settings, putting together ideas or concepts from different courses, working in teams to solve problems or apply course content, and discussing ideas from readings and classes with others outside of the classroom. Persisters in this study also placed great value in the development of critical thinking, interpersonal skills, working 
with others, and problem-solving skills. This reconceptualization of social and academic integration could provide a new perspective on adult student retention.

Lastly, many studies on adult learners have stressed external environment as an important construct (Bean \& Metzner, 1985; Christensen, 1991; Hall, 1997; Horn and Caroll, 1997; Hammer et al, 1998; Mercer, 1993; Wldokowski, 2001; Zajkowski, 1997). They concur that it is necessary to consider how external influences impact adults more heavily than the academic environment. This study confirms the impact of work conflicts and finances as important predictors of adult student persistence. Survey results confirmed the univariate significant correlation of finances and work influences (conflict) to the outcome variable of persistence. Logically, adult students' with appropriate money to complete school were significantly more likely to persist than that of those that did not believe they had the funds to remain enrolled. Also, a significant negative correlation existed with students' identifying a great extent of work/class conflict. Those that indicated a heightened level of conflict between their ability to complete class and remain competent at work, were less likely to persist.

On the contrary, family influences (conflict), significant life events, community influences, and hours of employment were not found to be significant in this sample's persistence behavior. This researcher's own experience had led to the hypothesis that significant life events would be one of the most significant predictors of students' ability to persist. However, the multivariate analysis displayed no significance of this specific variable. A crosstabs analysis of significant life event crossed with persistence showed that $86.2 \%$ of survey participants who had no significant life event persisted, and only 
$80.7 \%$ of those that did have a significant life event persisted. While a greater number of those who persisted did not have a stressful life event, the analysis was not significant at the .05 alpha level. Further study of this individual variable and the range of life events encountered is recommended to have a greater understanding of the nuances within the significant life event variable.

In conclusion, this research can contribute to existing theories of student persistence as it included three constructs related to entry, external, and internal environments and their relationship to adult student persistence. This study only examined adult students from a single program and as such adds to the adult student persistence literature by singling out one specific subgroup's experiences. Few national studies have compared the adult students' persistence behavior in degree completion programs, so this study provides a basis with which to examine differences in persistence by institution type. Further study can continue to look at the differences in persistence by institution and degree completion program types to determine how these variables adult learners as a whole.

\section{Implications for Practice}

Adult degree completion programs looking to increase persistence could conduct an analysis using the newly developed Theory of Adult Learner Persistence in Degree Completion Programs model. This study provides support for utilizing each of the variables examined for the development of specific action-oriented interventions to aid in adult student persistence. Development of policy at the institutional, local, state, and national level could result from the data analysis of age, ethnicity, educational goal, PLA credits, financial aid, active learning, institutional support, and external influences of 
adult learners in degree completion programs. This multivariate analysis was a singleinstitution study that provided a glimpse into the experiences of adult learners at a single institution. Further study could provide avenues toward innovative student tracking via an early alert system to provide intervention for adult learners. Thus, colleges and universities could improve their adult retention and graduation rates in comparison to those for traditionally aged students. This could be accomplished by initiating contact via Facebook, text alerts, and/or downloadable calendars compatible with smartphones and Outlook in order to maintain contact with adults and keep them engaged and invested in their academic progression to graduation. Institutions should also consider tracking graduation and employment statistics to realize the success and/or failure of programs so that they may provide students a better understanding of what they can expect from the learning outcomes and credentials received from individual degree completion programs. Producing more accountability for each program would also promote a culture of discipline encouraging students to become more accountable for their learning and educational attainment.

This research also illuminates the need for additional convenience options including weekend and online course offerings while maintaining the rigor of the academic curriculum. The value that these students place on flexible course options and prior learning assessment mirrors that of previous research and advances the case for creating adult-friendly practice nationwide. The ability to integrate credit for prior learning through experiential credit evaluation helps relieve some of the fears and anxiety of returning adults and empowers them through the reflection on the depth and breadth of learning they already have accumulated. It also debunks many misconceptions about the 
requirements of undergraduate study. Because many adults in degree completion programs have failed in previous attempts as traditional age students, they often feel nervous about their ability to complete formal academic work at a high level. Although the reintegration into a formal academic setting is challenging, many adult learners indicated that it is no more overwhelming than their current work load in their current job. Thus, orientation and prior learning assessment courses provide an avenue for adults to assimilate into a world in which they often were not previously successful.

Another key result is the need to address affordability and accessibility. Although students in this sample did not indicate cost as a barrier, those who believed they had the finances to complete the program persisted at a much higher level than those that experienced a financial shortfall. Although progress has been made on finding additional scholarships, grants, and loans specifically for adults, the amount of funding in comparison to that of traditional high school seniors is miniscule. Since adult learners are coming back in droves, it necessary for institutions and legislature to designate more aid for this growing population. The federal government has made strides in its reform of the G.I. Bill but adults outside of the military and lower socioeconomic groups find it difficult to secure to scholarships or financial aid.

Lastly, the respondents from this study illuminated the value placed on faculty and staff to aid in their continued enrollment and eventual graduation. Adults have little to no time to integrate in co-curricular activities on campus, so having a single point of contact or familiar office can build a relationship that helps foster success. Even though the advisor or faculty member might not remain the key contact once a student is enrolled, adults often maintain their relationships with faculty and staff throughout their 
college experience, continuing to seek assistance and support from these individuals until they graduate. Students have indicated that having someone available to listen to them and try to answer their questions is often enough to help them stay enrolled. Therefore, an essential component of any degree completion program is a single or small group of academic or faculty advisors available for timely and knowledgeable feedback.

In conclusion, it is essential that degree completion program seeking to increase enrollment, retention, and graduation of adult students focus on the individuals that deliver the student services and the curriculum to the adult learners. Adults are focused on real-world relevance and expect a level of service that they receive in the business environment. Unfortunately, the innovative student support and learning strategies described above are rarely found in traditional university programs (Ross-Gordon, 2011). Therefore, it is essential that more adult friendly practices (prior learning assessment, convenient course options, and evening and online student support) become integrated into the fabric of traditional four-year colleges and universities. If programs are able to manage the demands of students that identify as worker, spouse or partner, parent, caregiver, and community member with timely and informed feedback and guidance, higher levels of student persistence is sure to follow.

\section{Limitations of the Study}

As is the case for all research, this study has limitations. The first was the use of a single institution sample consisting of students from 2004 through 2011 in a single program of study in Occupational Training and Development and Workforce Leadership. While the use of single institution samples is common in doctoral research, caution should be used when generalizing the results beyond the current study. 
A second limitation is the use of self-report measures. Self-report measures offer benefits to the researcher such as their inexpensive use and ease of distribution, however using these measures raise the possibility of common source method variance producing inflated correlations among the variables of interest (Crampton \& Wagner, 1994).

Common method variance is a potential problem whenever data is collected from a single source, which is the case with the present study (Shuck, 2010). Several steps were taken to reduce the likelihood of biased findings, such as the assurance of participant anonymity (Podsakoff et al., 2003). This study also did not control for nonresponse bias while collecting data in the online survey (Rogelberg \& Luong, 1998). Missing values were reported for each descriptive statistic but all values were utilized for univariate and multivariate analyses.

Finally, the approach taken in this study involved measurement of individual respondents. This method asked individuals to report demographic information but also incorporated perception-based questions related to institutional and program services and policies. Social desirability bias could influence responses as participants were asked to report their own frequency of involvement in program activities, significant life events that occurred during their enrollment, and perceptions of program effectiveness (Pearson \& Porath, 2004). Clearly, reporting potentially sensitive information about one's advisor for a program they were a part of could have led to socially desirable responses. Respondents also might have inflated program effectiveness due to worry over complete anonymity. The population from the Occupational Training and Development and Workforce Leadership major did not maintain the same level of persistence as the sample respondents. Over $80 \%$ of the sample respondents were considered persisters whereas 
only $64 \%$ of the population of adult learners surveyed were considered persisters.

Nevertheless, there is little reason to believe that individual responses or concerns about confidentiality of responses influenced results because of the procedural steps taken using Dillman et al.'s (2009) Tailored Design Method for the online survey issued via Survey Monkey. So, while there are multiple limitations to the present study, the researcher took numerous strategic and cost-effective steps to limit its shortcomings.

\section{Conclusion}

The U.S. Census Bureau (2008) reported that 38 million working-age Americans have some college credits but no degree. Also, $60 \%$ of jobs in the United States will require a college degree by 2025 (Lumina Foundation, 2011). In order to fulfill this increased demand, an additional 166,000 graduates will be needed (Lumina Foundation, 2011). Furthermore, there is a three million person gap between the number of undergraduate degree holders that will be produced at current levels compared to what will be needed by employers in 2018 (Georgetown University Center for Education and the Workforce, 2011).

Initiatives are being formalized to address this shortage at the local, state, and national level including: "55,000 Degrees" in the Louisville metropolitan area, Kentucky's Double the Numbers 2020 goal, and nationally the Department of Education's introduction of legislation designed to increase educational attainment. However, very little funding or human resources go toward the population of adult learners that have the most potential to make significant inroads toward these lofty educational goals. 
Amidst this push for increased degree production, administrators and faculty in adult degree completion programs must ensure that quality practices are in place to maintain academic rigor. Institution must offer adequate administrative support, financial aid, and institutional resources to ensure the effectiveness of these types of programs. If our young people are thought of as "our future" then our adult population is our present. It is important that adults with some college and no degree reach higher levels of critical thought through formal baccalaureate education. The increase in knowledge will serve as an inspiration to our future generations solidifying the value and necessity of education and enlightenment while reaching local, state, and national goals of increased educational attainment.

This study adds to the persistence literature in three ways. First, from a theoretical framework, this study confirms that entry characteristics, external environment, and internal campus/academic factors have a significant effect on persistence among adult learners in degree completion programs at this four-year university. Secondly, the study furthers the literature, both practically and theoretically, regarding an understanding of adult learners as nontraditional students. Even though the sample of students came from a single institution, the study gives insight into the nuances of adult learners, particularly those in degree completion program. Lastly, the study shows how systematic policies at the state and college level to provide relevant curriculum, sufficient funding, and knowledgeable and caring faculty and staff have a direct impact on student success.

Additional research should be conducted regarding differences in student experiences by institution type. The experiences of adult learners should continue to be studied, as it has been found that they enter the higher education landscape with different 
backgrounds and have different experiences while on college campuses as compared to their traditional counterparts. Qualitative analysis and mixed methods research of the variables presented could provide rich detail and insight into the nuances of individual adult learner experiences. By continuing to study adult students and predictors of persistence, knowledge will continue to be created to help bridge the gap in educational degree attainment between adult and traditional students in the United States. 


\section{REFERENCES}

Adult Higher Education Alliance (October, 1998) The principles of good practice for alternative and external degree programs for adults [The Alliance Monograph]. Retrieved from http://ahea.org/principles/

Adult Learning in Focus (2008) National and state-by-state data CAEL and NCHEMS published report. Retrieved from http://www.cael.org/pdf/ALIF_highlights_\%20PRINT.pdf

Ahson, N. L., Gentemann, K. M., \& Phelps, L. (1998). Do stop outs return? A longitudinal study of re-enrollment, attrition and graduation. Paper presented at the 38th Annual Forum of the Association for Institutional Research. (ERIC Document Reproduction Service No. ED424800).

Aiken, L. S., \& West, S. G. (1991). Multiple regression: Testing and interpreting interactions. Newbury Park, CA: Sage.

American Association of State Colleges and Universities (AASCU). (2005). Student success in state colleges and universities: A matter of culture and leadership. New York: Author. Retrieved September 25, 2010, from http://www.calpoly.edu/ acadsen/documents/AASCU-GRO_Report_093005.pdf American College Testing (2010) What works in student retention? Fourth National Survey. Report for all colleges and universities, Iowa City, IA. 
Anderson, K. L. (1981). Post-high school experiences and college attrition. Sociology of Education, 54(1), 1-15.

Ash, D., \& Landes, L. (2010) Competitive City Report: Greater Louisville Project, Advancing a Competitive City. p. 1-8.

Ashburn, E. (2010). City U. of New York plans "a grand experiment": A new college. The Chronicle of Higher Education. Retrieved April 25, 2010 from http://chronicle.com/section/Home/5

Ashby, C. (2002) Report on adult learners and distance education. Government Accountability Office, Washington D.C. Retrieved September 27, 2010, from http://www.gao.gov/new.items/d03905.pdf

Aslanian, C. B. (2001). Adult students today. New York: The College Board.

Astin, A. (1971). Predicting academic performance in college: Selectivity data for 2300 American colleges. New York: The Free Press.

Astin, A. (1975). Preventing studenis from dropping out. San Francisco: Jossey-Bass.

Astin, A. (1993). What matters in college? Four critical years revisited. San Francisco: Jossey-Bass.

Astin, A.W. (1984). Student Involvement: A developmental theory for higher education. Journal of College Student Personnel, 25, 297-308.

Ashar, H. \& Skenes, R. (1993). Can Tinto's student departure model be applied to nontraditional students? Adult Education Quarterly, 43(2), 90-100. 
Atkinson. D., \& Correa, D.K, (2007). The 2007 state new economy index: Benchmarking economic transformation in the states Washington, D.C.: Ewing Marion Kauffman Foundation and Information Technology and Innovation Foundation.

Barefoot, B. O. (2004). Higher education's revolving door: Confronting the problem of student dropout in US colleges and universities. Open Learning, 19, 9-18.

Bash, L. (2003). Adult learners in the academy. Bolton, MA: Anker.

Beal, P.E., \& Noel, L. (1980). What works in student retention. Iowa City, Iowa: American College Testing Program.

Bean, J. P. (1980). Dropouts and turnover: The synthesis and test of a causal model of student attrition. Research in Higher Education, 12(2), 155-187.

Bean, J. P., \& Metzner, B. S. (1985). A conceptual model of nontraditional student attrition. Review of Educational Research, 55 (4), 485-540.

Berker, A., Horn, L., \& Carroll, C. (2003). Work fïrst, study second: Adult undergraduates who combine employment and postsecondary enrollment. Postsecondary Educational Descriptive Analysis Reports. Retrieved from EBSCOhost.

Bonk, C. J. (2009). The world is open: How web technology is revolutionizing education. San Francisco: Jossey-Bass.

Bradburn, E. M. (2002). Short-term enrollment in postsecondary education: Student background and institutional differences in reasons for early departure, 19961998. (NCES 2003-153). Washington, DC: U.S. Department of Education. 
Bradburn, E. M., Berger, R., National Center for Education Statistics (ED), W. C., \& MPR Associates, B. A. (2002). Beyond 9 to 5: The diversity of employment among 1992-93 college graduates in 1997. Postsecondary Education Descriptive Analysis Reports. Retrieved from EBSCOhost.

Bragg, D. D., Townsend, B. K., Ruud, C. M. (2009) The adult learner and the applied baccalaureate: Emerging lessons for state and local implementation. Office of Community College Research and Leadership (2009, January).

Braxton, J. M., \& Hirschy, A. S. (2005). Theoretical developments in the study of college student departure. In Seidman, A. College student retention (pp. 61-88) Westport, CT: Praeger Publishers.

Braxton, J. M., Hirschy, A. S., \& McClendon, S. A. (2004). Understanding äd reducing college student departure. ASHE-ERIC

Braxton, J. M., Milem, J. F., \& Sullivan A. S. (2000). The influence of active learning on the college student departure process. The Journal of Higher Education, 71(5), 569-590. Retrieved August 1, 2011, from Research Library. (Document ID: 59809687)

Bureau of Labor Statistics (2009). United States Department of Labor census data retrieved from http://www.bls.gov/

Burris, J. (1997). The adult undergraduate's experience of portfolio development: A multiple case study. Dissertation Abstracts International, 58, 2742. 
Byrd, S. (1990). Perceptions of barriers to undergraduate education by nontraditional students at selected non-public, liberal arts institutions in the mid-south. Doctoral dissertation, Louisiana State University, Baton Rouge, LA. Retrieved August 2, 2011 from http://etd.lsu.edu/docs/available/etd-0407103205042/unrestricted/McDonald_dis.pdf

Cabrera, A., Nora, A., \& Castaneda, M. B. (1993). College persistence: Structural equations modeling test of an integrated model of student retention. Journal of Higher Education, 64 (2), 123-139.

Cabrera, A. F., Nora, A., \& Castaneda, M. B. (1992). The role of finances in the persistence process: A structural model. Paper presented at the annual meeting of the American Educational Research Association, San Francisco, CA.

Cabrera, A. F., Burkum, K. R., \& LaNasa, S. M. (2005). Pathways to a four-year degree: Determinants of transfer and degree completion. In A. Seidman. (Ed.), Student retention: Formula for student success (pp. 155-214). New York: Rowman \& Littlefield.

Calcagno, J., Jenkins, D., Bailey, T., \& Crosta, P. (2006). Stepping stones to a degree: The impact of enrollment pathways and milestones on community college student outcomes. Education Commission of the States.

Canja, E. T. (2002). Lifelong learning: Challenges \& opportunities. CAEL Forum and News, 26-29.

Caison, A. L. (2005). Determinants of system retention: Implications for improving retention practice in higher education. Journal of College Student Retention, 6 (4), $425-441$. 
Carey, K. (2004). A matter of degrees: A report by the Education Trust. Washington, DC: Education Trust.

Carnevale, A. P., Smith, N., \& Strohl, J. (2010) Help wanted: Projections of jobs and education requirements through 2018. Georgetown University Center on Education and the Workforce, 45-46.

Childress, M. T., Dunavent, B. S., King, S., Schirmer, M., Smith-Mello, M., \& Watts, A. L., (Eds.). (2008). Visioning Kentucky's future measures and milestones 2008. Frankfort, KY: Kentucky Long-Term Policy Research Center.

Choy, S. (2002). Nontraditional students. The condition of education 2002 (NCES 2002012). National Center for Education Statistics. Washington, DC: U.S. Department of Education.

Choy, S., \& Premo, M. (1995). Profile of older undergraduates: 1989-90. (NCES 95167). U.S. Department of Education, National Center for Education Statistics. Washington, DC. Retrieved from http://nces.ed.gov/pubs95/web/95167.asp on June 27, 2011

Christensen, P. (1991). Comparison of adult baccalaureate graduates and nonpersisters. Paper presented at the Midwest Research-to-Practice Conference., St. Paul, MN. (ERIC Document Reproduction Service No. ED 378 307)

Chronicle of Higher Education (2010). The Chronicle almanac 2009-2010. College Board Advocacy (2009). How colleges organize themselves to increase student persistence: Four-year institutions. Retrieved September 24, 2010 from http://pas.indiana.edu/cb.index.cfm 
Cope, R. G., \& Hannah, W. (1974). Revolving college doors. New York: John Wiley \& Sons.

Council for Adult and Experiential Learning (CAEL). (2000). Prior learning assessment. [Online]. Available: http://www.cael.org/index2.html

Council for Adult and Experiential Learning (CAEL). (2006) Examining strategies and trends in educational assistance. CAEL's Tuition Survey [Online]. Available: http://www.edlinktuition.com/resources.html

Council for Adult and Experiential Learning (CAEL). (2010). Fueling the race to postsecondary success: A 48-institution survey of prior learning assessment and adult student outcomes. [Online]. Available: http:// www.cael.org/pdf/PLA_Fueling-the-Race.pdf

Crampton, S. M., \& Wagner, J. A. (1994). Percept-percept inflation in micro organizational research: An investigation of prevalence and effect. Journal of Applied Psychology, 79, 67-76.

Crim, S. (2006). An examination of social presence in an online learning environment. Unpublished doctoral dissertation, University of Louisville, Kentucky.

Cronin, J. M., \& Bachorz, P. M. (2006) The rising of Phoenix, and what it means for higher education. Journal of Education, 186 (1), 11-21.

Cross, P. (1981). Adults as learners: increasing participation and facilitating learning. San Francisco: Jossey-Bass.

Crouch, R. (2008). Debunking the myths: Immigration. Diversity Forum Series. University of Louisville, Louisville, KY. 
Cuccaro-Alamin, S. (1997). Postsecondary persistence and attainment. (NCES 97- 984). Washington, DC: U. S. Department of Education. Office of Educational Research and Improvement. National Center for Education Statistics.

Curtis, S. (2005). Increasing student retention through benchmarking and organizational improvement. University of Southern California. Extracted from ProQuest. (UMI No.3180491).

Dagavarian, D., \& Walters, W. (1993). Outcomes assessment of prior learning assessment programs. In Dagavarian, D. (Ed.) In support of prior learning assessment and outcomes assessment of prior learning assessment programs. Proceedings of the National Institute on the Assessment of Experiential Learning (Princeton, New Jersey, 1993). (ERIC Document Reproduction Service No. ED387613)

Dey, E. L., \& Astin, A. W. (1993). Statistical alternatives for studying college student retention: A comparative analysis of logit, probit, and linear regression. Research in Higher Education, 34 (5), 569-581.

Dickeson, R., \& Noel, L. (1992). Distinguishing adult persisters from adult dropouts: Multidimensional aspects of student motivation. Iowa City, IA: Noel/Levitz Centers.

Dillman, D. A. (1991). The design and administration of mail surveys. Annual Review of Sociology, 17, 225-249.

Dillman, D. A. (2000). Mail and internet surveys: The tailored design method ( $2^{\text {nd }}$ ed.). New York: John Wiley \& Sons. 
Dillman, D. A., Smyth, J. D., \& Christian, L. M. (2009). Internet, mail, and mixed-mode survey: The tailored design method. Hoboken, NJ: John Wiley \& Sons.

Dillman, D. A., Tortora, R. D., \& Bowker, D. K. (1999). Principles for constructing web surveys. Retrieved from http://survey.sesrc.wsu.edu/dillman/papers/websurveyppr.pdf

Dinmore, I. (1997). Interdisciplinarity and integrative learning: An imperative for adult education. Education, 117(3), 452-467. Retrieved July 31, 2011, from Research Library. (Document ID: 11496792)

Donaldson, J. E., \& Graham, S. (1990). A model of college outcomes for adults. Adult Education Quarterly, 50, 24-40.

Donaldson, J. F., \& Townsend, B. K. (2007). Higher education journals' discourse about adult undergraduate students. The Journal of Higher Education, 78(1), 27-50. Retrieved August 1, 2011, from Research Library. (Document ID: 1210818591). Durkheim, E. (1951). Suicide. New York: Free Press.

Elkins, S. A., Braxton, J. M., \& James, G. W. (1998). Tinto's separation stage and its influence on first-semester college student persistence. AIR 1998 Annual Forum Paper. Retrieved from EBSCOhost.

Eppler, M., \& Harju, B.. (1997). Achievement motivation goals in relation to academic performance in traditional and nontraditional college students. Research in Higher Education, 38(5), 557-573.

Farabaugh-Dorkins, C. (1991). Beginning to understand why older students drop out of college: A path analytic test of the Bean/Metzner model of nontraditional student attrition. AIR Professional File, 39, 1-12. 
Feldman, P. A. (2004). Bachelor's degree completion programs: Factors influencing success for adult students. (Unpublished doctoral dissertation). Arizona State University, United States -- Arizona.

Ferguson, G. A. (1981). Statistical analysis in psychology and education. New York: McGraw-Hill Book Company.

Field, A. (2005). Discovering statistics using SPSS (2nd ed.). London: SAGE Publications.

Fisher, V. (1991). An institutional evaluation of perceptions and expectations of a portfolio assessment program (life experience). Dissertation Abstracts International, 57, 2908.

Fitzpatrick, R. (2001). Is distance education better than the traditional classroom? Clear Point Inc.com. Retrieved July 31, 2011 from http://www.clearpnt.com/accelepoint/articles/r_fitzpatrick_060101.shtml

Gatz, C. (2011, June 27). 2010 Competitive city report: Progress but also stiff challenges after 10 years. Courier-Journal. A6-A7.

Gay, L. R., \& Airasian, P. W. (2003). Educational research: Competencies for analysis and applications. Upper Saddle River, N.J: Merrill/Prentice Hall.

Gravetter, F. J., \& Wallnau, L. B. (2007). Statistics for the behavioral sciences, $7^{\text {th }}$ Edition. Belmont, CA: Thomson Higher Education.

Greater Louisville Inc. (2010). Fifty-five thousand degrees initiative: Greater Louisville's education commitment. http://www.55000degrees.com/

Green, S. B. (1991). How many subjects does it take to do a regression analysis? Multivariate Behavioral Research, 26, 499-510. 
Gunsauley, C. (2011). UPS delivers tuition aid to recruit army of part-timers. Employee Benefit News. Source Media Inc. HighBeam Research 2.

Habley, W., \& Ricardo M. (1998). Current practices in academic advising: Final report on ACT's Fifth National Survey of Academic Advising. National Academic Advising Association \& Act Inc. Monograph Series No. 6.

Habley, W. R., \& McClanahan, R. (2004). What works in student retention? All survey colleges (ACT Research Report). Iowa City, IA: ACT. 20.

Hadfield, J. (2003). Recruiting and retaining adult students. New Directions for Student Services, 102, 17-25.

Hall, N. (1997). Variables that enhance the persistence of older female graduate students. Dissertation Abstracts International, 53, 1610.

Hammer, L. B., Grigsby, T. D., \& Woods, S. (1998). The conflicting demands of work, family, and school among students at an urban university. The Journal of Psychology, 132(2), 220-226.

Hanniford, B., \& Sagaria, M. (1994). The impact of work and family roles on associate and baccalaureate degree completion among students in early adulthood. Paper presented at the annual meeting of the American Educational Research Association (New Orleans, LA). (ERIC Document Reproduction Service No. ED $370520)$.

Harrington, J. (1993). Why they stay: a study on the persistence of re-entry women. Initiatives, 55(4), 17-24.

Hinkle, D. E., \& Wiersma, W. (2009). Applied statistics for the behavioral sciences. Gardners Books. 
Hoffman, \& Reindl, (2011) Compete to complete - Improving postsecondary attainment among adults, National Governor's Association (NGA) Center for Best Practices. Horn, L. (1996). Nontraditional students: Trends in Enrollment from 1986 to 1992 and persistence and attainment among 1989-90 beginning postsecondary students (NCES 97-578). Washington, DC: U.S. Department of Education.

Horn, L. (1998). Stopouts or stayouts? Undergraduates who leave college in their first year (NCES 1999-087). Washington, DC: U.S. Department of Education.

Horn, L., \& Berger, R. (2005). College persistence on the rise?: Changes in 5-year degree completion and postsecondary persistence rates between 1994 and 2000 (NCES 2005-156). Washington, DC: U.S. Department of Education.

Hosmer, D. W., \& Lemeshow, S. (2000). Applied logistic regression ( $2^{\text {nd }}$ ed.). New York: John Wiley \& Sons.

Houle, C.O. (1961). The inquiring mind. Madison, WI: University of Wisconsin Press.

Hunt J. B., \& Tierney, T. J. (2006). American higher education: How does it measure up for the $21^{\text {st }}$ century? (San Jose, CA: The National Center for Public Policy and Higher Education).

Iffert, R. E. (1957). Retention and withdrawal of college students. U. S. Office of Education, Bulletin 1957, no. 1. Washington, DC: U.S. Government Printing Office.

Ishitani, T. T. (2006). Studying attrition and degree completion behavior among firstgeneration college students in the United States. The Journal of Higher Education, 77(5), 861-885. Retrieved August 2, 2011, from Research Library. (Document ID: 1137308921) 
Justice, E. M., \& Dornan, T. M. (2001). Metacognitive differences between traditional age and non-traditional age college students. Adult Education Quarterly 51(3), 236-249.

Kasworm, C. (1990). Adult undergraduates in higher education: A review of past research perspectives. Review of Educational Research, 60, 345-372.

Kasworm, C. (1993). An alternative perspective on empowerment of adult undergraduates: Advising Contemporary Education, 64(3), 162-165.

Kasworm, C. (2001) A case study of adult learner experiences of an accelerated degree program. Paper presented at the American Educational Research Association Conference, Seattle, April 2001.

Kasworn, C. (2003a). Adult meaning making in the undergraduate classroom. Adult Education Quarterly, 53, 81-98.

Kasworm, C. (2003b), Setting the stage: Adults in higher education. New Directions for Student Services, 102, 3-10.

Kasworm, C. (2005). Adult student identity in an intergenerational community college classroom. Adult Education Quarterly, 56, 3-20.

Kasworm, C., Sandmann, L. R., \& Sissel, P. A. (2000). Adult learners in higher education. In A. L. Wilson and E. R. Hayes (Eds.), Handbook of adult and continuing education, (pp. 449-463). San Francisco: Jossey-Bass.

Kazis, R., Vargas, J., \& Hoffman, N. (2007). Double the numbers: Increasing postsecondary credentials for underrepresented youth. Harvard Education Press, Boston, MA. 
Kember, D. (1989). A longitudinal-process model of drop-out from distance education. Journal of Higher Education, 60 (3), 278-301.

Kentucky Council for Postsecondary Education (2005, November 15; revised 2006, June 29). 2020 educational attainment methodology. Retrieved February 17, 2009, from http://cpe.ky.gov/NR/rdonlyres/7BEF83C6-E7C9-4072-90C34753DF16B776/0/2020_Targets_and_Projections_Methodology_20060629.pdf

Kentucky Council on Postsecondary Education. (2007). Double the numbers: Kentucky's plan to increase college graduates. N.p.: Author.

Kentucky Council for Postsecondary Education. (2010, July). One year system level retention of first-time freshman: Kentucky public institutions. Frankfort: Kentucky Council for Postsecondary Education.

Kerka, S. (1997). Adult career counseling in a new age: Social integration for adults (ERIC Digest No. 167).

Kimmel, S. B., \& McNeese, M. N. (2006). Barriers to business education: Motivating adult learners. Journal of Behavioral and Applied Management, 7(3), 292-303. Retrieved August 2, 2011, from ABI/INFORM Global. (Document ID: 1061331651$)$

Kirby, P. G., Biever, J. L., Martinez, I. G., \& Gomez, J. P. (2004). Adults returning to school: The impact on family and work. The Journal of Psychology, 138(1), 6576. 
Klein-Collins, R., Sherman, A., \& Soares, L. (2010) Degree completion beyond institutional boarders: Responding to the new reality of mobile and nontraditional learners. Center for American Progress: The Council for Adult and Experiential Learning,http://www.cael.org/Forum_and_News/IndexNov2010_files/CAPandC AELExecSummary.pdf

Knowles, M. (1980) The modern practice of adult education: From pedagogy to andragogy. New York: Association Press.

Knowles, M. S., Swanson, R. A., \& Holton, E. F. (2011). The adult learner: The definitive classic in adult education and human resource development. Butterworth-Heinemann.

Kolowich, S. (2011). Model of the moment. Inside Higher Education, Retrieved August 11, 2011 from http://www.insidehighered.com/news/2011/05/09/

Kowalski, C., \& Cangemi, J. (1983). College dropouts: Some research findings. In Kowalski, C. \& Cangemi, J. (Eds.) Perspectives in higher education. New York: Philosophical Library.

Kratzer, D. F. (2009). Factors influencing adult learner intentions to complete a bachelor's degree. Doctoral dissertation, University of Louisville, Louisville, KY. Retrieved April 1, 2010, from author.

Kuh, G. (2008). Diagnosing why some students don't succeed. Chronicle of Higher Education, 55 (16), A72.

Lang, M., \& Ford, C. A. (1988). Black student retention in higher education. Springfield, IL: Charles C. Thomas. 
Leech, N. L., Barrett, K. C., \& Morgan, G. A. (2005). SPSS for intermediate statistics: Use and interpretation. Mahwah, N.J: Lawrence Erlbaum.

Lomax, R. G. (2007). Statistical concepts: A second course (3 ${ }^{\text {rd }}$ ed.). Mahwah, N.J.: Lawrence Erlbaum Associates.

Losty, B., \& Kreilick, D. (1982). Who succeeds? Perceptions of graduates and inactive students of a nontraditional bachelor of arts degree program. Alternative Higher Education: The Journal of Nontraditional Studies, 6, 258-267.

Lumina Foundation (2011) Goal 2025: Increasing Postsecondary Attainment: Retrieved July 31, 2011 from http://www.luminafoundation.org/goal_2025/goal3.html

Malhotra, N. K., Shapero, M., Sizoo, S., \& Munro, T. (2007). Factor structure of deterrents to adult participation in higher education. Journal of College Teaching and Learning, 4(12), 81-90. Retrieved from http://www.cluteinstituteonlinejournals.com/PDFs/719.pdf

Martin, L. (1990). Dropout, persistence, and completion in adult secondary and prevocational programs. Adult Literacy and Basic Education, 14, 159-174.

McCaffrey, S. (1989). A key to survival: The retention of adult students in an external degree program. Paper presented at the annual meeting of the Association for the Study of Higher Education, Atlanta, Georgia. (ERIC Document Reproduction Service No. ED 313 974)

McCormick, A., Geis, S., Vergun, R., \& Carroll, D. (1995). Profile of part-time undergraduates in postsecondary education: 1989-90. (NCES 95-173). Washington, DC: U.S. Department of Education. Office of Educational Research and Improvement. National Center for Education Statistics. 
McGinley, L. (1995). Transformative learning and prior learning assessment. Paper presented at the National Conference on Alternative and External Degree Programs for Adults, Columbus, OH. (ERIC Document Reproduction Service No. ED 402510$)$

McGivney, V. (1996). Staying or leaving the course: Non-completion and retention of mature students in further and higher education. Leicester, England: National Institute of Adult Continuing Education.

McGivney, V. (2004) Understanding persistence in adult learning, Open Learning, 19 (1), 33-46.

McMahon, W. W. (2000). Education and development: Measuring the social benefits. Oxford University Press, London.

McMillan, J. H., \& Schumacher, S. (2001). Research in higher education: A conceptual introduction, $5^{\text {th }}$ edition. New York: Longman, Inc.

McNeely, J. H., \& United States. (1938). College student mortality. Washington: U.S. Govt. Print.

Mercer, D. (1993). Older coeds: Predicting who will stay this time. Journal of Research and Development in Education, 26, 153-163.

Merriam, S. B., Caffarella, R. S., \& Baumgartner, L. (2007). Learning in adulthood: A comprehensive guide. San Francisco: John Wiley \& Sons.

Metzner, B., \& Bean, J. (1987). The estimation of a conceptual model of nontraditional undergraduate student attrition. Research in Higher Education, 27(1), 15-38.

Mishler, C., Davenport, M. (1983). The mixed-age college classroom: Report of a pilot study at UW-Green Bay. Wisconsin Univ., Green Bay. Assessment Center. 
Myers, L. S., Gamst, G., \& Guarino, A. J. (2006). Applied multivariate research: Design and interpretation. Thousand Oaks, CA: Sage.

NACADA. (1999). NACADA standards for advising distance learners. Retrieved from the NACADA Clearinghouse of Academic Advising Resources.

National Center for Educational Statistics (1995). The condition of education, 1995. Washington DC: U.S. Department of Education.

National Center for Educational Statistics (2000). The condition of education, 2000. Washington DC: U.S. Department of Education.

National Center for Education Statistics (2002). The condition of education, 2002. Washington, DC: U.S. Department of Education.

National Center for Public Policy in Higher Education. (2006). Measuring up 2006. San Jose, CA.

New England Adult Research Network. (1999). Factors influencing adult student persistence in undergraduate degree programs. Amherst, MA: Victoria Dowling, University of Massachusetts.

Noel-Levitz, Inc. (2008). National Attitudes Report. https://www.noellevitz.com/papersresearch-higher-education/2011/2011-national-freshman-attitudes-report

Nora, A. (2001). The depiction of significant others in Tinto's "rites of passage": A reconceptualization of the influence of family and community in the persistence process. Journal of College Student Retention, 3(1), 41-56.

Nunnally, J. C. (1967). Psychometric theory. New York: McGraw-Hill. 
O'Toole, D. M., Stratton, L. S., \& Wetzel, J. N. (2003). A longitudinal analysis of the frequency of part-time enrollment and the persistence of students who enroll part time. Research in Higher Education, 44, 519-537.

Pantages, T. J., \& Creedon, C. F. (1978) Studies of college attrition: 1950-1975. Review of Educational Research, 48, No. 1, 49-101.

Pascarella, E. T., \& Terenzini, P. T. (1979). Interactive influences in Spady and Tinto's conceptual models of college dropout. Sociology of Education, 52, 197-210.

Pascarella, E.T., \& Terenzini, P.T. (1983). Predicting voluntary freshman year persistence/withdrawal behavior in a residential university: A path analytic validation of Tinto's model. Journal of Educational Psychology, 75(2), 215-226.

Pascarella, E. T., \& Terenzini, P. T. (2005). How college affects students: Vol. 2. San Francisco: Jossey-Bass.

Pascarella, E. T., Terenzini, P. T., \& Wolfle, L. M. (1991). Orientation to college and freshman year persistence/withdrawal decisions. The Journal of Higher Education, 57, 155-175.

Pascarella, E. T., Pierson, C. T., Wolniak, G. C., \& Terenzini, P. T. (2004). Firstgeneration college students: Additional evidence on college experiences and outcomes. The Journal of Higher Education, 75, 249-284.

Pearson, C. M., \& Porath C. L. (2005). On incivility, its impact, and directions for future research. In R. M. Griffin \& A. M. O'Leary-Kelly (Eds.), The dark side of organizational behavior (pp. 403-425). San Francisco: Jossey-Bass.

Pedhazur, E. J., \& Scmelkin, L. (1991) Measurement, design, and analysis: An integrated approach. Hillsdale, NY: Lawrence Erlbaum Associates Publishers. 
Peng, C.Y., So, T.S.H., Stage, F. K., \& St. John, E. P. (2002). The use and interpretation of logistic regression in higher education journals: 1988-1999. Research in Higher Education, 43(3), 259-293.

Podsakoff, N., MacKenzie, S. B., Lee, J., \& Podsakoff, P. M. (2003). Common method bias in behavioral research: A critical review of the research and recommended remedies. Journal of Applied Psychology, 88, 879-903.

Pusser, B. Breneman, D. W., Gansneder, B. M., Kohl, K. J., Levin, J. S., Milam, J. H. (2007, March) Returning to learning: Adults' success in college is key to America's future. Indianapolis: Lumina Foundation for Education.

Quigley, B.A., \& Uhland, R. L. (2000). Retaining adult learners in the first three critical weeks: A quasi-experimental model for use in ABE programs. Aduit Basic Education, 10(2), 55. Retrieved August 1, 2011, from Career and Technical Education. (Document ID: 61157676).

Ramist, L. (1981). College student attrition and retention. (College Board Report No. 811). New York: College Entrance Examination Board.

Riggert, S. C., Boyle, M., Petrosko, J. M., Ash, D., \& Rude-Parkins, C. (2006). Student employment and higher education: Empiricism and contradiction. Review of Educational Research, 76. 63-92.

Rogelberg, S. G. \& Luong, A. (1998). Nonresponse to mailed surveys: A review and guide. Current Directions in Psychological Science, 7, 60-65.

Ryder, R., Bowman, R., \& Newman, P. (1994). Nontraditional students: Perceived barriers to degree completion. College Student Affairs Journal, 13(2), 5-13. 
Sadler, W., Cohen, F., \& Kockesen, L. (1997), Factors affecting retention behavior: A model to predict at-risk students. AIR Annual Forum Paper. (ERIC Document Reproduction Service No. ED 410885 ).

Scammacca, N. K., \& Dodd, B. G. (2005). An investigation of educational outcomes for students who earn college credit through the college-level examination program. College Board Research Report No 2005-5.

Scott, C., Burns, A., \& Cooney, G. (1996). Reasons for discontinuing study: The case of mature age female students with children. Higher Education, 31, 233-253.

Seidman, A. (2005). College student retention: Formula for student success. Westport, CT: Praeger Publishers.

Sherry, L. (1996). Issues in distance learning. Retrieved July 7, 2001 from http://www.cudenver.edu.public/education/edschool/issues.html

Shields, N. (1994). Retention, academic success, and progress among adult, returning students: A comparison of the effects of institutional and external factors. NACADA Journal, 14, 13-24.

Shuck, B. (2010). Employee engagement: An examination of antecedent and outcome variables. Doctoral dissertation, Florida International University, Miami, FL. Retrieved April 15, 2011, from author.

Sikora, A. C. (2002). A profile of participation in distance education: 1999-2000 (NCES 2003-154). 177 National Center for Education Statistics. Washington, DC: U.S. Department of Education.

Simmons, D. (1995). Retraining dislocated workers in the community college: Identifying factors for persistence. Community College Review, 23(2), 47-58. 
Smith, K., \& McCormick, D. (1992). Translating experience into learning. Adult Learning, 3(5), 22-25.

Snyder, G. (1990). Persistence of community college students receiving credit for prior learning. Doctoral dissertation, University of Pennsylvania, Philadelphia, PA. Retrieved August 1, 2011, from http://books.google.com/books/about/Persistence_of_community_college_student .html?id=WQsuOAAACAAJ

Snyder, T. D., \& Dillow, S. A. (2007). Digest of education statistics 2006 (NCES 2007017). National Center for Education Statistics. Washington, DC: U.S. Department of Education.

Spady, W. (1970). Dropouts from higher education: An interdisciplinary review and synthesis. Interchange. 1, 64-85.

Spady, W. (1971). Dropouts from higher education: Toward an empirical model. Interchange, 2, 38-62.

Stahl, V. V., \& Pavel, D. M. (April 21, 1992). Assessing the Bean and Metzner model with community college student data (Report No. JC 920209). San Francisco: American Educational Research Association. (ERIC Document Reproduction Service No. 344639) .

Stevens, J. (2009). Applied multivariate statistics for the social sciences. Hillsdale, N.J: L. Erlbaum Associates.

St. John, E., \& Starkey, J. (1995). The influence of prices on the persistence of adult undergraduates. Journal of Student Financial Aid, 25(2), 7-17. 
Summerskill, J. (1962). Dropouts from college. In N. Sanford (Ed.), The American college (pp. 627-657). New York: John Wiley \& Sons.

Taniguchi, H., \& Kaufman, G. (2005) Degree completion among nontraditional college students: Part-time student barriers. Social Science Quarterly, 86, 912-927.

Task Force on Adult Degree Completion Programs. (2000, June). Adult degree completion programs. Retrieved October 6, 2010, from http://www.ncacihe.org/resources/ adctf/ADCPRept.pdf

Taylor, J. A. (2000). Adult degree completion programs: A report to the board of trustees from the Task Force on Adult Degree Completion Programs and the award of credit for prior learning at the baccalaureate level. North Central Association of Colleges and Schools, Chicago, IL. Commission on Institutions of Higher Education.

Thomas, R., \& Chickering, A. W. (1984). Education and identity revisited. Journal of College Student Personnel, 25(5), 392-99. Retrieved from EBSCOhost.

Tierney, W. G. (1999). Models of minority college-going and retention: Cultural integrity vs. cultural suicide. Journal of Negro Education, 68(1), 80-91.

Tinto, V. (1975). Dropout from higher education: A theoretical synthesis of recent research. Review of Educational Research, 45, 89-125.

Tinto, V. (1982). Limits of theory and practice in student attrition. The Journal of Higher Education, 43(6), 687-700.

Tinto, V. (1993). Leaving college: Rethinking the causes and cures of student attrition $\left(2^{\text {nd }} \mathrm{Ed}\right.$.). Chicago: University of Chicago Press. 
Tinto, V. (1998).Colleges as communities: Taking research on student persistence seriously. The Review of Higher Education, 21, 167-177.

Tinto, V. (2006). Research and practice of student retention: What next? Journal of College Student Retention, 8(1), 1-19.

Topping, T. (1996). An institutional evaluation of perceptions and expectations of prior learning assessment options (experiential learning). Dissertation Abstracts International, 57, 2908.

Turner, B., \& Krumenauer, G. (2010). The value of a bachelor's degree. WorkSource Quality Information, Oregon Employment Department. Retrieved August 19, 2011 from http://www.qualityinfo.org/olmisj/ArticleReader?itemid=00001862

Tweedell, C.B. (2000, October). A theory of adult learning and implications for practice. Paper presented at the meeting of the Midwest Educational Research Association Annual Meeting. Chicago, IL.

U.S. Census Bureau (2008). American community survey, 2008. Retrieved December 29, 2011, from http://www.census.gov/acs/www/

U.S. Census Bureau (2009). State-level mean household income and selected income, 2009. Retrieved October 12, 2011, from http://www.census.gov/hhes/www/income/reports.html

U.S. Census Bureau (2011). Current population survey, 2011. Retrieved February 12 , 2011, from http://www.census.gov

U.S. Department of Education, National Center for Education Statistics (2008). The condition of education 2008 (NCES 2008-031). Retrieved February 25, 2009 from http://nces.ed.gov/fastfacts/display.asp?id=27 
Vann, B., \& Hinton, B. (1994). Workplace social networks and their relationship to student retention in on-site GED programs. Human Resource Development Quarterly, 5, 141-151.

Webb, M. (1989). A theoretical model of community college student degree persistence. Community College Review, 16(4), 42-49.

Weidman, J. (1985). Retention of nontraditional students in postsecondary education. Paper presented at the Annual Meeting of the American Educational Research Association, Chicago, IL. (ERIC Document Reproduction Service No. ED 261 195)

Wlodkowski, R. J. (1999). Enhancing adult motivation to learn: A comprehensive guide for teaching all adults. The Jossey-Bass higher and adult education series. San Francisco: Jossey-Bass Publishers.

Wlodkowski, R. J., Mauldin, J. E., \& Campbell, S. (2002) Early exit: Understanding adult attrition in accelerated and traditional postsecondary programs. Synopsis: Higher education research highlights. Indianapolis: Lumina Foundation for Education, July, 2002.

Wlodkowski, R. J., Mauldin, J. E., \& Gahn, S. W. (2001). Learning in the fast lane: Adult learners' persistence and success in accelerated college programs, Indianapolis: Lumina Foundation for Education.

Woosley, S. (2004). Stop-out or drop-out? An examination of college withdrawals and re-enrollments. Journal of College Student Retention, 5, 293-303.

Zajkowski, M. (1997). Price and persistence in distance learning. Open Learning, 12, 1223. 
Zito, E. (1991). Student financial aid and major choice among undergraduates: A national study. (Doctoral dissertation, University of Minnesota, Minneapolis, MN, 1991). Retrieved October 12, 2011, from http://dms.oum.edu.my/oumlib/sites/default/files/file_attachments/odlresources/4463/enhancing-adult-student.pdf 


\section{Appendix A}

\section{Survey Instrument \\ Adult Learner Persistence Survey}

Thank you for taking time to complete this survey about the Adult Student Persistence. The next page provides a detailed review of the informed consent and confidentiality. The remainder of the study will take approximately 5-10 minutes to complete.

Thank you again for your time. Your responses will help us better understand the factors that impact adult student degree completion.

\section{SECTION ONE}

1. Do you agree to participate in this study?

$\circ$ Yes

o No

2. What is your current enrollment status?

o Currently enrolled

- Not taking classes this semester but intend to return to the program

- Not taking classes and do NOT intend to return to the program

- Graduated from the program

3. What is your gender?

- Male ofemale o Other

4. What is your age?

० 25-35 $\quad$ 56-65

० 36-45 066 or older

० 46-55

5. What is your racial/ethnic background?
- American Indian
- Black or African American
- Pacific Islander
- White or Caucasian
- Asian
- Hispanic or Latino
- Other/Multiracial 
6. What is the highest level of formal education obtained by your parents? Mother Father

$\begin{array}{lll}0 & 0 & \text { Elementary school or less } \\ 0 & 0 & \text { Some high school } \\ 0 & 0 & \text { High school graduate } \\ 0 & 0 & \text { Some college } \\ 0 & 0 & \text { College degree } \\ 0 & 0 & \text { Some graduate school } \\ 0 & 0 & \text { Graduate degree } \\ 0 & 0 & \text { Do not know }\end{array}$

7. How long has/had it been since you last took any graded college course prior to beginning the Workforce Leadership program or Occupational Training and Development program?
0 Less than 1 year
o 9-15 years
- 1-4 years
c More than 15
o 5-8 years

8. How many TOTAL college credits had you completed at any college or university upon admission to the Workforce Leadership program or Occupational Training and Development program (Give your best estimate)?

9. What is your highest educational goal?
- Certificate o Master's
- Associate's o Doctoral
- Bachelor's

10. How many children do/did you have during your enrollment?
$\circ 0$
03
01
- 4 or more
02

11. During your initial enrollment in the Workforce Leadership or Occupational Training and Development program what was your marital status (choose one)?
- Never married
- Separated
- Married/Partnered
o Divorced
- Previously married
- Widowed

12. What was your annual household income during your initial enrollment in the Workforce Leadership program or Occupational Training and Development program?
- Less than $\$ 15,000$
○ $\$ 61,000-75,999$
o $\$ 15,000-25,999$
- $\$ 76,000-99,999$
o $\$ 26,000-40,999$
- $\$ 100,000$ or more
o $\$ 41,000-60,999$ 
13. Given other possible priorities and alternatives, how IMPORTANT is/was it to you to complete a bachelor's degree?

- Very unimportant $\quad$ Important

o Unimportant $\quad$ Very important

o Neither unimportant or important

14. Please RANK your reasons for returning to complete a bachelor's degree ( 1 being highest and 5 being lowest priority).

Personal fulfillment __ Inspire family/children

Work advancement__ Career change

_ Maintain current employment

\section{Section Two}

15. On average, how many credits are/were you enrolled in per semester?
o $1-3$
$010-12$
○ $4-6$
- More than Twelve
$07-9$

16. What is/was your overall GPA?
0.2 .09 or less
○ $3.10-3.59$
$02.10-2.59$
○ $3.60-4.00$
○ $2.60-3.09$

17. To what extent does/did this university provide resources for you to be a successful student?
○ Not at all
- To a great extent
- To a small extent
o To a very great extent
- To some extent

18. How many times during program enrollment have or did you meet individually with an academic advisor or academic counselor and talked with him/her at least 10 minutes or more (in-person, phone, email correspondence)? Give your best estimate.
$00 \quad 03$
0104 or more
02

19. How many times during program enrollment have or did you meet with an instructor OUTSIDE THE CLASSROOM or OUTSIDE THE ONLINE ENVIRONMENT, and spoken with him/her for 10 minutes or more (Give your best estimate)?
$\circ 0$
03
01
- 4 or more
$\circ 2$ 
20. To what extent:

\section{| Not at all | To a Small Extent | To Some Extent |To a Great Extent |To a Very Great Extent |}

- Is/was your advisor knowledgeable about your academic plan towards degree completion?
1
2
3
4
5

- Does/did your advisor care about you personally?

123

4

5

- Are/were your instructors knowledgeable about the content of each course within the program?

$$
1
$$

2

3

4

5

- Do/did instructors in this program care about you personally?

1

2

3

4

21. Do/did you receive:

- Financial aid (not scholarships)

o Yes O No

- Scholarships

$\circ$ Yes ONo

22. Please rank your reasons for selecting the Workforce Leadership or Occupational Training and Development program ( 1 being highest and 5 being lowest rating)?

- Cost

Reputation of institution

- Convenience (location)

Speed of Completion in specific program

_ Convenience (course delivery options)

23. What kind of courses do/did you take during your time in the Workforce Leadership program or Occupational Training and Development program?

O Online only o In-class only $\quad$ Both (online \& in-class)

24. To what extent:

| Not at all | To a Small Extent | To Some Extent |To a Great Extent |To a Very Great Extent |

- Are/were you able to choose flexible course options that fit your life circumstances?
1
2
3
4
5

- Are/were sufficient course offerings within your program of study offered?

$\begin{array}{lllll}1 & 2 & 3 & 4 & 5\end{array}$

- Are/were processes and procedures for enrolling convenient?

$\begin{array}{lllll}1 & 2 & 3 & 4\end{array}$

- Did/do you have a clear plan of courses to take to complete graduation requirements?

1

2
3

4 
25. To what extent has your experience in the Workforce Leadership program or Occupational Training and Development program contributed to your knowledge, skills, and personal development in the following areas?

| Little to none | Some Impact| Quite a bit | A Great Deal of Impact |Very Great Deal|

- Critical thinking skills? 1

- Interpersonal Skills? $1 \quad 2$

- Working with others? 12

- Problem-solving skills? 1

$\begin{array}{ll}2 & 3 \\ 2 & 3 \\ 2 & 3 \\ 2 & 3\end{array}$

45

45

45

4

26. In your experience in the Workforce Leadership program or Occupational Training and Development program, how often have you done each of the following?

| Not at all | To a Small Extent | To Some Extent |To a Great Extent |To a Very Great Extent |

- Did/do work in teams to complete assignments, solve problems, or apply course content
1
2
3
4
5

- Did/do assignments have application in the real-world setting

$\begin{array}{lllll}1 & 2 & 3 & 4 & 5\end{array}$

- Put together ideas or concepts from different courses when completing assignments

$\begin{array}{lllll}1 & 2 & 3 & 4 & 5\end{array}$

- Discussed ideas from your readings or classes with others outside of class (students, family members, co-workers, etc.)

$$
1
$$

2

3

4

5

27. To what extent:

| Not at all | To a Small Extent | To Some Extent |To a Great Extent |To a Very Great Extent |

- Do you view Prior Learning Assessment (ELFH 300 Portfolio Credit, DSST, CLEP, Test-out) as a time saving avenue for degree completion?
1
2
3
4
5

- Are/were you more likely to complete your degree because of credits awarded from Prior Learning Assessment?

1

2

3

4

5

- Will/did you finish your degree faster as a result of credits awarded from Prior Learning Assessment?

\section{Section Three}

$$
12
$$

3

4

5

28. How many hours per week are/were you employed during enrollment in the Workforce Leadership program or Occupational Training and Development program?
- 0-20 hours
- 41-50 hours
- 21-30 hours
- 51 or more

o 31-40 hours 
29. Please indicate your employment status during enrollment in the Workforce Leadership program or Occupational Training and Development program:

- Full-time

- Part-time

- Unemployed

30. To what extent:

| Not at all | To a Small Extent | To Some Extent |To a Great Extent |To a Very Great Extent |

- Do/did you experience schedule conflicts between completing class assignments and your work schedule?

1

2

3

4

5

- Do/did you experience schedule conflicts between completing class assignments and your family responsibilities?

1

2

3

4

5

- Do/did you experience schedule conflicts between completing class assignments and your community organization commitments (clubs, church, volunteer, children's school groups, friend's groups, etc.)?

1

2

3

4

5

- Do/did you believe you have the financial resources to complete your degree?

1

2

3

4

5

31. Have you experienced one or more significant life event during your enrollment in this program (military deployment, birth of child, family illness, personal illness, marriage, divorce, loss of employment, etc.)?

Yes ONo

32. If you answered yes in question 31 , please list event(s).

33. Do/did you receive tuition assistance from your employer?

o Yes o No

34. If you answered yes in question 33, how important is/was tuition assistance from your employer?
- Not at all
- To a great extent
- To a small extent
- To a very great extent
o To some extent 
35. To what extent do/did each of the following people encourage you to continue your studies in the Workforce Leadership or Occupational Training and Development program?

| Not at all | To a Small Extent | To Some Extent |To a Great Extent |To a Very Great Extent |

- Spouse or partner? 1

- Other family? 1

- Employer(s)? 12

- Close friends? 12

- Instructors? 1

- Classmates? 12

\section{3}

3

3

3

3

3
5

5

5

5

5

5

36. Is there any additional information related to your experience in the Workforce Leadership or Occupational Training and Development Program that you would like to share? If so, please use the space below.

Thank you very much for your cooperation in filling out this questionnaire 


\section{Appendix B}

\section{Correlation Tables}

Correlations among Persistence and Student Entry Characteristics

\begin{tabular}{|c|c|c|c|c|c|c|c|c|c|c|c|}
\hline Variable & Persist & Gender & Age & Ethnicity & Parent Ed & $\begin{array}{l}\text { Previous } \\
\text { Credits }\end{array}$ & $\begin{array}{l}\text { Educ. } \\
\text { Goal }\end{array}$ & $\begin{array}{l}\text { Number } \\
\text { Children }\end{array}$ & $\begin{array}{l}\text { Marital } \\
\text { Status }\end{array}$ & Income & Motivation \\
\hline Persist & 1.00 & & & & & & & & & & \\
\hline Gender & .032 & 1.00 & & & & & & & & & \\
\hline Age & -.046 & $.172 * *$ & 1.00 & & & & & & & & \\
\hline Ethnicity & -.019 & -.082 & -.024 & 1.00 & & & & & & & \\
\hline Parent Ed & .042 & -.061 & $-.275^{* *}$ & .076 & 1.00 & & & & & & $\S$ \\
\hline $\begin{array}{l}\text { Previous } \\
\text { credits }\end{array}$ & .050 & -.075 & -.036 & -.037 & .037 & 1.00 & & & & & \\
\hline Educ. Goal & $.202^{* *}$ & -.007 & $-.161^{* *}$ & -.017 & $.153 * *$ & .022 & 1.00 & & & & \\
\hline $\begin{array}{l}\text { Marital } \\
\text { Status }\end{array}$ & .035 & $-.231 * *$ & .002 & $.248^{* *}$ & -.004 & -.058 & -.060 & $.308^{* *}$ & 1.00 & & \\
\hline Income & -.026 & -.087 & .044 & $.256^{* *}$ & .047 & -.043 & .021 & .078 & $.308^{* *}$ & 1.00 & \\
\hline Motivation & .081 & $.099^{*}$ & $-.107^{*}$ & -.051 & -.043 & -.024 & $.099^{*}$ & .084 & -.058 & -.043 & 1.00 \\
\hline
\end{tabular}


Correlations among Persistence and Internal Campus/Academic Environment

\begin{tabular}{|c|c|c|c|c|c|c|c|c|c|c|}
\hline Variable & Persist & $\begin{array}{l}\text { Credits } \\
\text { per } \\
\text { semester }\end{array}$ & $\begin{array}{l}\text { Overall } \\
\text { GPA }\end{array}$ & $\begin{array}{l}\text { Univ. } \\
\text { Resources }\end{array}$ & $\begin{array}{l}\mathrm{N} \text { of Adv. } \\
\text { Appt. }\end{array}$ & $\begin{array}{l}\text { Advisor } \\
\text { Knowledge }\end{array}$ & $\begin{array}{l}\text { Advisor } \\
\text { Care }\end{array}$ & $\begin{array}{l}\mathrm{N} \text { of } \\
\text { Instruct. } \\
\text { Mtgs. }\end{array}$ & $\begin{array}{l}\text { Instructor } \\
\text { Content } \\
\text { Knowledge }\end{array}$ & $\begin{array}{l}\text { Instructor } \\
\text { Care }\end{array}$ \\
\hline Persist & 1.00 & & & & & & & & & \\
\hline $\begin{array}{l}\text { Credits per } \\
\text { semester }\end{array}$ & $.183^{* *}$ & 1.00 & & & & & & & & \\
\hline $\begin{array}{l}\text { Overall } \\
\text { GPA }\end{array}$ & $.121^{*}$ & $.148^{* *}$ & 1.00 & & & & & & & \\
\hline $\begin{array}{l}\text { Univ. } \\
\text { Resources }\end{array}$ & $.273^{* *}$ & $.136^{* *}$ & .075 & 1.00 & & & & & & \\
\hline $\begin{array}{l}\mathrm{N} \text { of Adv. } \\
\text { Appt. }\end{array}$ & $.233^{* *}$ & $.234^{* *}$ & .074 & $.220^{* *}$ & 1.00 & & & & & \\
\hline $\begin{array}{l}\text { Advisor } \\
\text { Knowledge }\end{array}$ & $.217^{* *}$ & $.156^{* * *}$ & .040 & $.423^{* *}$ & $.350^{* *}$ & 1.00 & & & & \\
\hline $\begin{array}{l}\text { Advisor } \\
\text { Care }\end{array}$ & $.246^{* *}$ & $.240^{* *}$ & .025 & $.421^{* *}$ & $.447 * *$ & $.712^{* *}$ & 1.00 & & & \\
\hline $\begin{array}{l}\mathrm{N} \text { of } \\
\text { Instruct. } \\
\text { Mtgs. }\end{array}$ & $.117^{*}$ & $.126^{*}$ & $.103^{*}$ & $.240^{* *}$ & $.437^{* * *}$ & $.170^{* *}$ & $.190^{*}$ & 1.00 & & \\
\hline $\begin{array}{l}\text { Instructor } \\
\text { Content } \\
\text { Knowledge }\end{array}$ & $.144 * *$ & $.207 * *$ & .021 & $.370^{* *}$ & $.190^{* *}$ & $.406^{* *}$ & $.466^{* *}$ & $.206^{* *}$ & 1.00 & \\
\hline $\begin{array}{l}\text { Instructor } \\
\text { Care }\end{array}$ & $.263^{* *}$ & $.225^{* *}$ & .034 & $.412^{* *}$ & $.266^{* *}$ & $.493^{* *}$ & $.655^{* *}$ & $.259^{* *}$ & $.577^{* *}$ & -.043 \\
\hline
\end{tabular}


Correlations among Persistence and Internal Campus/Academic Environment (contin.)

\begin{tabular}{|c|c|c|c|c|c|c|c|}
\hline Variable & Persist & Scholarships & Financial Aid & $\begin{array}{l}\text { Flexible Course } \\
\text { Options }\end{array}$ & Skills Development & Active Learning & PLA Utility \\
\hline Persist & 1.00 & & & & & & \\
\hline Scholarships & $.178 * *$ & 1.00 & & & & & \\
\hline Financial Aid & $.161^{* *}$ & $.253^{* *}$ & 1.00 & & & & \\
\hline $\begin{array}{l}\text { Flexible Course } \\
\text { Options }\end{array}$ & $.317^{* *}$ & $.123 *$ & $.125^{*}$ & 1.00 & & & \\
\hline $\begin{array}{l}\text { Skills } \\
\text { Development }\end{array}$ & $.339 * *$ & $.184^{* *}$ & $.173^{* *}$ & $.525^{* *}$ & 1.00 & & లి \\
\hline Active Learning & $.331^{* *}$ & $.251^{* *}$ & $.175^{* *}$ & $.475^{* *}$ & $.661^{* *}$ & 1.00 & \\
\hline PLA Utility & $.159^{* *}$ & .003 & .014 & $.266^{* *}$ & $.242 * *$ & $.245^{* *}$ & 1.00 \\
\hline
\end{tabular}

${ }^{*} p<.05{ }^{* *} p<.01$ 
Correlations among Persistence and External Environment

\begin{tabular}{|c|c|c|c|c|c|c|c|c|}
\hline Variable & Persist & $\begin{array}{l}\text { Hours } \\
\text { Employed }\end{array}$ & Work Influences & $\begin{array}{l}\text { Family } \\
\text { Influences }\end{array}$ & $\begin{array}{l}\text { Community } \\
\text { Influences }\end{array}$ & Finances & Barrier & \\
\hline Persist & 1.00 & & & & & & & \\
\hline Hours Employed & -.096 & 1.00 & & & & & & \\
\hline Work Influences & $-.138^{* *}$ & $.383^{* *}$ & 1.00 & & & & & \\
\hline $\begin{array}{l}\text { Family } \\
\text { Influences }\end{array}$ & -.077 & $.274^{* *}$ & $604^{* *}$ & 1.00 & & & & $\hat{\text { ) }}$ \\
\hline $\begin{array}{l}\text { Community } \\
\text { Influences }\end{array}$ & -.013 & $.204^{* *}$ & $.422^{* *}$ & $.577^{* *}$ & 1.00 & & & \\
\hline Finances & $.228^{* *}$ & $.099^{*}$ & .010 & .049 & .066 & 1.00 & & \\
\hline Barriers & -.095 & $.348^{* *}$ & $.825^{* *}$ & $.873^{* *}$ & $.796^{* *}$ & .041 & 1.00 & \\
\hline
\end{tabular}


Correlations among Persistence and External Environment (contin.)

\begin{tabular}{|c|c|c|c|c|c|c|c|}
\hline Variable & Persist & $\begin{array}{l}\text { Significant } \\
\text { Life Event }\end{array}$ & $\begin{array}{l}\text { Encourage: Spouse } \\
\text { or Partner }\end{array}$ & $\begin{array}{l}\text { Encourage: } \\
\text { Other Family }\end{array}$ & $\begin{array}{l}\text { Encourage: } \\
\text { Employer }\end{array}$ & $\begin{array}{l}\text { Encourage: } \\
\text { Friends }\end{array}$ & Encouragement \\
\hline Persist & 1.00 & & & & & & \\
\hline $\begin{array}{l}\text { Significant } \\
\text { Live Event }\end{array}$ & .073 & 1.00 & & & & & \\
\hline $\begin{array}{l}\text { Encourage: } \\
\text { Spouse or } \\
\text { Partner }\end{array}$ & $.200^{* *}$ & .069 & 1.00 & & & & \\
\hline $\begin{array}{l}\text { Encourage: } \\
\text { Other Family }\end{array}$ & $.205^{* *}$ & .007 & $.516^{* *}$ & 1.00 & & & \\
\hline $\begin{array}{l}\text { Encourage: } \\
\text { Employer }\end{array}$ & $.110^{*}$ & -.012 & $.293 * *$ & $.359 * *$ & 1.00 & & \\
\hline $\begin{array}{l}\text { Encourage: } \\
\text { Friends }\end{array}$ & $.233^{* *}$ & -.019 & $.267^{* *}$ & $.504^{* *}$ & $.556^{* *}$ & 1.00 & \\
\hline $\begin{array}{l}\text { Encouragemen } \\
\mathrm{t}\end{array}$ & $.286^{* *}$ & .015 & $.612^{* *}$ & $.720^{* *}$ & $.702^{* *}$ & $.777^{* *}$ & 1.00 \\
\hline
\end{tabular}




\section{UR R I C UL U M V I T A E \\ MATHEW J. B ER G M A N \\ College of Education \& Human Development \\ 168 Education Building \\ University of Louisville \\ Louisville, KY 40292 \\ $502-852-2570$ \\ matt.bergman@louisville.edu}

\section{EDUCATION}

University of Louisville - Louisville, KY

Ph.D. Educational Leadership and Organizational Development (May, 2012)

Concentration: Educational Administration

Research Focus: Adult Education, Adult Development, and Prior Learning Assessment

Appalachian State University - Boone, NC

M.A. Higher Education Administration (2006)

Union College - Barbourville, KY

B.S. Education Certif. K-12, Sports Management, \& Physical Education (1999)

Minors: Business Administration \& Health

Cum Laude

\section{PROFESSIONAL EXPERIENCE}

\section{Senior Academic Counselor/Instructor 2007 - Present}

College of Education and Human Development, University of Louisville

- Responsible for academic planning and counseling for over 500 active students in the B.S. in Workforce Leadership major

- Develop curriculum and instruct ELFH 300 Prior Learning Assessment

- Assist in the planning and management of course scheduling (Online, GE, Norton's, \& UofL)

- Provide administrative and instructional support to part-time and full-time faculty

- Serve as a liaison between University Departments (e.g., Registrar, Bursar), Delphi Center for Teaching and Learning, CEHD, Advising Center, Academic Departments, and Faculty

- Serve as a liaison to Council on Postsecondary Education for state initiatives

- Troubleshoot student problems of various types (e.g., enrollment, technical, attendance)

- Assisted in the growth of enrollment from 132 to over 400 currently enrolled students

- Assist in the creation and implementation of recruiting strategies

- Master Advisor Certified 


\section{Senior Admissions Counselor 2006 - 2007}

J.B. Speed School of Engineering, University of Louisville

- Responsible for planning and execution of ten summer orientation sessions -Coordinate, manage, and assist advising sessions, tablet PC training, faculty introduction, student scheduling assistance and supervision, Student Orientation Staff management

- Coordinated out-of-state recruiting - Organize and implement recruiting strategies for St. Louis, Indianapolis, Cincinnati, Nashville, Evansville areas

- Completed weekly data reports - Chart progress, measure effectiveness of recruiting activities, review student files, and assess student credentials during application process

- Assisted in the creation and maintenance of recruiting materials -. Member of departmental recruitment publication concept and design team

- Scheduled and conduct campus visits with prospective students and their families - Counsel and interview students about college selection, major, and financial aid

- Coordinated Retention Programs - Developing programs to give all Speed students access to support services and provide early intervention to at risk students

- Assisted in planning and implementation of GES 101 - Intro to Engineering - Member of committee responsible for curriculum design and delivery

- Responsible for all financial aid programs at the Speed School of Engineering - Director of Financial aid programs for all freshmen and departmental scholarships

- Managed University Reports, budget balances, and data collection through ULink, PeopleSoft, Excel, Access, SPSS

\section{Graduate Assistant 2006}

Freshman Seminar/Learning Assistance Program, Appalachian State University

- Assisted with recruitment, selection, and training of 56 Peer Leaders

- Responsible for development of instructional materials including the faculty resource manual and the Freshman Seminar Handbook

- Conducted research and execute SPSS statistical data reports

- Assisted with assessment and evaluation of curriculum

- Coordinated university and Freshman Seminar award processes, specifically the Durham and Brantz awards

- Conducted updates of Summer Preview handbooks

\section{Admissions Counselor $2004-2005$}

Office of Enrollment Management, Lees-McRae Coilege

- Produced largest number of applications (36\%) and enrolled students (42\%) in 2005 among seven member admissions counselor staff

- Responsible for recruitment in Ohio, Kentucky, Florida, and the North Carolina Piedmont region

- Director of Student Ambassadors (Led student group responsible for assistance with campus tours, orientation, open house and scholar's day)

- Responsible for training and leadership of the Student TeleCounselors (a student group responsible for contacting prospective students)

- Member of the QEP (Quality Enhancement Plan for SACS accreditation) 
- Participated in college fairs in North Carolina, Kentucky, Tennessee, Ohio, Virginia, and Florida

- Conducted Private High School recruitment visits in Ohio, Florida, and North Carolina

- Attended Southern Association of College Admissions (SACAC) Conference - Nashville, TN

- Coordinated planning of Scholar's Day (40 high school seniors invited to campus for one day competition to receive a full tuition scholarship)

Outside Sales Representative $2002-2004$

Ferguson Enterprises - Boone, NC

- Achieved $\$ 250,000$ of growth over prior year's sales within six months of employment

- Managed 140 new accounts throughout Western North Carolina

- Implemented $\$ 320,000$ of HVAC product in three locations

- Recorded over Two Million dollars in Sales in 2003

Sales Representative 1995 - 2002

Hughes Supply - Greenville, SC \& Monroe, OH

- Managed outside sales activity in South Carolina and Southwest Ohio

- Recorded sales of over 1.1 million dollars for the fiscal year of 2001

- Posted highest sales numbers in territory 046 history, in month of October 2000

- Successfully achieved $152 \%$ of sales quota in last quarter of 2000

Arena Football Kicker 1999 - 2001

Charleston Swamp Foxes - Charleston, SC

- Professional Place Kicker in the Arena II Football League

\section{UNIVERSITY TEACHING EXPERIENCE}

ELFH 300 Prior Learning Assessment

Freshmen Seminar - Appalachian State University

Introduction to Golf - Lees-McRae College

Introduction to Engineering - Speed School, University of Louisville

Program Orientation/Prior Learning Assessment - College of Education and Human Development,

University of Louisville

COMMUNITY SERVICE

New Albany Redevelopment Commission

SOUL Welcome Weekend Community Service

Martin Luther King Jr. Day of Service

Welcome Weekend

Develop New Albany

\section{PROFESSIONAL MEMBERSHIP \& COMMITTEES}

\section{University of Louisville}

Online Learning Strategic Planning Committee 2012

Celebration of Teaching and Learning 2011 Executive Planning Committee 
Veterans \& Military Student Task Force

University Wide Advisory Council

Kentucky Adult Learner Initiative

NACADA - National Academic Advising Association

KACADA - Kentucky Academic Advising Association

Honors Council

Welcome Weekend Committee

KASCAC - Kentucky Association for College Admission and Counseling

NACAC - National Association for College Admission and Counseling

Orientation Advisory Committee

Chair of Speed School Scholarship Committee

LeaderShape Advisory Board

Appalachian State University

New Directions Planning Committee

Learning Communities Institute

Freshman Seminar Scholarship Committee

General Education Task Force Sub-Committee

Peer Leader Selection Committee

Higher Education Forum Planning Committee

Durham and Brantz Award Committees

\section{PRESENTATIONS}

Bergman, M., \& Williams, M. (2011, November) The changing face of alumni: The implications for a growing base of adult learners in our universities. Presented at Council for the Advancement and Support of Education (CASE) Kentucky Conference, Lexington, KY.

Pentecost, M., \& Bergman, M. (2011, October) Elevating your leadership jkills. Presented at National Academic Advising Association (NACADA) National Conference, Denver, CO.

Bergman, M., Anthony, M.D., Atkinson, J. (2008, September). Returning to college: Implications for adults and universities. Southern Association of College Student Affairs (SACSA) Hilton Head, SC.

Bergman, M., Hampton, B., Johnson, T., Pentecost, M. (2008, October). Coaching employees to Reach their bighest potential. Presented at National Academic Advising Association (NACADA) National Conference, Chicago, IL.

Bergman, M. (2008, December). Re-orientation of adult leamers: Strategies for successful assimilation to the new academic experience. University Wide Advising Conference Sharing Event, Louisville, KY.

\section{AWARDS \& ACCOMPLISHMENTS}

Provost's Award for Exemplary Advising 2011 (Professional Advisor of the Year)

Delphi Center for Teaching and Learning 2010-2011 Faculty Favorite

Provost's Award for Exemplary Advising - Nominee 2010

ESGR Patriot Award - Support of Military and Veteran Students 2009

Outstanding Staff Member for Adult Student Learners (Metroversity Award) 2009

Selected to Coordinate Welcome Weekend Open House for J.B. Speed School of Engineering 2007 (tripled attendance through marketing efforts)

Pillar Award - City of New Albany Historic Restoration of the year 2008 
LeaderShape Institute - Cluster Facilitator - University of Louisville Inaugural Year 2007

Presidential nomination to join the Strategic Planning Task Force at Lees-McRae College

Educational Scholarship Award from AmeriCorps for service to Avery County Habitat for Humanity

Coached Thomas More Women's Soccer Team to best record in School History

Achieved Sales Award for $\$ 200,000$ in gross profit in 2003

Promoted four times within four years at Hughes Supply

Mid-South Conference - Athlete of the Year Award at Union College

\section{CURRENT RESEARCH AND ACADEMIC INTEREST AREAS}

Adult Education, Prior Learning Assessment, Adult Development:

Learner Characteristics that impact persistence among adult learners in degree completion programs at the bachelor's level 